Portland State University

PDXScholar

7-21-2021

\title{
Relationship Between Image Spectroscopy Spatial Resolution and Crown Level Tree Species Classification Accuracy
}

Andrew Richard Fritter

Portland State University

Follow this and additional works at: https://pdxscholar.library.pdx.edu/open_access_etds

Part of the Geographic Information Sciences Commons, and the Remote Sensing Commons Let us know how access to this document benefits you.

\section{Recommended Citation}

Fritter, Andrew Richard, "Relationship Between Image Spectroscopy Spatial Resolution and Crown Level Tree Species Classification Accuracy" (2021). Dissertations and Theses. Paper 5782.

https://doi.org/10.15760/etd.7653

This Thesis is brought to you for free and open access. It has been accepted for inclusion in Dissertations and Theses by an authorized administrator of PDXScholar. Please contact us if we can make this document more accessible: pdxscholar@pdx.edu. 


\title{
Relationship Between Image Spectroscopy Spatial Resolution and Crown Level Tree Species Classification Accuracy
}

by

Andrew Richard Fritter

A thesis submitted in partial fulfillment of the requirements for the degree of

\author{
Master of Science \\ in \\ Geography
}

Thesis Committee:

Geoffrey Duh, Chair

Christopher Grant

Martin Lafrenz

Scott Nowicki

Portland State University

2021 


\begin{abstract}
Hyperspectral imagery has become a common remote sensing data type used in tree species classifications because of its rich spectral signals that allow the detection of the variations in canopy reflectance. While high spatial resolution hyperspectral imagery provides fine spatial resolution for discerning surface objects, it has the inherent drawbacks of expensive acquisition costs, large data sizes, and can be computationally taxing to use. This study attempts to determine a relationship between crown level tree species classification accuracy and hyperspectral spatial resolution. Future tree species classification projects can make use of this relationship by targeting a spatial resolution that best avoids the drawbacks of hyperspectral imagery. I processed a 37-band hyperspectral mosaic that has a 0.3 meters resolution and resampled it to $0.5,1.0,2.0$, 3.0, and 5.0 meters mosaics and used a support vector machine (SVM) classifier to create tree species classifications for each of the resampled mosaics to examine the relationship between spatial resolution and classification accuracies. The mosaic covers a $50 \mathrm{sq}-\mathrm{km}$ study site in El Dorado County, California. The classifier used tree species data that I collected in the field as training and validation data. The results show that there was no significant classification accuracy difference between the resolutions. The averaged overall accuracies were highest when using the 1.0 meters mosaic $(73.23 \%)$ and dropped when increasing or decreasing the spatial resolutions. The 5.0 meters mosaic yielded a minimum overall accuracy of $64.42 \%$. The finding suggests that spatial resolution is not a critical factor in classification accuracy, indicating that reasonable classification results can be achieved using either coarser resolution imagery, such as those collected with satellite or airborne sensors, or fine resolution imagery, such as those collected with unmanned aerial vehicles (UAV). The crown size of the trees appears to be an important
\end{abstract}


factor mediating classification accuracy and image resolution. The knowledge gained in this study could help remote sensing project managers to determine a resolution that best fits their budget and computational power. 


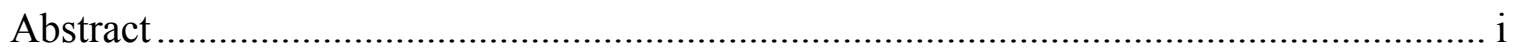

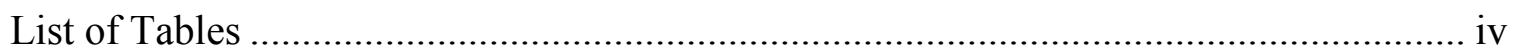

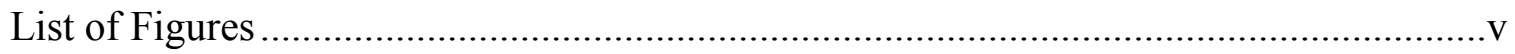

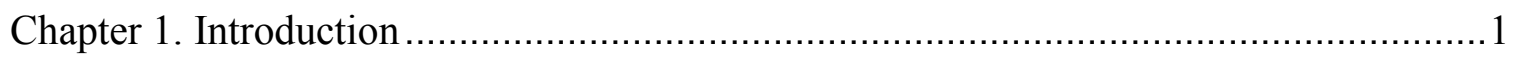

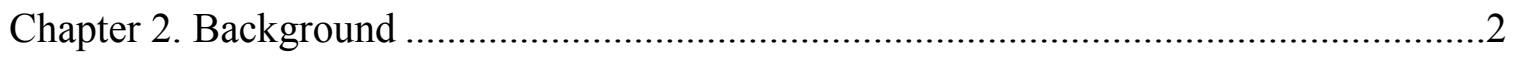

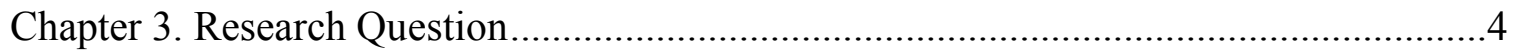

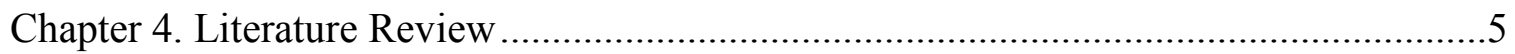

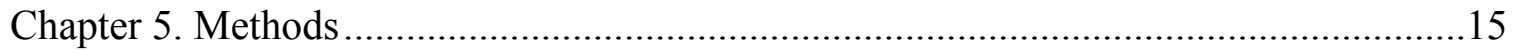

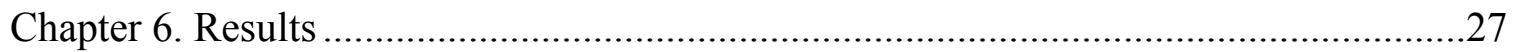

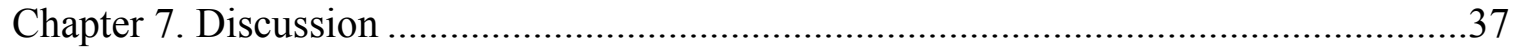

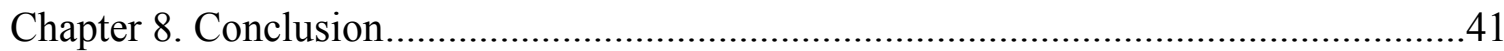

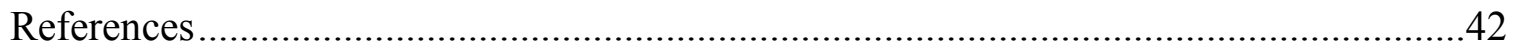

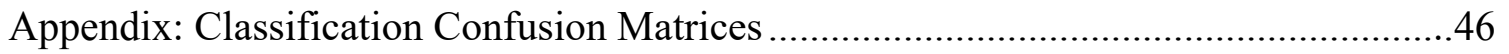




\section{List of Tables}

Table 1. Tree species name and sample count of surveyed tree crown polygons .............28

Table 2. Per-class pixel count and percent of total classified pixels from each of the

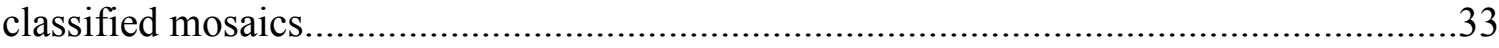

Table 3. Overall accuracy and kappa statistic for ten classification iterations per pixel size. Averaged overall accuracy and kappa for each pixel size along the bottom.............35 


\section{List of Figures}

Figure 1. Trends in tree species classification publications (Fassnacht et al., 2016).........5

Figure 2. A representation of a hyperspectral image. The pixels of a hyperspectral image are composed of contiguous bands representing values from the visible to the shortwave infrared region of the electromagnetic spectrum (Goetz, 2007) .......................................

Figure 3. Spectral signatures of 20 dominant trees from Zhao et. al (2016) .....................8

Figure 4. A linear Support Vector Machine example in two dimensions (Burges, 1998) 11

Figure 5. The extent of the study area displayed in a true color display of the hyperspectral mosaic.

Figure 6. Example of the three types of masks combined to include in the tree species classification. The mask data source in the left column and the derived mask in the right column. The final combined mask in the bottom right..................................................24

Figure 7. Field survey tree sample location and species..........................................28

Figure 8. Range of tree crown area for each species. The points along the range lines represent the averaged crown areas

Figure 9. Examples of hyperspectral images with different spatial resolutions in true color display

Figure 10. Example tree species classification results from each of the six spatial resolutions

Figure 11. Tree species classification result of the study area. The resolution of the classified raster is one meter. See Figure 9 for map legend.

Figure 12. A. Classification time versus cell size. B. Classification time versus cell count

Figure 13. Classification accuracy range and averaged overall accuracy for each pixel..36 
Figure 14. Average producer's accuracy versus pixel resolution. Average producer's accuracy was created by calculating the mean producer's accuracy from the ten classifications created at each resolution. 


\section{Chapter 1. Introduction}

Hyperspectral imagery has become a common remote sensing data type used in tree species classifications because of its rich spectral signals that allow the detection of the variations in canopy reflectance (Fassnacht et al., 2016). High spatial resolution hyperspectral imagery has the inherent drawbacks of expensive acquisition costs, large data sizes, and can apply strain to computational resources (Peña et al., 2013; Dalponte et al., 2008). The main goal of this research is to examine how image spatial resolution affects the classification accuracy. The knowledge gained in this study could help remote sensing project managers to determine a resolution that best fits their budget and computational power. In this paper, I attempt to determine the relationship between the spatial resolution of hyperspectral imagery and the affect it has on tree species classification accuracy.

Tree species classification is a form of remote sensing-based image classification used to map the distribution of trees and their species. The classification maps have applications in precision forestry, fire risk management, and invasive species monitoring (Dalponte et al., 2012; Colgan et al., 2012; Asner et al., 2015 \#2).

Over the past 35 years, remotely sensed data has become increasingly more extensive and available due to advancements in sensing technologies and publicly accessible satellite data (Fassnacht et al., 2016). This trend, coupled with improvements in computational capabilities, has led to increases in tree species classification complexity and popularity (Fassnacht et al., 2016). A more in-depth understanding of the relationship between hyperspectral imagery and their classifications can lead to improvements in tree species classification mapping and further its applications. 


\section{Chapter 2. Background}

Digital image classification routines have been used to generate tree species maps at different forest scales. Some research has classified tree species using relatively lowresolution imagery to create dominant species maps that cover large areas. Martin et al. (1998) determined the dominant forest species composition at a coarse grain, tree stand scale. Their study used 20m AVIRIS hyperspectral imagery. According to Martin et al. (1998), they found that it was not possible to adequately investigate the classification of individual deciduous species because most of the deciduous stands in the study area were a mix of three or more species. At low resolutions, each pixel was larger than the tree crowns mapped in the scene. Martin et al. (1998) mapped dominant forest stand species, but studies have used fine resolution imagery to classify species type at an individual tree scale. For example, Alonzo et al. (2013) determined the species of individual tree crowns using $3.7 \mathrm{~m}$ resolution hyperspectral imagery. Roth et al. (2015) compared tree species classification results from fine and coarse grain images of the same scene and concluded that changing the resolution of imagery used in species classifications altered the final accuracy. Peña et al. (2013) found that resampling images from a native $0.3 \mathrm{~m}$ resolution to coarser pixel sizes decreased the overall classification accuracy.

A review of 129 publications of tree species classification articles by Fassnacht et al. (2016) saw overall classification accuracies between 55-98\%. They found that the resolution of remote sensing data, tree species count, and complexity of ecology contributed to the range of accuracies and hypothesized that there may be a relationship between image resolution and classification accuracy. The goal of this research is to 
examine how image spatial resolution affects the classification accuracy using hyperspectral images that were resampled to different spatial resolutions. 


\section{Chapter 3. Research Question}

What is the relationship between spatial resolution and classification accuracy for tree species classifications using hyperspectral imagery at an individual tree crown scale? This paper compares the accuracy of tree species classifications at altered ground sample resolutions to derive a resolution-accuracy relationship. I hypothesized that the highest resolution achieves the greatest overall accuracy. This result would align with and confirm the results of a previous study by Peña et al. (2013), which researched the relationship on an alternative set of species in Chile.

I am interested in the relationship because it will help inform future hyperspectral project managers with determining image collection specifications. Acquiring hyperspectral data can be expensive when mounted to a fixed-wing aircraft. A better understanding of the relationship between spatial resolution and achievable image classification accuracy will help determine if unmanned aerial vehicles (UAV) or satellite platforms are a viable and more desirable image collection alternative for mapping tree species distributions. 


\section{Chapter 4. Literature Review}

\subsection{Publishing Trends in Tree Species Classification Research}

Publications using digital image classification to classify tree species in remote sensing data have substantially increased over 35 years (Fassnacht et al., 2016). This change is a function of the increased availability of remote sensing imagery and LiDAR data. Figure 1 provides a graph of tree species classification-related publication trends based on the review performed by Fassnacht et al. (2016). Compared with multispectral and airborne LiDAR, hyperspectral classification articles saw the biggest increase from 2005-2010 to 2010-2015, until Fassnacht et al. (2016) was published.

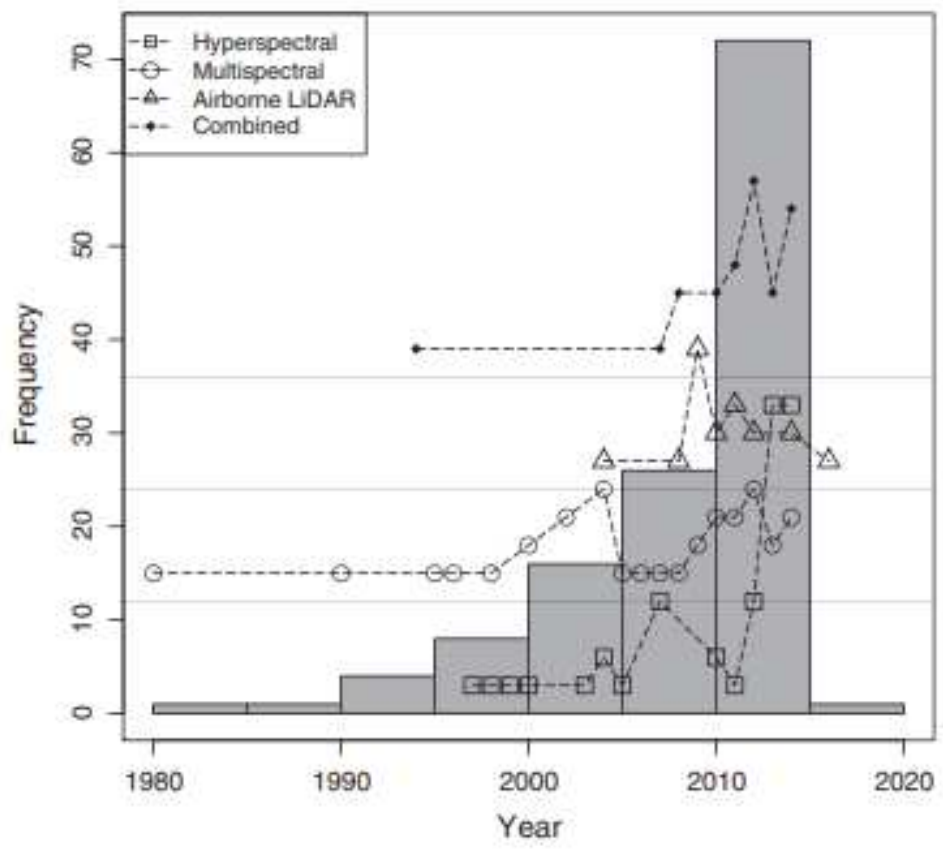

Figure 1. Trends in tree species classification publications (Fassnacht et al., 2016).

\subsection{Hyperspectral Imagery}

Hyperspectral imaging, also called image spectroscopy, is a type of remote sensing imagery. Goetz and Strivastava (1985) defined it as "the acquisition of images in 
hundreds of contiguous, registered, spectral bands such that for each pixel a radiance spectrum can be derived." Though Goetz and Strivastava (1985) were defining hyperspectral imagers that recorded using analog film, modern electronic sensors collect the same passive signal (Goetz, 2007). Hyperspectral sensors are commonly mounted to aerial platforms onboard fixed-wing aircraft as well as satellite and UAV platforms (Goetz, 2007, Coulter et al., 2007).

Hyperspectral sensors typically collect hundreds of contiguous bands from the visible to near-infrared (VNIR) region of the electromagnetic spectrum and stretch into the shortwave infrared (SWIR) region (Coulter et al., 2007). The wavelengths of these regions range from around $0.4 \mu \mathrm{m}$ to $2.5 \mu \mathrm{m}$ (Goetz, 2007). This range is useful because sensors are able detect strong radiative signals without large amounts of atmospheric interference, and because this range corresponds well with detecting the chemical and physical properties of surface features. The spectral reflectance properties of a target are captured and stored across a hyperspectral image's contiguous bands (Green et al., 1998). Figure 2 displays how the bands of a hyperspectral image are compiled and represent spectral values. 


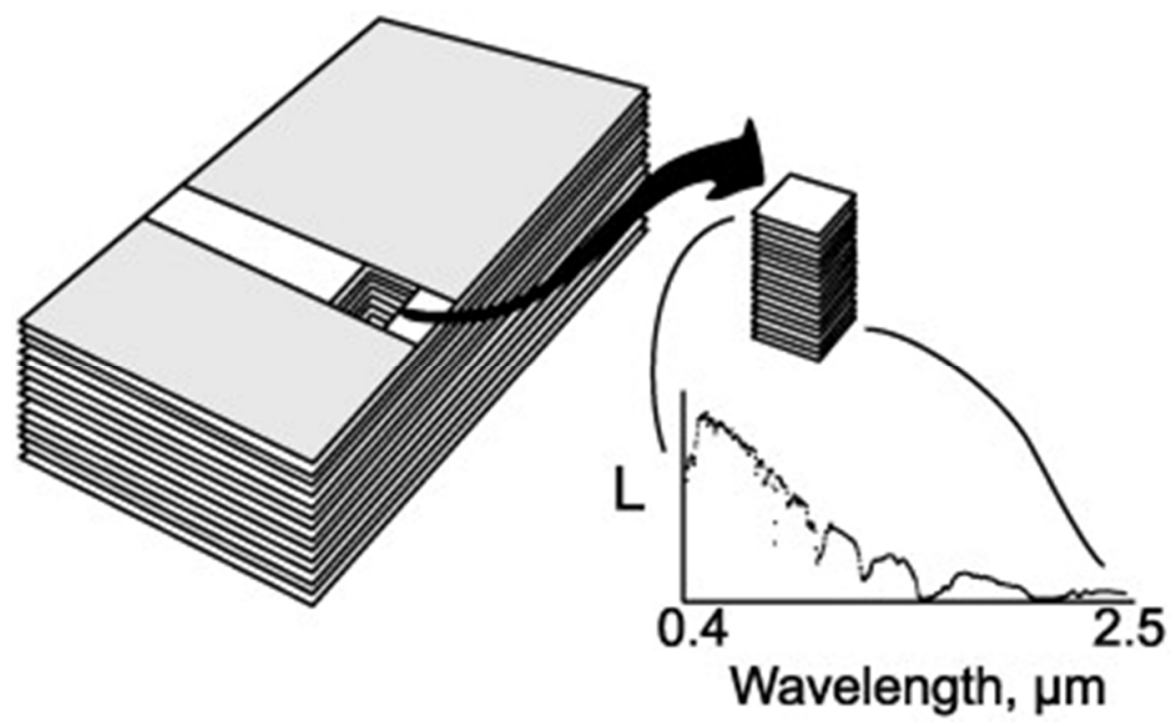

Figure 2. A representation of a hyperspectral image. The pixels of a hyperspectral image are composed of contiguous bands representing values from the visible to the shortwave infrared region of the electromagnetic spectrum (Goetz, 2007).

Researchers initially used hyperspectral imagery to detect geologic surface composition (Meer et al., 2012). Tree species, like surface minerals, have been identified in hyperspectral imagery through categorization of their unique reflectance spectra (Asner et al., 2015 \#2). Distinctive biophysical and biochemical properties determine a tree's reflectance spectrum (Asner, 1998; Asner et al., 2015 \#1). These properties, unique to different tree species, create identifiable scattering patterns across the VNIR and SWIR wavelengths (Asner, 1998; Asner et al., $2015 \# 2$ ) 


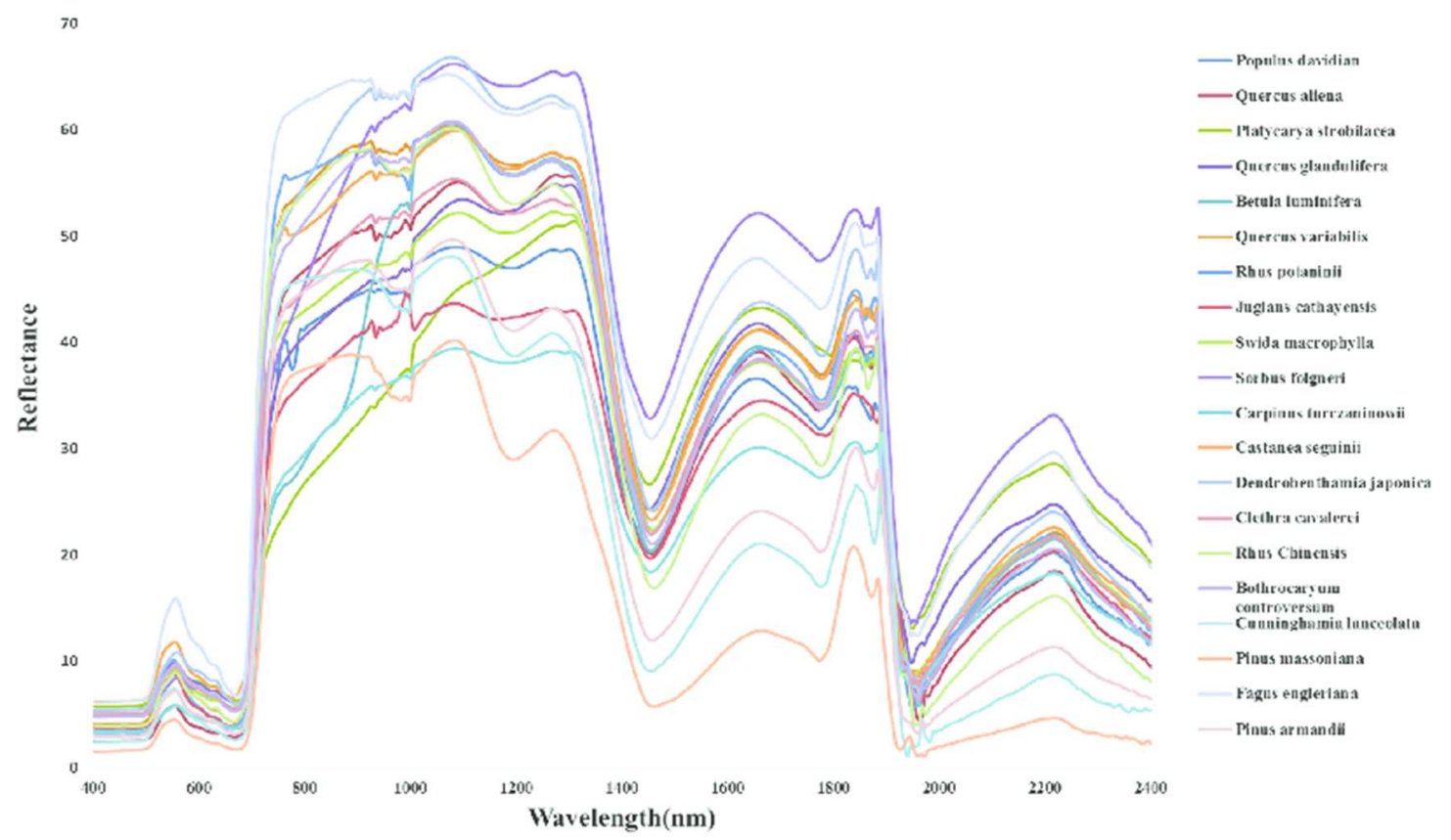

Figure 3. Spectral signatures of 20 dominant trees from Zhao et. al (2016).

\subsection{LiDAR}

LiDAR, short for light detection and ranging, is a technology that uses laser pulses and the known speed of light to create a three-dimensional digital representation of a target (Gatziolis and Andersen, 2008). LiDAR sensors are mounted on aircraft to target and model landscape terrain (Gatziolis and Andersen, 2008). Researchers use LiDAR datasets to create digital elevation models (DEM) and feature height rasters (FHR) among other forms of analysis (Koch, 2010).

LiDAR data provides three-dimensional tree structure information such as tree height and crown width (Reitberger et al., 2008). Lidar-derived tree structure information has been used as ancillary data during hyperspectral imagery to improve tree species classifications (Reitberger et al., 2008). The perimeters of individual trees have been extracted from FHRs to create vectors representing tree crowns (Colgan et al., 2012; Zhang and Qiu, 2012). LiDAR-derived tree crown polygons have been used in 
conjunction with raster classifications to vectorize classification results and inventory trees (Zhang and Qiu, 2012; Alonzo et al., 2013). In the review of tree species classifications by Fassnacht et al. (2016), 56 of 129 publications used tree crown polygons as part of their methodology. In general, the use of LiDAR FHR and crown polygons in conjunction with multi- or hyperspectral imagery improves tree species classification accuracy.

\subsection{Digital Image Classification}

Digital image classification is a computer-based process that categorizes pixels in an image into classes based on their values. There are two general types of digital image classification, unsupervised and supervised. One major difference between the two is how the classes are defined.

In unsupervised classification, the user does not define the categories through pixel training. Lu and Weng (2007, p. 803) define unsupervised classification as "clustering-based algorithms used to partition the image into several classes based on the statistical information inherent in the image." Commonly used unsupervised classifiers are ISODATA (Ball and Hall, 1965) and K-means (Burrough et al., 2000). Unsupervised classifications are limited in their use because their results do not always correspond with informal classes.

During supervised classification, the user defines the classes before running the classifier (Richards, 2013). The user selects training pixels for each category, and the resultant classification categorizes the remaining pixels in the image into the user-defined categories. A survey of classification methods by Lu and Weng (2007) suggests that a 
supervised classification is optimal when land cover types are known and sufficient reference data is available to identify target features within the imagery.

Rapid increases in computation capacity and open source environments have assisted the rise of advanced classification algorithms such as machine learning (Hsu et al., 2003, Mountrakis et al., 2011), decision tree (Pal, 2005), and deep learning classifiers (Chen et al., 2014). The review by Fassnacht et al. (2016) found that support vector machine (SVM), a machine learning algorithm, was the most widely used classifier when classifying tree species.

SVM is advantageous for remote sensing scenes with complex class variability and high-dimensional data ( $\mathrm{Lu}$ and Weng, 2007). This advantage is beneficial for tree species classifications due to the complex spectral diversity of species-rich forests and the high-dimensionality hyperspectral imagery. SVM requires less training data than other machine learning algorithms, which helps regions with limited surveyed ground truth data. However, SVM demands a sizable computational cost due to an inherently complex algorithm and requires functional parameter tuning, which is a process to find the best combination of SVM parameters that yields the most accurate classification results (Hsu et al., 2003, Mountrakis et al., 2011).

SVM is a per-pixel classifier that clusters image spectra into a multidimensional feature-space, dimensions based on the number of input bands, and plots each data point by values. Hyperplanes separate the feature-space pixel clusters, defining how each pixel is classified (Hsu et al., 2003, Mountrakis et al., 2011). Figure 3 provides an example of simple linear hyperplane functionality. 
Per-pixel classifiers assign each pixel in an image into one of the classification's mutually exclusive classes. Spectral variability within heterogeneous landscape units can cause per-pixel classification results to be noisy due to inherent variation within the same class, such as incident light differences across tree crowns (Janssen and Molenaar, 1994). Vector data subdivide images into parcels, and the statistical attribution of per-pixel classification results helps avoid variation (Aplin et al., 2001; Blaschke, 2010).

Attribution of pixel results to vector data is often called per-field classification (Lu and Weng, 2007), receiving its name from agricultural field studies. Zhang and Qiu (2012) attributed the results of a tree species classification to tree crown polygons to avoid outlier results from spectral variation across tree crowns. Tree crown complexity can lead to the misalignment of imagery and tree crown vectors. Misalignment creates drawbacks such as statistical errors caused by the inclusion of non-crown pixels.

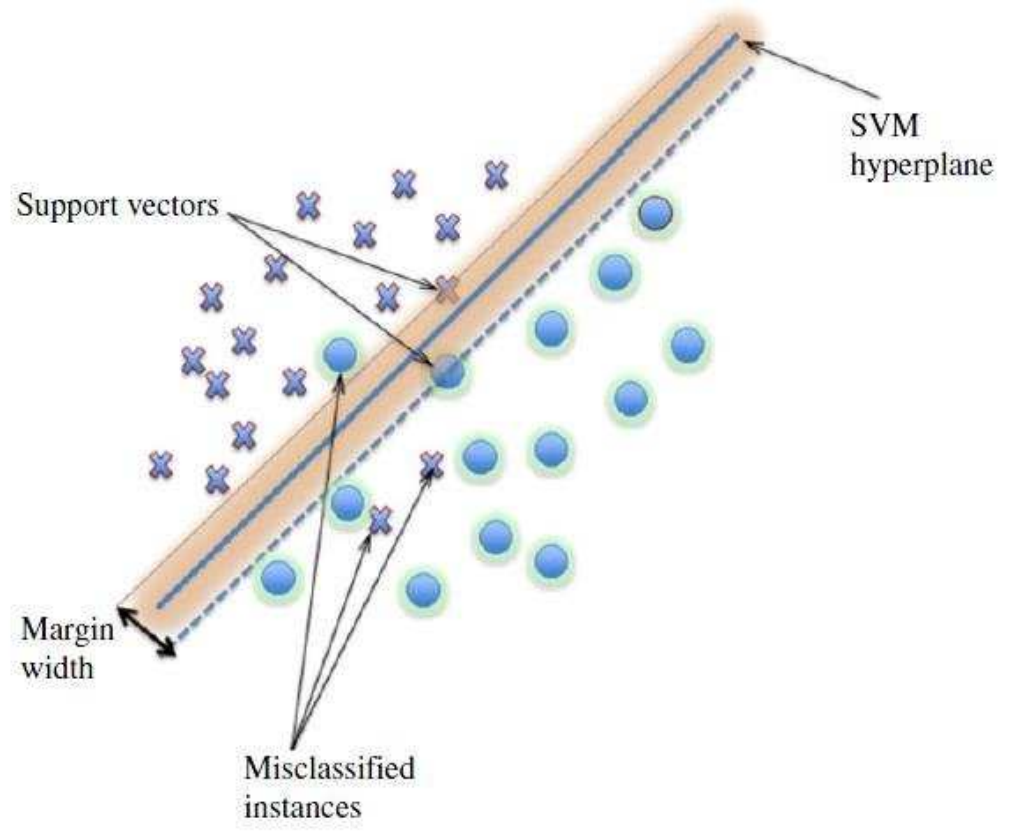

Figure 4. A linear Support Vector Machine example in two dimensions (Burges, 1998). 


\subsection{Tree Species Classification Scheme and Class Count}

A classification scheme defines the categories that classified objects get arranged by. In digital image classification, classification schemes define the classes that the classifier discriminates the scene's pixels into (Jensen, 1996). Species-level classification schemes are typical in remote sensing-based tree classifications (Roth et al., 2015; Peña et al., 2013). Studies have also classified using genus schemes (Dalponte et al., 2013) and simultaneous classification of both species and genus (Jensen et al., 2012).

The species classification review by Fassnacht et al. (2016) found that class counts were highly variable across publications, ranging from three to seventeen species. Jensen et al. (2012) and Ferreira et al. (2016) classified less than ten species. Both included "other" classes which act as a catch-all for trees that do not match any of the species put forth for classification. Alonzo et al. (2013) included fifteen species in their urban forest study, and Colgan et al. (2012) produced results with sixteen species, both including one "other" category.

\subsection{Classification Scale and Spatial Resolution}

Tree species classification scales range from classifying tree stands to individual tree crowns. Tree-stand scale classifications have utilized imagery such that a single pixel is composed of many trees (Roth et al., 2015). At a tree-crown scale, at least one or more pixels represent a single tree (Fassnacht et al., 2016; Alonzo et al., 2013).

Roth et al. (2015) attempted to determine an optimal spatial resolution for standlevel species classifications using a range of low resolution hyperspectral images. Their study resampled imagery to 20,40 , and 60 meter pixel resolutions. Dominant species 
were classified using each resolution, and the results were compared. They found that stand-level dominant species classification accuracy increases at coarse resolutions up to 60 meters, with an overall accuracy range of 61 to $96 \%$. Peña et al. (2013) similarly sought to find a relationship between crown-level species classification accuracies and image resolution. The Peña et al. (2013) study used much higher resolutions of $0.3,0.6$, $0.9,1.2,1.5$, and 1.8 meters. The results of Peña et al. (2013) show higher resolution pixels produced the highest accuracy classifications. However, they also warn of excessive spectral complexity between pixels with a higher spatial resolution, confusing their classifications.

Pixel size affects the measured light stored as a pixel value (Coulter et al., 2007). Coarse pixel sizes reduce spectral variability by averaging a larger area's spectral response (Dalponte et al., 2013; Roth et al., 2015). A coarse pixel resolution has the potential to mix the spectral response of multiple tree species or non-tree related objects into a single pixel value. Mixed pixels are likely to be misclassified during digital image classification. The misclassification is due to the variance of mixed pixels from the training pixels used to define each species (Dalponte et al., 2013).

\subsection{Accuracy Assessment}

A tree species classification's accuracy is derived using reference data of known tree species in a scene (Baldeck and Asner, 2014). A confusion matrix is a widely used accuracy assessment method of digital image classifications (Foody, 1996; Jensen et al., 2012; Lu and Weng, 2007). The user's and producer's accuracy of each species, the overall accuracy, and the classifications kappa statistic can be determined using a 
confusion matrix (Jensen et al., 2012; Lu and Weng, 2007). The overall accuracies of the species classification publications reviewed by Fassnacht et al. (2016) ranged from 65\%$100 \%$, which are considered as acceptable accuracies of tree species maps derived from remotely sensed imagery. 


\section{Chapter 5. Methodology}

I resized a high-resolution hyperspectral image to produce six images with degraded resolutions and used an SVM classifier to perform tree species classifications from each of the resolutions. In July 2016, I conducted a tree survey to collect tree species data for SVM classification training and validation. Half of the trees from the field survey dataset were randomly assigned as classification training trees, while the other half were for classification validation. SVM ingested pixels from the tree crowns of trees labeled as "training" to train the classification. The tree species classification results were cross referenced with the validation trees to determine classification accuracy using a confusion matrix. To prevent sampling and training bias, I performed ten classifications for each resolution and reassigned the surveyed trees as either training or validation trees after each classification.

\subsection{Study Site}

The Sierra Nevada is a North American mountain range between California's Central Valley and the Great Basin, primarily running along California's eastern border. Included within the Sierra Nevada are three national parks and nine national forests. The region provides valuable resources for timber, grazing, minerals, water, and hydropower (Centers for Water and Wildland Resources, 1996). The forest land is also used for outdoor activities and is considered sacred to some communities.

The study site (Figure 4) is a forested region within the western Sierra Nevada, in El Dorado County. Starting at the town of Placerville, the study area extends south, 
covering 50 square kilometers. The elevation of the site is around 1800 feet above sea level.

Ecologists categorize the western Sierra Nevada forests into five biotic zones. Starting from the highest elevation downward, these are alpine, subalpine, upper montane, lower montane, and foothills. The study site sits at a transition zone between foothills and lower montane. The tree types in the study area are primarily woodland and chaparral trees with some mixed conifers. Urban forest landscapes and ornamental tree species are also present due to residential areas within the study site.

Contact between trees and power lines cause many of California's wildfires (Cal Fire, 2018 \#2). The Department of Forestry and Fire Protection (Cal Fire) produces California Fire Hazard Severity maps for California's counties. According to their 2016 fire hazard map, Cal Fire designated the study area as moderate to high fire risk. From the Cal Fire incident archive, in 2016, California experienced 6959 wildfires that burned 669,000 acres. Fire suppression cost during 2015-2016 was $\$ 608$ million (CalFire, 2018 $\# 1)$.

To prevent fire ignition, vegetation management teams have combined electrical utility infrastructures, mapped using GIS (Jensen and Cowen, 2011), and tree species classification results to identify high fire risk trees. According to Cal Fire's Fire Prevention Field Guild, vegetation management teams modify their fire prevention method based on a tree's species (California, 2008). Some species of conifer call for having their tops removed to prevent fire. Many hardwood species have stressed or dead limbs removed, while others such as grey pine or eucalyptus call for complete removal. 
Aside from fire management, tree classifications have acted as data for climate and ecology research (Van Ewijk et al., 2014). Tree stress and mortality, fire fuel, and susceptibility to invasive pests are potential risks associated with climate change throughout some regions of Sierra Nevada (Anderegg et al., 2015). Creating tree species maps for the study area could provide a more informed response to fire management issues and forest ecology. 


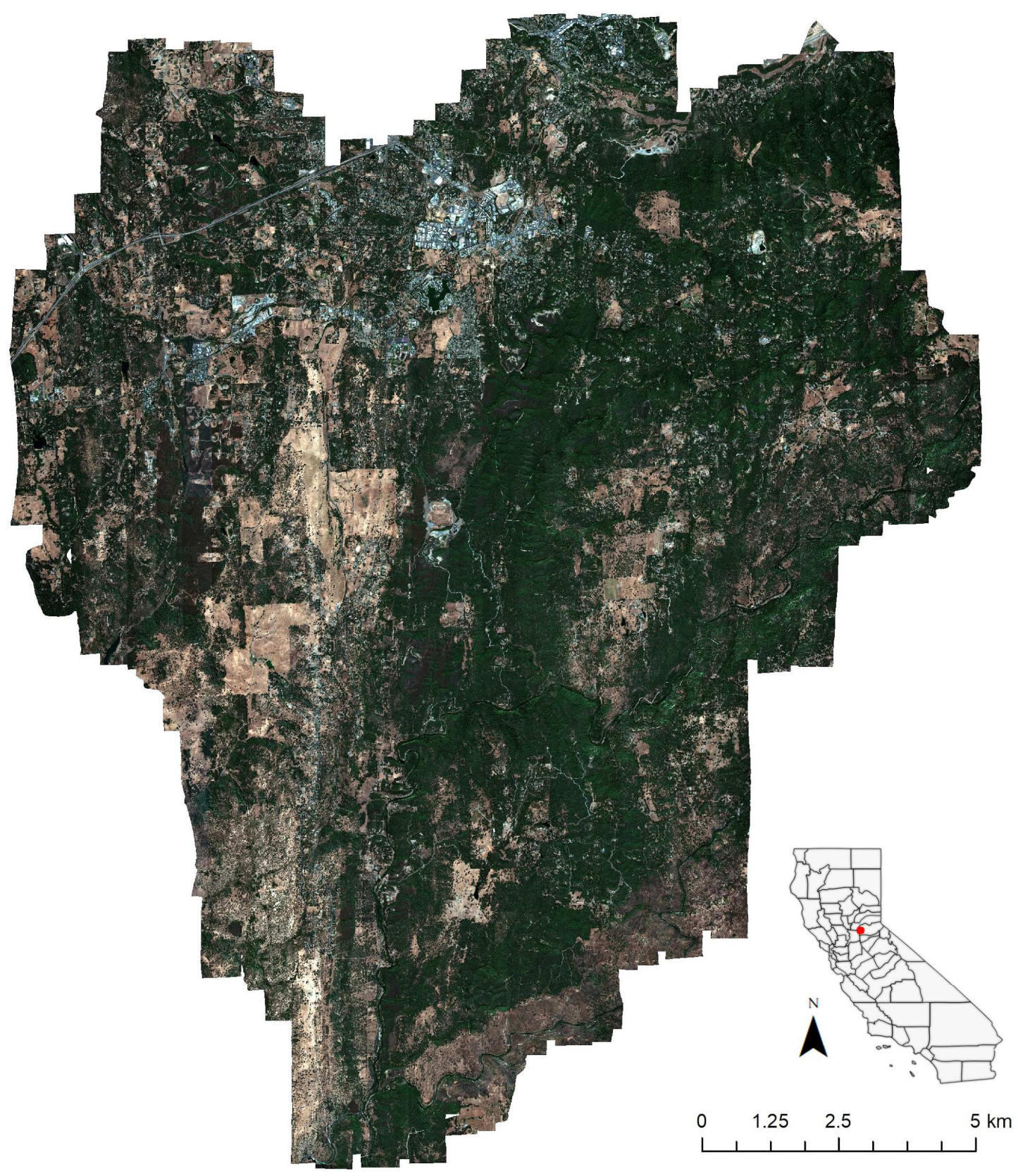

Figure 5. The extent of the study area displayed in a true color display of the hyperspectral mosaic. 


\subsection{Data}

\subsubsection{Hyperspectral Imagery}

For this study, I used a hyperspectral image mosaic as input data for tree species classification. The hyperspectral imagery was collected by Quantum Spatial Incorporation (QSI) in July 2016 using a Headwall Photonics E-Series VNIR sensor. Forty-two hyperspectral flight line images were collected to cover the entire study site. Sensor operators set the native image resolution of the imagery to achieve a $0.3 \mathrm{~m}$ ground sample size and 111 bands between $0.4 \mu \mathrm{m}$ and $1.0 \mu \mathrm{m}$.

During the course of my thesis research, I worked for QSI as a hyperspectral analyst and processed the hyperspectral images that I used in my research as a part of my job. I converted raw hyperspectral images to radiance using Headwall Photonic's SpectralView software. The software converts each pixel's digital number value to watts per steradian per square meter. The conversion makes use of a sensor-specific factory calibrated correction provided by Headwall Photonics.

As light travels through the atmosphere, photons become altered due to scattering and absorption from atmospheric compounds before encountering an airborne sensor (Green et al., 1998). The light is changed to varying magnitudes across the spectral range depending on atmospheric composition and condition. Atmospheric correction routines attempt to ensure that pixel values match surface reflectance and that spectral magnitudes match across flight lines (Gao et al., 2009). An atmospheric correction converts imagery from radiance to reflectance values (Beisl et al., 2008).

I performed an atmospheric correction on each of the hyperspectral flight lines using ATCOR-4 (Airborne and Topographic Correction) software's Rugged Terrain 
Correction by ReSe Applications. ATCOR-4 utilizes a radiative transfer model. To perform the correction, ATCOR-4 required the aircraft's altitude, elevation, latitude, longitude, and sun angle of each pixel. ATCOR-4 allowed for an aerosol and water vapor column to be specified. The software used these to best model the atmosphere during image collection. I chose a "Rural" aerosol condition and set the water vapor content to $0.4 \mathrm{~cm}$; reasonable values for the study area during the summer.

Following the atmospheric correction, I orthorectified the hyperspectral flightline images using Parge (Parametric Geocoding and Orthorectification) software by ReSe Applications. The orthorectification required a DEM, sensor GPS data, and aircraft attitude angles. Boresight angles determined the sensor's angular offset from the aircraft. Parge's semi-automatic boresight calibration procedure calculated the boresight angles. The procedure followed the standard method for a push-broom sensor, using repeated features within overlapping cross-hatch flight lines to determine offsets. Boresight angles were adjusted until orthorectified pixel misalignment was less than three pixels. Once the boresight angles were determined, flight lines were batch orthorectified.

Following the radiometric and geometric calibration steps, I used ENVI's Mosaic tool to combine the flight lines into a single mosaic. The mosaic step made ordered the flightlines by acquisition order, placing the flightlines collected last on top. No feathering setting was applied to preserve the pixel values and avoid creating mixed pixels.

The full contiguous range of hyperspectral bands are often more than needed in terms of a spectral sample when classifying tree species (Baldeck and Asner, 2014). I removed highly correlated spectra using ENVI's Resize tool to reduce the hyperspectral 
mosaic's data size. The mosaic was resized to every third band starting at the first band, contracting from 111 to 37 bands.

\subsubsection{Feature Height Raster}

A LiDAR dataset supplied three-dimensional information of the study area. QSI acquired and processed the LiDAR dataset in June 2016. The data they produced was a DEM and the highest hit raster with a spatial resolution of 0.076 meters. The pixel values of the highest hit raster represent the height of objects on the surface plus the elevation of the surface. I created a feature height raster (FHR) using ENVI's Band Math tool by subtracting the DEM from the highest hit raster.

\subsubsection{Tree Field Survey}

I performed a field survey of the study area in July 2016. The survey occurred over four days. The purpose of the survey was to sample the location and species of trees visible in the imagery to train and validate the tree species classifications.

I sampled over 300 trees throughout the study area where public roads and paths were available. Portions of the study area were not accessible due to private land restrictions. The samples were logged in Google Earth using a field computer. To create a sample, I identified the species of a tree in the field and located the same tree in Google Earth's imagery. I then placed a marking point on the imaged tree crown and labeled it with the appropriate species name. Once back from the field, I located trees sampled trees in the hyperspectral imagery by referencing the Google Earth imagery. I drew polygons around the perimeter of sampled tree crowns visible in the $0.3 \mathrm{~m}$ hyperspectral mosaic. 
Pixel values within the tree crown polygon represent spectral signatures for training the tree species classification. The majority of the classified pixels in each crown polygon represent the classified tree species of the crown polygon and were compared to the surveyed tree species in the accuracy assessment. If the surveyed tree was not visible in the hyperspectral imagery or if the surveyed tree was in question in any way, then the surveyed tree record was not used.

\subsection{Data Preparation}

\subsubsection{Pixel Resolution Resizing}

I resized the 0.3 meter 37 band reflectance mosaic five times, creating $0.5,1.0$, 2.0, 3.0, and 5.0 meter mosaics. ENVI's Resize Data tool created the new mosaics. The tool allows users to specify a resampling method. The Pixel Aggregate method closely represents the pixel values that would have been recorded if the image was originally captured at the new pixel size. Pixel Aggregate uses a weighted average of all the pixels that contribute to the resampled pixel to derive a new resampled value.

\subsubsection{Mask Creation}

Masks limited the classification to pixels that represent trees. A mask is a raster that corresponds with a classification input raster, specifying the classification to skip the pixels covered by the mask.

To exclude non-vegetated pixels from the classification, I created Normalized Difference Vegetation Index (NDVI) masks. I used ENVI to calculate NDVI rasters from 
each mosaic and fed them into ENVI's Create Mask tool. I set the masking threshold to a minimum allowable NDVI value of 0.7 .

In addition to the non-vegetated mask derived from NDVI, I also created a shadow mask for each of the six mosaics using ENVI's Create Mask tool. Pixels with a reflectance value of 0.1 or less on the IR reflectance band (with a wavelength of 0.8 microns) were shadows of trees.

To ensure that all ground and short objects were excluded from the classification, I created a height mask by labeling pixels with an FHR value of 2 meters or lower using ENVI's Create Mask tool. I then used GDAL's warp function to create a resized height mask for each of the six mosaics. 


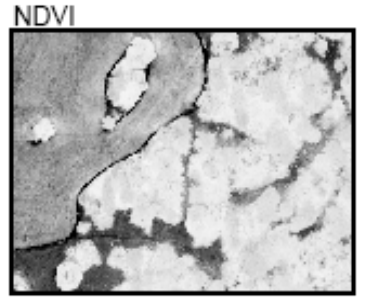

Infrared Band

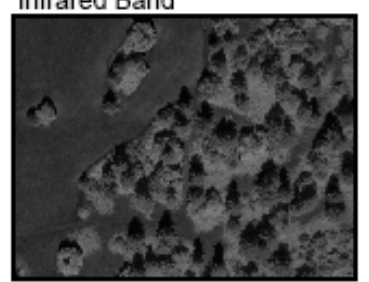

Feature Height

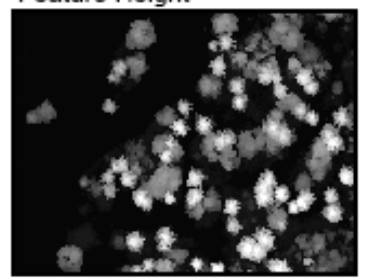

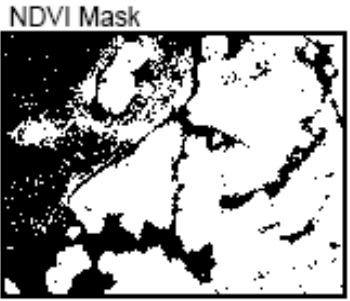

Shadow Mask

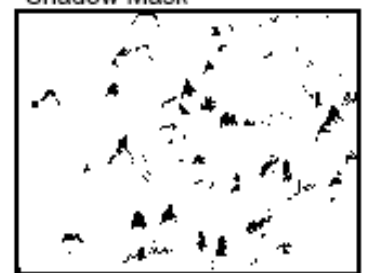

Height Mask

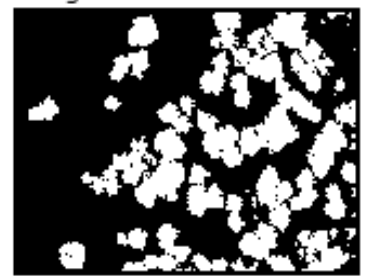

Combined Mask

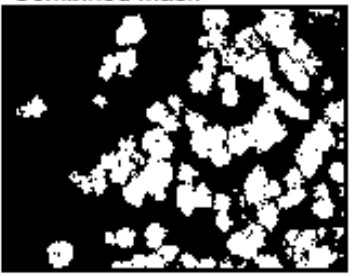

Figure 6. Example of the three types of masks combined to include in the tree species classification. The mask data source in the left column and the derived mask in the right column. The final combined mask in the bottom right.

The final combined classification mask for each spatial resolution contains pixels that were labeled as being short, non-vegetated, or shadow in the height, NDVI, and shadow masks. Figure 6 provides a visual example of the mask creation and combing process. 


\subsection{Tree Species Classification}

I used the machine learning python module SciKit-Learn (https://scikitlearn.org/stable/modules/svm.html\#) to perform the SVM classification. SciKit-Learn provides a few SVM classifier options. I set the SVM classifier's kernel type to radial basis function (RBF), which allows the classifier to build complex, non-linear decision boundaries for classification. An RBF SVM classifier has two primary parameters. The C parameter sets the decision function margin and the gamma parameter determines how far a single training pixel reaches its decision boundaries (https://scikitlearn.org/stable/auto_examples/svm/plot_rbf_parameters.html). A high C value creates finer decision boundaries that enclose the support vectors of the training data better. A high gamma value reduces the reach of a support vector to its decision boundaries. The values for both parameters were set using SciKit-Learn's built-in cross-validation routine. Cross-validation determines the optimal $\mathrm{C}$ and gamma values by taking a small subset of pixels and running test classifications on them. A range of $\mathrm{C}$ and gamma values were tested until the routine determined the highest performing paired values. The incremental changing values for $\mathrm{C}$ used the formula $2 \square$, where $\mathrm{x}$ ranged as an integer from -2 to 8 . The values for gamma were created using the same formula, where $\mathrm{x}$ ranged as an integer from -9 to 1 .

The pixels within the tree crown polygons were used to train the classifier. The tree polygons were randomly split 50-50 and designated as either a training or validation tree. All unmasked pixels with a center point within the training polygons were used to train the classifier. 
The hyperspectral mosaic was classified ten times at each resolution. Once each of the six resolution mosaics was classified using the same set of training trees, the tree crown polygons were reshuffled and randomly assigned again as either for training or for validation. In total, there were 60 classified tree species raster maps. I also recorded the processing time to complete the first classification of each resolution

\subsection{Accuracy Assessment}

I created sixty confusion matrices, 10 for each of the six resolution results. The confusion matrices compared the classified results to the true species type for each of the validation polygons. The output of the SVM classifier is a classified raster. All of the classified pixels within a tree crown do not always match with the same species. To determine a single class for a tree crown, the tree crown polygons were used. A tree's class was set to match the majority of classified pixels within each tree crown polygon.

A mean averaged overall accuracy and kappa were determined for each resolution to condense the 60 confusion matrices. These were created by averaging the initial overall accuracies and kappa statistics from 10 confusion matrices within a resolution. 


\section{Chapter 6. Results}

\subsection{Tree Survey}

Once I converted the surveyed tree dataset to tree crown polygons, eleven dominant species had sufficient sample counts (Table 1). Canyon Live Oak and Ponderosa Pine had the highest sample rate. I grouped the Eucalyptus trees into a genuslevel class because of their limited count at a species level. I created the Other Conifer and Other Broadleaf categories to group species with low sample counts. The Other Conifer class consists of Coastal Redwood, Aleppo Pine, and Jeffery Pine. The Other Broadleaf class consists of Big Leaf Maple, Black Locust, London Plane, Tree of Heaven, Black Walnut, and Fremont Cottonwood.

Figure 7 is a map of the distribution of surveyed trees. Tree distribution was limited to roads and public locations due to a large amount of private land throughout the study site.

Figure 8 details the variation in tree crown size through a graphing display of polygon areas ranges for each species. Valley Oak had the greatest area range and Deodar Cedar had both the smallest range and lowest average crown area. 
Table 1. Tree species name and sample count of surveyed tree crown polygons.

\begin{tabular}{|l|l|c|}
\hline \multicolumn{1}{|c|}{ Common Name } & \multicolumn{1}{c|}{ Scientific Name } & Sample Count \\
\hline Cedar, Deodar Cedar & Cedrus deodara & 22 \\
\hline Cedar, Incense Cedar & Calocedrus decurrens & 32 \\
\hline Eucalyptus & Eucalyptus (genus) & 15 \\
\hline Oak, Blue Oak & Quercus douglasii & 43 \\
\hline Oak, California Black Oak & Quercus kelloggii & 65 \\
\hline Oak, Canyon Live Oak & Quercus chrysolepis & 82 \\
\hline Oak, Valley Oak & Quercus lobata & 44 \\
\hline Pine, Gray Pine & Pinus sabiniana & 46 \\
\hline Pine, Ponderosa Pine & Pinus ponderosa & 82 \\
\hline Other Conifer & & 21 \\
\hline Other Broadleaf & & 27 \\
\hline
\end{tabular}

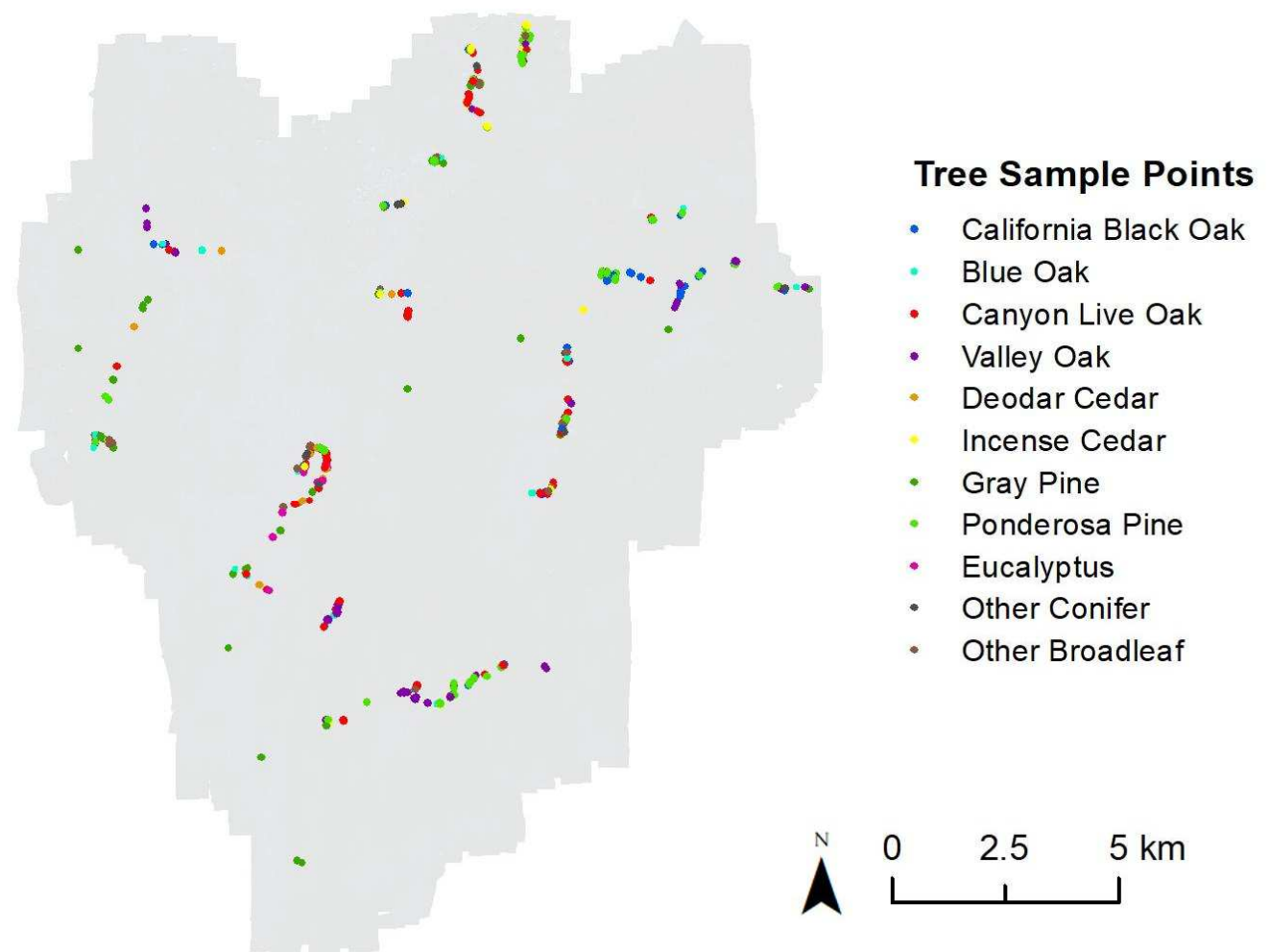

Figure 7. Field survey tree sample location and species. 


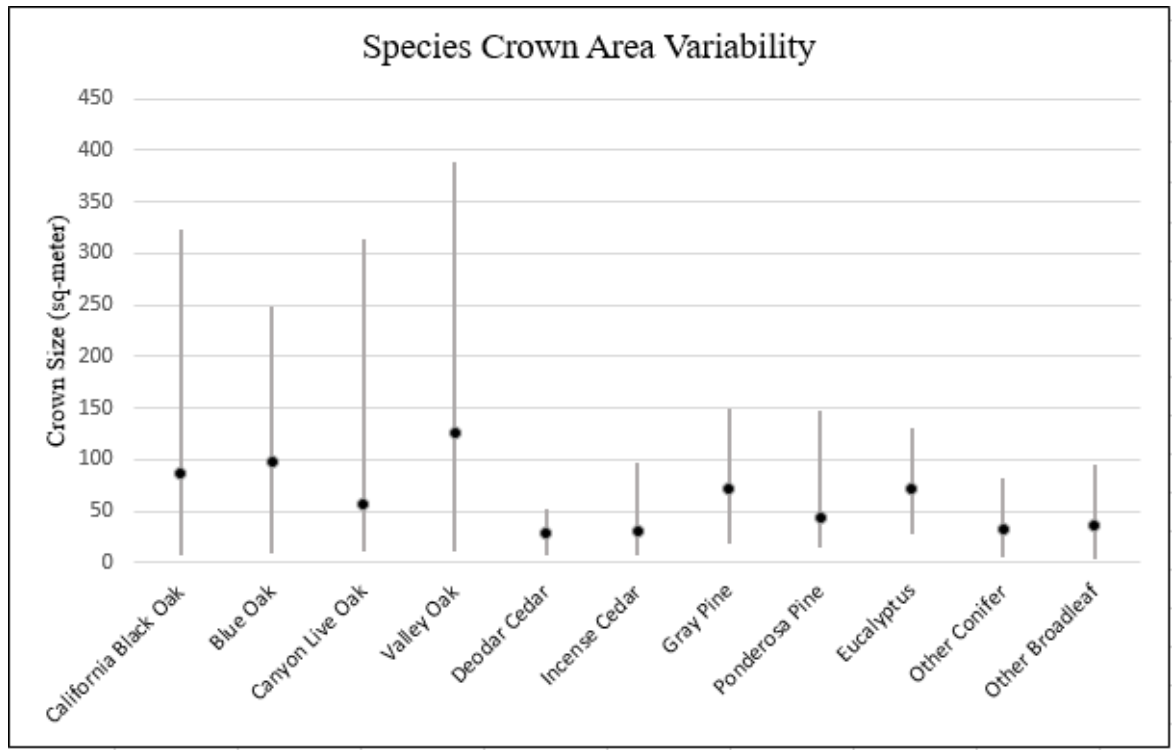

Figure 8. Range of tree crown area for each species. The points along the range lines represent the averaged crown areas.

\subsection{Resize Hyperspectral Mosaics}

I spectrally calibrated, orthorectified, and mosaicked hyperspectral flight lines with a 0.3 meters spatial resolution. The result is a hypercube mosaic with 111 spectral bands and a file size of $1.8 \mathrm{~TB}$. Reducing the bands to 37 , leaving one out of every third band, reduced size of the 0.3 meter mosaic to $602 \mathrm{~GB}$.

I spatially resized the $0.3 \mathrm{~m}$ hyperspectral mosaic to $0.5,1.0,2.0,3.0$, and 5.0 meters (Figure 9). This procedure reduced the data size significantly to $217 \mathrm{~GB}, 55 \mathrm{~GB}$, 14GB, $6 \mathrm{~GB}$, and $2 \mathrm{~GB}$, respectively. 

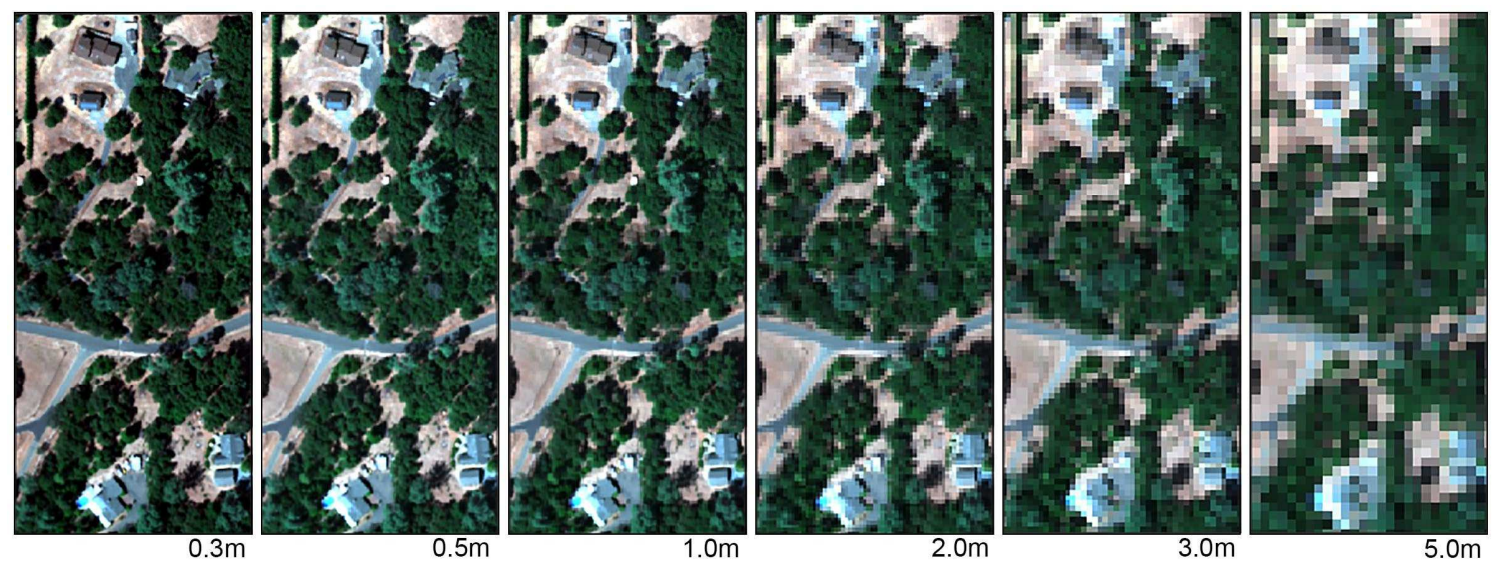

Figure 9. Examples of hyperspectral images with different spatial resolutions in true color display.

\subsection{Classification Results}

I classified all the hyperspectral mosaics using SVM on pixels that were outside the classification mask. The classification masks were created by combining an NDVI mask, a shadow mask, and an FHR derived height mask into a single combined mask for each resolution.

The result of the classification step was 60 classified tree species raster maps, 10 for each resolution. Each map has 9 tree species. They are California Black Oak, Blue Oak, Canyon Live Oak, Valley Oak, Deodar Cedar, Incense Cedar, Gray Pine, Ponderosa Pine, and one genus class (Eucalyptus). In addition, there are two "other" classes (Other Conifer and Other Broadleaf).

Figure 10 displays a sample classification result at each resolution. Figure 11 displays a $1.0 \mathrm{~m}$ tree species classification of the entire study site. The gap in the middle of classification is due to limited LiDAR coverage. 
The species results seem to match the observations from the aggregated field survey data. Based on the classification in Figure 11 and the species pixel counts in Table 2, the study site is dominated by Canyon Live Oak (37\%) and California Black Oak (18\%) with a sizable Ponderosa Pine population (7\%). The species dominance and distribution match the field survey's result.

A large population of Blue oak exists on the western side of the study area and a large pocket of Ponderosa Pine sits in the northeast section. The existence of oak dominance in the west and Ponderosa Pine in the east may mark a transition from foothill woodlands to lower montane biozones. The average elevation increases towards the northeast of the study site. The elevation increase supports the classification results of Ponderosa Pine clustered in the northeast region.
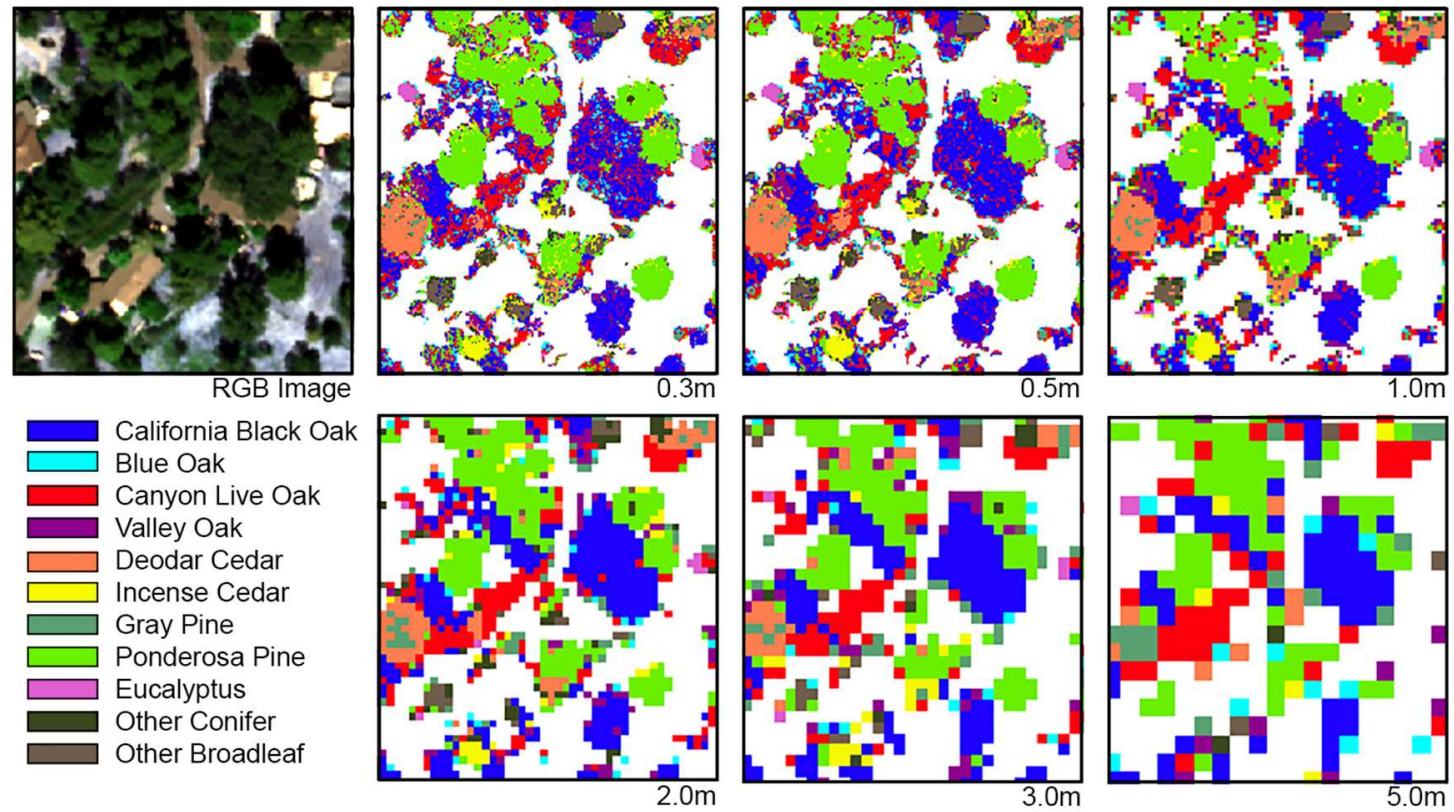

Figure 10. Example tree species classification results from each of the six spatial resolutions. 


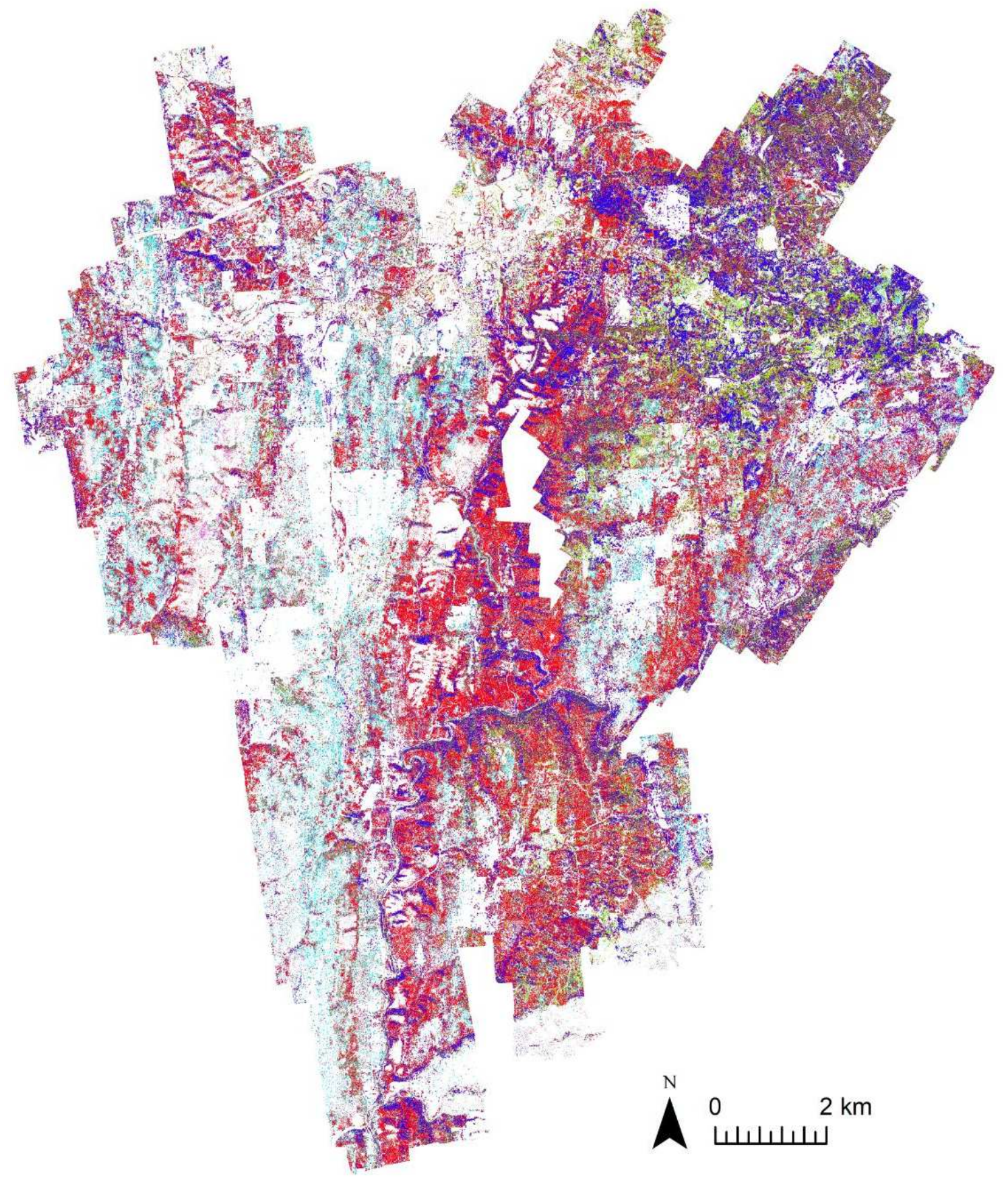

Figure 11. Tree species classification result of the study area. The resolution of the classified raster is one meter. See Figure 9 for map legend. 
Table 2. Per-class pixel count and percent of total classified pixels from each of the classified mosaics.

\begin{tabular}{|c|c|c|c|c|c|c|}
\hline Class & $\begin{array}{c}\text { Pixels Count } \\
(\mathbf{0 . 3 m})\end{array}$ & $\begin{array}{c}\text { Percent of } \\
\text { Total Pixels } \\
(0.3 \mathrm{~m}) \\
\end{array}$ & $\begin{array}{c}\text { Pixels Count } \\
(0.5 \mathrm{~m})\end{array}$ & $\begin{array}{c}\text { Percent of } \\
\text { Total Pixels } \\
(0.5 \mathrm{~m}) \\
\end{array}$ & \begin{tabular}{|c|}
$\begin{array}{c}\text { Pixels Count } \\
(1.0 \mathrm{~m})\end{array}$ \\
\end{tabular} & $\begin{array}{c}\text { Percent of } \\
\text { Total Pixels } \\
(1.0 \mathrm{~m}) \\
\end{array}$ \\
\hline Blue Oak & $150,742,736$ & 16.60 & $61,816,197$ & 15.60 & $12,457,839$ & 12.55 \\
\hline $\begin{array}{l}\text { California } \\
\text { Black Oak }\end{array}$ & $162,575,527$ & 17.91 & $74,914,273$ & 18.91 & $17,935,507$ & 18.06 \\
\hline $\begin{array}{l}\text { Canyon Live } \\
\text { Oak }\end{array}$ & $300,950,260$ & 33.15 & $131,893,152$ & 33.29 & $37,198,525$ & 37.46 \\
\hline $\begin{array}{l}\text { Deodar } \\
\text { Cedar }\end{array}$ & $30,338,385$ & 3.34 & $12,649,834$ & 3.19 & $1,830,152$ & 1.84 \\
\hline Eucalyptus & $13,413,210$ & 1.48 & $6,600,293$ & 1.67 & $1,196,192$ & 1.20 \\
\hline Gray Pine & $45,058,384$ & 4.96 & $18,933,511$ & 4.78 & $5,216,315$ & 5.25 \\
\hline $\begin{array}{l}\text { Incense } \\
\text { Cedar }\end{array}$ & $13,146,717$ & 1.45 & $7,594,046$ & 1.92 & $1,333,854$ & 1.34 \\
\hline $\begin{array}{l}\text { Ponderosa } \\
\text { Pine } \\
\end{array}$ & $68,478,841$ & 7.54 & $25,703,803$ & 6.49 & $7,396,299$ & 7.45 \\
\hline Valley Oak & $76,648,041$ & 8.44 & $34,532,257$ & 8.72 & $9,909,204$ & 9.98 \\
\hline \begin{tabular}{|l} 
Other \\
Broadleaf
\end{tabular} & $33,564,072$ & 3.70 & $16,619,307$ & 4.20 & $3,680,843$ & 3.71 \\
\hline $\begin{array}{l}\text { Other } \\
\text { Conifer }\end{array}$ & $13,019,704$ & 1.43 & $4,900,943$ & 1.24 & $1,139,628$ & 1.15 \\
\hline & $\begin{array}{c}\text { Pixels Count } \\
(\mathbf{2 . 0 m}) \\
\end{array}$ & $\begin{array}{c}\text { Percent of } \\
\text { Total Pixels } \\
(2.0 \mathrm{~m}) \\
\end{array}$ & $\begin{array}{c}\text { Pixels Count } \\
(3.0 \mathrm{~m}) \\
\end{array}$ & $\begin{array}{c}\text { Percent of } \\
\text { Total Pixels } \\
(2.0 \mathrm{~m}) \\
\end{array}$ & \begin{tabular}{|c|}
$\begin{array}{c}\text { Pixels Count } \\
(5.0 \mathrm{~m})\end{array}$ \\
\end{tabular} & $\begin{array}{c}\text { Percent of } \\
\text { Total Pixels } \\
(5.0 \mathrm{~m}) \\
\end{array}$ \\
\hline Blue Oak & $3,848,573$ & 15.36 & $1,866,756$ & 16.77 & 659,006 & 16.44 \\
\hline $\begin{array}{l}\text { California } \\
\text { Black Oak } \\
\end{array}$ & $5,231,071$ & 20.88 & $2,592,081$ & 23.28 & 759,053 & 18.94 \\
\hline $\begin{array}{l}\text { Canyon Live } \\
\text { Oak }\end{array}$ & $9,315,314$ & 37.18 & $4,340,366$ & 38.98 & $1,644,936$ & 41.04 \\
\hline $\begin{array}{l}\text { Deodar } \\
\text { Cedar } \\
\end{array}$ & 169,432 & 0.68 & 40,249 & 0.36 & 16,677 & 0.42 \\
\hline Eucalyptus & 183,491 & 0.73 & 58,148 & 0.52 & 28,778 & 0.72 \\
\hline Gray Pine & $1,169,823$ & 4.67 & 455,023 & 4.09 & 160,437 & 4.00 \\
\hline $\begin{array}{l}\text { Incense } \\
\text { Cedar }\end{array}$ & 502,687 & 2.01 & 281,636 & 2.53 & 125,593 & 3.13 \\
\hline \begin{tabular}{|l|} 
Ponderosa \\
Pine \\
\end{tabular} & $1,899,358$ & 7.58 & 744,034 & 6.68 & 273,766 & 6.83 \\
\hline Valley Oak & $2,003,429$ & 8.00 & 587,832 & 5.28 & 284,940 & 7.11 \\
\hline $\begin{array}{l}\text { Other } \\
\text { Broadleaf }\end{array}$ & 365,877 & 1.46 & 150,640 & 1.35 & 41,203 & 1.03 \\
\hline $\begin{array}{l}\text { Other } \\
\text { Conifer }\end{array}$ & 365,877 & 1.46 & 17,463 & 0.16 & 13,401 & 0.33 \\
\hline
\end{tabular}


Figure 12 provides details on the processing time to complete the first classification at each mosaic resolution. When resolution increases from coarse to fine, the classification time increases. The pixel count of the $0.3 \mathrm{~m}$ mosaic was much more than the $5.0 \mathrm{~m}$ mosaic, which is the likely culprit for increasing processing time. As the pixel size approaches 0 , the processing time increases exponentially toward infinite.
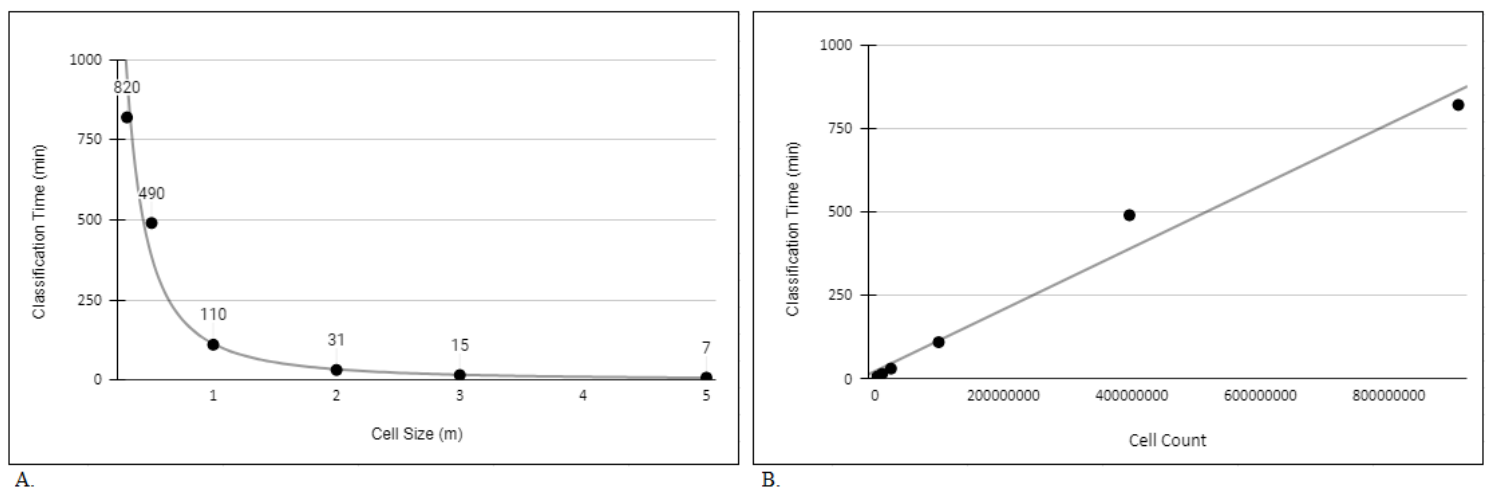

Figure 12. A. Classification time versus cell size. B. Classification time versus cell count.

\subsection{Accuracy Assessment}

I calculated the accuracy of each classification. To do this, I used a confusion matrix which compared the validation tree dataset from the field survey to the classified majority species within each tree crown polygon. For individual confusion matrix results, see the appendix. The overall accuracy and kappa statistic from each classification is listed in Table 3. Table 3 also provides an averaged overall accuracy and kappa statistic for each resolution.

The TV_\# represents each time a classification was created using a new randomly assigned training and validation dataset. 
The 1.0 meter imagery produced classifications with the greatest average overall accuracy and kappa. The 5.0 meter imagery produced the lowest accuracy. The 2.0 meter image produced the greatest range in classification accuracies. Figure 13 details the overall classification accuracy range for each pixel resolution. Figure 14 shows that Valley Oak experienced the highest average producer's accuracy across each resolution, while both Other Conifer and Other Broadleaf were consistently low.

Table 3. Overall accuracy and kappa statistic for ten classification iterations per pixel size. Averaged overall accuracy and kappa for each pixel size along the bottom.

\begin{tabular}{|l|c|c|c|c|c|c|c|c|c|c|c|c|}
\hline & $\mathbf{0 . 3} \mathbf{~ m}$ & $\mathbf{0 . 3} \mathbf{m}$ & $\mathbf{0 . 5} \mathbf{~ m}$ & $\mathbf{0 . 5} \mathbf{~ m}$ & $\mathbf{1 . 0} \mathbf{~ m}$ & $\mathbf{1 . 0} \mathbf{~ m}$ & $\mathbf{2 . 0} \mathbf{m}$ & $\mathbf{2 . 0} \mathbf{~ m}$ & $\mathbf{3 . 0} \mathbf{~ m}$ & $\mathbf{3 . 0} \mathbf{~ m}$ & $\mathbf{5 . 0} \mathbf{~ m}$ & $\mathbf{5 . 0} \mathbf{~ m}$ \\
\hline TV 1 & 65.79 & 0.613 & 71.05 & 0.67 & 74.35 & 0.709 & 72.81 & 0.691 & 73.28 & 0.696 & 65.14 & 0.601 \\
\hline TV 2 & 70.18 & 0.662 & 69.3 & 0.65 & 74.35 & 0.709 & 72.17 & 0.686 & 71.05 & 0.671 & 61.09 & 0.557 \\
\hline TV 3 & 69.06 & 0.648 & 70.67 & 0.67 & 70.09 & 0.659 & 73.13 & 0.693 & 70.48 & 0.664 & 68.2 & 0.636 \\
\hline TV 4 & 66.08 & 0.616 & 69.6 & 0.65 & 73.48 & 0.699 & 73.36 & 0.698 & 73.36 & 0.698 & 63.35 & 0.583 \\
\hline TV 5 & 69.43 & 0.651 & 73.04 & 0.69 & 72.49 & 0.686 & 70.56 & 0.663 & 68.83 & 0.643 & 61.09 & 0.554 \\
\hline TV 6 & 71.93 & 0.683 & 71.62 & 0.68 & 70.48 & 0.666 & 72.37 & 0.687 & 69.16 & 0.65 & 67.58 & 0.629 \\
\hline TV 7 & 67.98 & 0.638 & 72.73 & 0.69 & 75.98 & 0.728 & 75.11 & 0.718 & 72.12 & 0.682 & 65.26 & 0.602 \\
\hline TV 8 & 68.42 & 0.643 & 71.93 & 0.68 & 73.04 & 0.694 & 68.56 & 0.642 & 70.87 & 0.668 & 60.65 & 0.551 \\
\hline TV 9 & 69.26 & 0.649 & 73.04 & 0.693 & 73.16 & 0.694 & 68.26 & 0.639 & 70.26 & 0.66 & 63.8 & 0.585 \\
\hline TV 10 & 70.61 & 0.666 & 74.89 & 0.714 & 74.89 & 0.714 & 75.88 & 0.725 & 73.57 & 0.699 & 68.06 & 0.635 \\
\hline & OA & Kappa & OA & Kappa & OA & Kappa & OA & Kappa & OA & Kappa & OA & Kappa \\
\hline Avg & 68.87 & 0.647 & 71.79 & 0.679 & 73.23 & 0.696 & 72.22 & 0.684 & 71.3 & 0.673 & 64.42 & 0.593 \\
\hline
\end{tabular}

*OA = Overall Accuracy 


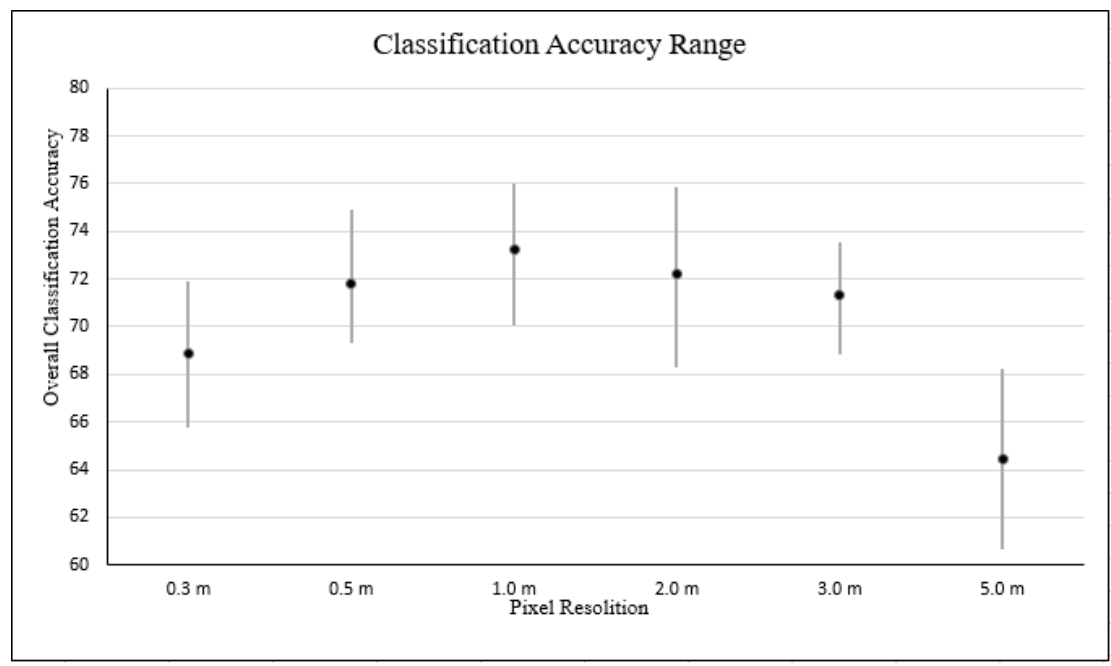

Figure 13. Classification accuracy range and averaged overall accuracy for each pixel resolution.

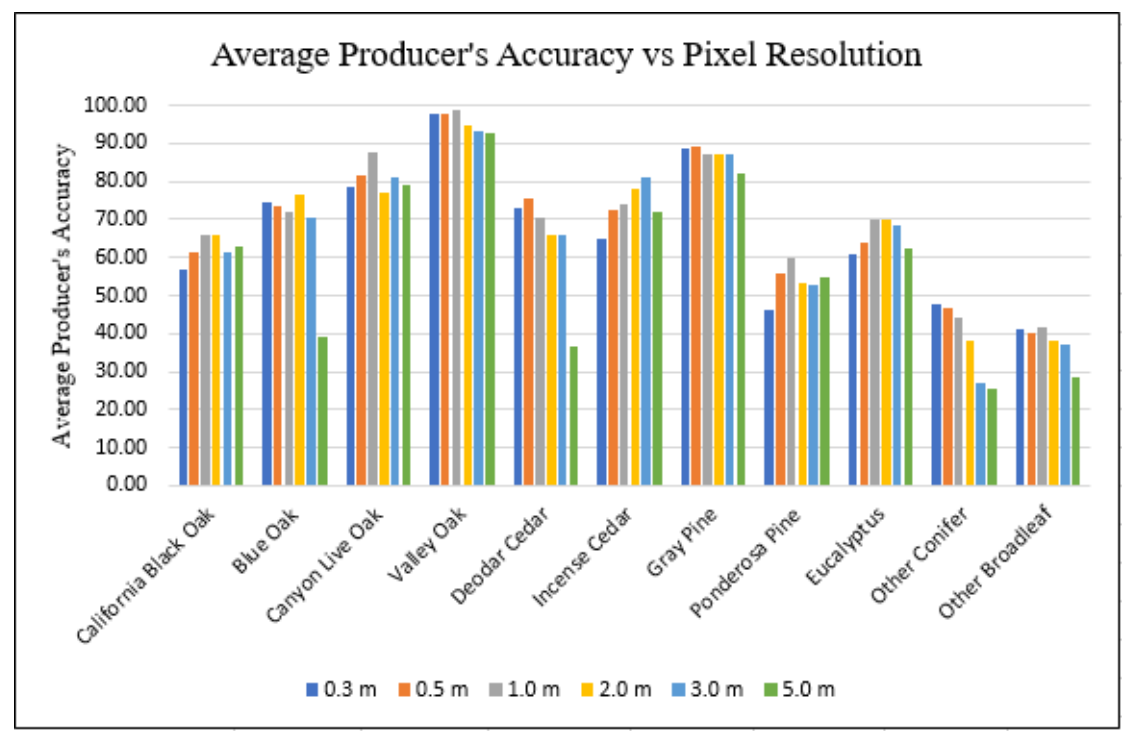

Figure 14. Average producer's accuracy versus pixel resolution. Average producer's accuracy was created by calculating the mean producer's accuracy from the ten classifications created at each resolution. 


\section{Chapter 7. Discussion}

By comparing the classification results at each resolution, the results suggest that tree species classification accuracy is a function of hyperspectral image resolution. However, depending on the user or use case of the species maps, the range in classification accuracies maybe be considered negligible or significant.

It is possible that at higher resolutions, the pixels were able to capture natural inter-crown biophysical variability which may have produced too much variance in each species class for the classification to perform successfully. This explanation may be a reason why the tree crowns in the high-resolution classifications displayed in figure 10 were not classifying homogeneously but instead were composed of mixed species.

The drop in classification accuracy of the low-resolution images may be a result of the pixel size being larger than a portion of the surveyed tree crowns. Around $10 \%$ of the tree crowns were less than 25 square meter, which is the ground footprint size of the 5 meter pixels. The spectral values of a pixel larger than a tree crown would represent reflected light from both the tree and its surroundings. Mixed pixels likely confused the classifier and produced a decrease in classification accuracy.

Valley Oak experienced consistently high producer's accuracy across each resolution (Figure 14). Valley Oak also had some of the largest tree crown areas (Figure 8). The large crown size likely contributed to the high producer's accuracy by allowing more pixels to be included in the majority analysis which determined the final class for each tree crown. Deodar Cedar had an exceptionally small average tree crown, as well as producer's accuracies that were much lower than the Valley Oak's. It is difficult to determine a relationship between species-specific accuracy and tree crown size, however, 
Other Broadleaf and Other Conifer both had consistently poor producer's accuracies with somewhat small crown sizes (Figure 14 and 8). Their crown sizes may have been a contributing factor that caused their accuracies to be low.

The results of this study indicate that my hypothesis was wrong. My expectations for this study were that the images with the highest spatial resolutions would produce the greatest accuracy. The $1.0 \mathrm{~m}$ and $2.0 \mathrm{~m}$ mosaics produced the highest average overall accuracies, while the $0.3 \mathrm{~m}$ image produced the second-lowest overall accuracy.

Peña et al. (2013) performed a similar study to this one, degrading the spatial resolution of a hyperspectral image to test for optimal tree species classification resolutions. They used the spectral angle mapper classifiers to classify common trees in the Rio Clarillo reserve in Chile. The best overall and per-class accuracy of Peña et al. (2013) was reached with their highest spatial resolution of $0.3 \mathrm{~m}$. They suggest, however, that a pixel size just a little smaller than the tree crown diameter is the most appropriate to represent the spatial variability of the trees of interest. The discrepancy between the results of this study compared to Peña et al. (2013) could be a result of differing crown diameters between the two sets of the species of interest.

I believe that one of the largest limitations of this study was the lack of a thoroughly designed field survey. This caused the training and validation dataset to be statistically biased. Due to the limited area of public access, the field survey was not able to achieve a uniformly random distribution of sampled trees. Measuring \& Monitoring Plant Populations, a guide to plant populations sampling by Elzinga et al. (1998), indicates that a random cluster sampling methodology similar to the one used in this research is more appropriately used for smaller geographic regions. They mention that a 
disadvantage to cluster sampling methodology is that it is difficult to figure out how many clusters need to be sampled in order to appropriately represent the population of interest. Sampling using a grid-cell method, which divides the study site using a grid, would help increase sample distribution and uniformity. The sample count per species was also low. Little effort was made to match the count per species to the study site's natural species population count. One method for ensuring that species sample count is proportionate to the natural species population is to use existing data from the study site (Elzinga et al., 1998). U.S. Forest Service provides reference species population data through their publicly available CalVeg vegetation classification maps (Existing Vegetation - CalVeg, 2004). With a larger and more thoroughly distributed field survey, the classification results may reveal a more reliable relationship between tree species classification accuracy and hyperspectral spatial resolution.

An interesting result from of this study was the relationship between pixel resolution and classification time. The time to classify the $0.3 \mathrm{~m}$ image ( 820 minutes) was close to two orders of magnitude more than the $5.0 \mathrm{~m}$ image ( 7 minutes) while still achieving a comparable averaged overall accuracy (Figure 12 A). The classification time increases exponentially when the resolution increases (Figure $12 \mathrm{~A}$ ) and the classification time increases linearly with the pixel count as the resolution increases (Figure $12 \mathrm{~B}$ ). This indicates that computational time is proportional to the number of pixels used in the classification. Users should factor in pixel count and computational time when selecting a resolution.

The results of this study are significant because they suggest that reasonable classification results can be achieved using imagery at scales associated with airborne 
sensors, as well as UAV and high-resolution satellite imagery. Airborne scale acquisition costs are high and require skilled personnel. UAV image collection campaigns may be a more cost-efficient way to collect imagery for tree species classification. Future studies should use the relationship identified in this study to help them choose a resolution that best fits their budget and computational power.

The classification accuracy results are relatively low, in the mid $60 \%$ to mid $70 \%$ range. Continued research should attempt to further understand the relationship between classification accuracy to hyperspectral imagery resolution while also working toward achieving higher accuracy results. The classification input for this study was a simple reduced-band reflected raster. Studies have had success improving their species classification accuracy by including image-derived products into their classification. Bands from principal component analysis and vegetation indices have been used as classification inputs to increase results (Jensen et al., 2012 \& Krishnayya, 2014). Derived image products and improved tree survey data may reveal a more detailed relationship between accuracy and spatial resolution. 


\section{Chapter 8. Conclusion}

Hyperspectral imagery has become a common remote sensing data type used in tree species classifications. High spatial resolution hyperspectral imagery has the inherent drawbacks of expensive acquisition costs, large data sizes, and can be computationally taxing to use. This study attempted to find a relationship between spatial resolution of hyperspectral imagery and tree species classification accuracy. By comparing the classification results at each resolution, the results suggest that tree species classification accuracy is not related to hyperspectral image resolution. Depending on the user or use case of the classification maps, the variations in classification accuracies maybe be considered negligible. The crown size of the trees appears to be an important factor mediating classification accuracy and image resolution. Tree species with smaller crown size are more likely to be misclassified on images with coarser resolution. The classification processing time for higher resolutions was much larger than at lower spatial resolution, appearing to the number of pixels being classified. Future research may further investigate the relationship by comparing classification results produced from more comprehensive field survey datasets and image-derived products. 


\section{References}

Alonzo, M., Roth, K., \& Roberts, D. (2013). Identifying Santa Barbara's urban tree species from AVIRIS imagery using canonical discriminant analysis. Remote Sensing Letters, 4(5), 513-521.

Anderegg, W. R., Jeffrey, L., Hicke, A., Fisher R. A., Allen, C. D, Aukema, J., Bentz, B., Hood, S., Lichstein, J. W., Macalady, A. K., McDowell, N., Pan, Y., Raffa, K., Sala, A., Shaw, J. D., Stephenson, N. L., Tague, C., \& Zeppel, M. (2015) Tree Mortality from Drought, Insects, and Their Interactions in a Changing Climate. New Phytologist, 208(2015), 674-683.

Aplin, P., \& Atkinson, P. M. (2001). Sub-pixel land cover mapping for per-field classification. International Journal of Remote Sensing, 22(14), 2853-2858.

Asner, G. P. (1998). Biophysical and Biochemical Sources of Variability in Canopy Reflectance. Remote Sensing of Environment, 64(3), 234-253.

Asner, G. P., Brodrick, P. G., Anderson, C. B., Vaughn N., Knapp, D. E., \& Martin, E. M. (2015). Progressive Forest Canopy Water Loss during the 2012-2015 California Drought. Proceedings of the National Academy of Sciences, 113(2).

Asner, G. P., Ustin, S. L., Townsend, P. A., Martin, R. E., \& Chadwick, K. D. (2015). Forest biophysical and biochemical properties from hyperspectral and LiDAR remote sensing. Land Resources Monitoring, Modeling and Mapping with Remote Sensing, 429-448.

Baldeck, C., \& Asner, G. P. 2014. Improving Remote Species Identification through Efficient Training Data Collection. Remote Sensing, 6(4), 2682-2698.

Ball, G. H., \& Hall, D. J. (1965) Isodata, a Novel Method of Data Analysis and Pattern Classification. Stanford Research Inst.

Beisl, U., Telaar, J., \& von Schönemark, M. (2008) Atmospheric Correction, Reflectance Calibration and BRDF Correction for ADS40 Image Data. Proceedings of the XXI ISPRS Congress, Commission VII.

Blaschke, T. (2010). Object based image analysis for remote sensing. ISPRS Journal of Photogrammetry and Remote Sensing, 65(1), 2-16.

Burges, C. (1998). A tutorial on support vector machines for pattern recognition. Data Mining and Knowledge Discovery, 2(2), 121-167.

Burrough, P.A., van Gaans, P.M.F., \& MacMillan, R.A. (2000) High-Resolution Landform Classification Using Fuzzy K-Means. Fuzzy Sets and Systems, 113(1), $37-52$.

Cal Fire, S. of. California (2018). CAL FIRE Investigators Determine Causes of 12 Wildfires in Mendocino, Humboldt, Butte, Sonoma, Lake, and Napa Counties.

Cal Fire, S. of. California. (2018). Statewide Fire Map. Statistics \& Events. http://cdfdata.fire.ca.gov/incidents/incidents_statsevents 
California, S. of. (2008). Power Line Fire Prevention Field Guide. Engineering Field Guide

Centers for Water and Wildland Resources. (1996). Status of the Sierra Nevada: Summary of the Sierra Nevada Ecosystem Project Report. Davis (CA): CWWR, University of California. Wildland Resources Center Report, no. 39.

Chen, Y., Lin Z., Zhao X., Wang, G., \& Gu, Y. (2014) Deep learning-based classification of hyperspectral data. IEEE J. Sel. Topics Appl. Earth Observ. Remote Sens., 7(6), 2094-2107.

Colgan, M., Baldeck, C., Féret, J., \& Asner, G. (2012). Mapping Savanna Tree Species at Ecosystem Scales Using Support Vector Machine Classification and BRDF Correction on Airborne Hyperspectral and LiDAR Data. Remote Sensing, 4(11), 3462-3480.

Coulter, D., Hauff, P. L., \& Kerby, W. L. (2007) Airborne Hyperspectral Remote Sensing. Fifth Decennial International Conference on Mineral Exploration, Toronto, ON, Canada, 9-12, 375-386.

Dalponte, M., Bruzzone, L., \& Gianelle, D. (2008). Fusion of Hyperspectral and LIDAR Remote Sensing Data for Classification of Complex Forest Areas. IEEE Transactions on Geoscience and Remote Sensing, 46(5), 1416-1427.

Dalponte, M., Orka, H. O., Gobakken, T., Gianelle, D., \& Naesset, E. (2013). Tree Species Classification in Boreal Forests with Hyperspectral Data. IEEE Transactions on Geoscience and Remote Sensing, 51(5), 2632-2645.

Elzinga, C. L., Salzer, D.,\& Willoughby, J. Measuring \& Monitoring Plant Populations. U.S. Department of the Interior, Bureau of Land Management, National Applied Resource Sciences Center, 1998.

Existing Vegetation - CALVEG, [ESRI personal geodatabase]. (2004). McClellan, CA: USDA-Forest Service, Pacific Southwest Region.

Fassnacht, F. E., Latifi, H., Stereńczak, K., Modzelewska, A., Lefsky, M., Waser, T. L., Straub, C., \& Ghosh, A. (2016). Review of studies on tree species classification from remotely sensed data. Remote Sensing of Environment, 186. 64-87.

Ferreira, M. P., Zortea, M., Zanotta, D.C., Shimabukuro, Y. E., \& Filho, C. (2016). Mapping tree species in tropical seasonal semi-deciduous forests with hyperspectral and multispectral data. Remote Sensing of Environment, 179, 6678.

Foody, G. M. (1996). Approaches for the production and evaluation of fuzzy land cover classifications from remotely-sensed data. International Journal of Remote Sensing, 17(7), 1317-1340.

Gao, B. C., Montes, M. J., Davis, C. O., \& Goetz, A. F. (2009). Atmospheric correction algorithms for hyperspectral remote sensing data of land and ocean. Remote Sensing of Environment, 113. 
Gatziolis, D., \& Andersen H. E. (2008). A guide to LIDAR data acquisition and processing for the forests of the Pacific Northwest. Gen. Tech. Rep. PNW-GTR768. Portland, OR: U.S. Department of Agriculture, Forest Service, Pacific Northwest Research Station. 32 p. DOI: https://doi.org/10.2737/PNW-GTR-768

Goetz, A. F. H., \& Strivastava, V. (1985), Mineralogical mapping in the Cuprite mining district. Proceedings of the Airborne Imaging Spectrometer (AIS) Data Analysis Workshop: Jet Propulsion Laboratory Publication, 85(41), 22-29.

Goetz, A. F. (2007). Three decades of hyperspectral remote sensing of the Earth: A personal view. Remote Sensing of Environment, 113.

Green, R. O., Eastwood, M. L., Sarture, C. M., Chrien, T. G., Aronsson, M., Chippendale, B. J., Faust, J. A., Pavri, B. E., Chovit, C. J., Solis, M., Olah, M. R., \& Williams. O. (1998). Imaging Spectroscopy and the Airborne Visible/Infrared Imaging Spectrometer (AVIRIS). Remote Sensing of Environment, 65(3), 227248.

Hsu, C. W., Chang, C. C., \& Lin, C. J. (2003). A practical guide to support vector classification. Department of Computer Science, National Taiwan University.

Janssen, L.L.F., and M. Molenaar. Terrain Objects, Their Dynamics and Their Monitoring by the Integration of GIS and Remote Sensing. IEEE Transactions on Geoscience and Remote Sensing, vol. 33, no. 3, 1994, pp. 749-758., doi:10.1109/36.387590.

Jensen, J. R. (1996) Introductory Digital Image Processing: a Remote Sensing Perspective. Prentice-Hall, 1996.

Jensen, J. R., \& Cowen, D. C. (2011). Remote Sensing of Urban/Suburban Infrastructure and Socio-Economic Attributes. The Map Reader: 153-163.

Jensen, R. R., Hardin, P. J., \& Hardin, A. J. (2012). Classification of urban tree species using hyperspectral imagery. Geocarto International, 27(5), 443-458.

Koch, B. 2010. Status and future of laser scanning, synthetic aperture radar and hyperspectral remote sensing data for forest biomass assessment. ISPRS Journal of Photogrammetry and Remote Sensing, 65(6), 581-590.

Krishnayya, N.S.R.. (2014). Hyperspectral Data Dimensionality Reduction and the Impact of Multi-seasonal Hyperion EO-1 Imagery on Classification Accuracies of Tropical Forest Species. Photogrammetric Engineering and Remote Sensing. 80. 10.14358/PERS.80.8.773.

Lu, D., \& Weng, Q. (2007). A survey of image classification methods and techniques for improving classification performance. International Journal of Remote Sensing, 28(5), 823-870.

Martin, M., Newman, S., Aber, J., \& Congalton, R. (1998). Determining Forest Species Composition Using High Spectral Resolution Remote Sensing Data. Remote Sensing of Environment, 65(3), 249-254. 
Meer, F., Werff, H., Ruitenbeek, F,. Hecker, C. A., Bakker, W. H., Noomen, M. F., Meijde, M., Carranza, E., Smeth, J., \& Woldai, T. (2012). Multi- and hyperspectral geologic remote sensing: A review. International Journal of Applied Earth Observation and Geoinformation, 14(1), 112-128.

Mountrakis, G., Im, J., \& Ogole, C. (2011). Support vector machines in remote sensing: A review. ISPRS Journal of Photogrammetry and Remote Sensing, 66(3), 247259.

Pal, M. (2005) Random forest classifier for remote sensing classification. International Journal of Remote Sensing, 26(1) 217-222. DOI: $\underline{10.1080 / 01431160412331269698}$

Peña, M. A., Cruz, P., \& Roig, M. (2013). The effect of spectral and spatial degradation of hyperspectral imagery for the Sclerophyll tree species classification. International Journal of Remote Sensing, 34(20), 7113-7130.

Reitberger, J., Krzystek, P., \& Stilla, U. (2008). Analysis of full waveform LIDAR data for the classification of deciduous and coniferous trees. International Journal of Remote Sensing, 29(5), 1407-1431.

Roth, K. L., Roberts, D. A., Dennison, P. E., Alonzo, M., Peterson, S. H., \& Beland, M. (2015). Differentiating plant species within and across diverse ecosystems with imaging spectroscopy. Remote Sensing of Environment, 167, 135-151

Van Ewijk, K. Y., Randin, C. F., Treitz, P. M., \& Scott, N. A. (2014). Predicting finescale tree species abundance patterns using biotic variables derived from LiDAR and high spatial resolution imagery. Remote Sensing of Environment, 150, 120131.

Zhang, C., \& Qiu, F. (2012). Mapping Individual Tree Species in an Urban Forest Using Airborne LiDAR Data and Hyperspectral Imagery. Photogrammetric Engineering \& Remote Sensing, 78(10), 1079-1087.

Zhao, Y., Zeng, Y., Zhao, D., Wu, B., \& Zhao, Q. (2016). The Optimal Leaf Biochemical Selection for Mapping Species Diversity Based on Imaging Spectroscopy. Remote Sensing 8.3, 216. 
Appendix: Classification Confusion Matrices

A. Confusion matrix for individual classification runs of $0.3 \mathrm{~m}$ images.

\begin{tabular}{|c|c|c|c|c|c|c|c|c|c|c|c|c|c|}
\hline $0.3 m \# 1$ & BO & DC & $\mathrm{E}$ & GP & IC & LO & PP & Vo & BO & $O D$ & $\mathrm{OC}$ & Count & Producer's \\
\hline Blue Oak & 11 & 0 & 0 & 0 & 0 & 5 & 0 & 3 & 1 & 0 & 0 & 20 & 55.00 \\
\hline Deodar Cedar & 0 & 7 & 0 & 1 & 0 & 0 & 1 & 0 & 1 & 0 & 1 & 11 & 63.64 \\
\hline Eucalyptus & 1 & 0 & 7 & 0 & 0 & 0 & 0 & 0 & 0 & 0 & 0 & 8 & 87.50 \\
\hline Gray Pine & 0 & 0 & 0 & 21 & 0 & 0 & 0 & 0 & 0 & 0 & 0 & 21 & 100.00 \\
\hline Incense Cedar & 0 & 0 & 1 & 0 & 12 & 0 & 1 & 0 & 0 & 0 & 1 & 15 & 80.00 \\
\hline Live Oak & 7 & 1 & 0 & 0 & 0 & 24 & 0 & 1 & 5 & 0 & 0 & 38 & 63.16 \\
\hline Ponderosa Pine & 0 & 1 & 0 & 0 & 2 & 1 & 36 & 1 & 0 & 0 & 1 & 42 & 85.71 \\
\hline Valley Oak & 2 & 0 & 0 & 0 & 0 & 1 & 0 & 11 & 6 & 1 & 0 & 21 & 52.38 \\
\hline Black Oak & 2 & 0 & 0 & 0 & 0 & 9 & 0 & 6 & 13 & 2 & 0 & 32 & 40.63 \\
\hline Other Deciduous & 0 & 0 & 1 & 0 & 0 & 1 & 1 & 1 & 1 & 4 & 1 & 10 & 40.00 \\
\hline Other Conifer & 0 & 1 & 0 & 0 & 4 & 0 & 0 & 1 & 0 & 0 & 4 & 10 & 40.00 \\
\hline Count & 23 & 10 & 9 & 22 & 18 & 41 & 39 & 24 & 27 & 7 & 8 & Accuracy & Kappa \\
\hline User's & 47.83 & 70.00 & 77.78 & 95.45 & 66.67 & 58.54 & 92.31 & 45.83 & 48.15 & 57.14 & 50.00 & 65.79 & 0.613 \\
\hline $0.3 \mathrm{~m} \# 2$ & BO & DC & $\mathrm{E}$ & GP & IC & LO & PP & vo & $\mathrm{BO}$ & $O D$ & OC & Count & Producer's \\
\hline Blue Oak & 16 & 0 & 0 & 0 & 0 & 3 & 0 & 0 & 1 & 0 & 0 & 20 & 80.00 \\
\hline Deodar Cedar & 0 & 8 & 0 & 2 & 1 & 0 & 0 & 0 & 0 & 0 & 0 & 11 & 72.73 \\
\hline Eucalyptus & 1 & 0 & 5 & 0 & 0 & 0 & 0 & 0 & 0 & 1 & 0 & 7 & 71.43 \\
\hline Gray Pine & 0 & 1 & 0 & 21 & 0 & 0 & 0 & 0 & 0 & 0 & 0 & 22 & 95.45 \\
\hline Incense Cedar & 0 & 1 & 0 & 0 & 11 & 0 & 3 & 0 & 0 & 0 & 0 & 15 & 73.33 \\
\hline Live Oak & 4 & 0 & 0 & 0 & 0 & 26 & 0 & 2 & 7 & 0 & 0 & 39 & 66.67 \\
\hline Ponderosa Pine & 0 & 1 & 0 & 0 & 1 & 2 & 34 & 1 & 0 & 0 & 0 & 39 & 87.18 \\
\hline Valley Oak & 3 & 0 & 0 & 0 & 0 & 3 & 1 & 10 & 2 & 1 & 0 & 20 & 50.00 \\
\hline Black Oak & 2 & 0 & 0 & 0 & 0 & 5 & 0 & 6 & 19 & 1 & 0 & 33 & 57.58 \\
\hline Other Deciduous & 0 & 1 & 0 & 0 & 2 & 2 & 0 & 0 & 1 & 6 & 0 & 12 & 50.00 \\
\hline Other Conifer & 0 & 1 & 0 & 0 & 3 & 0 & 0 & 1 & 0 & 1 & 4 & 10 & 40.00 \\
\hline Count & 26 & 13 & 5 & 23 & 18 & 41 & 38 & 20 & 30 & 10 & 4 & Accuracy & Kappa \\
\hline User's & 61.54 & 61.54 & 100.00 & 91.30 & 61.11 & 63.41 & 89.47 & 50.00 & 63.33 & 60.00 & 100.00 & 70.18 & 0.662 \\
\hline $0.3 \mathrm{~m} \# 3$ & BO & $D C$ & $\mathrm{E}$ & GP & IC & LO & PP & VO & $\mathrm{BO}$ & OD & OC & Count & Producer's \\
\hline Blue Oak & 12 & 0 & 0 & 0 & 0 & 4 & 0 & 2 & 2 & 0 & 0 & 20 & 60.00 \\
\hline Deodar Cedar & 0 & 10 & 0 & 0 & 0 & 0 & 0 & 0 & 0 & 1 & 0 & 11 & 90.91 \\
\hline Eucalyptus & 1 & 0 & 5 & 0 & 0 & 0 & 0 & 0 & 1 & 0 & 0 & 7 & 71.43 \\
\hline Gray Pine & 0 & 0 & 0 & 21 & 0 & 0 & 0 & 0 & 1 & 0 & 0 & 22 & 95.45 \\
\hline Incense Cedar & 0 & 0 & 1 & 0 & 6 & 0 & 4 & 0 & 0 & 1 & 3 & 15 & 40.00 \\
\hline Live Oak & 1 & 0 & 0 & 0 & 0 & 31 & 1 & 4 & 1 & 0 & 0 & 38 & 81.58 \\
\hline Ponderosa Pine & 0 & 0 & 1 & 0 & 2 & 0 & 34 & 1 & 0 & 2 & 0 & 40 & 85.00 \\
\hline Valley Oak & 0 & 0 & 0 & 0 & 0 & 3 & 1 & 6 & 9 & 0 & 0 & 19 & 31.58 \\
\hline Black Oak & 0 & 1 & 0 & 0 & 0 & 5 & 0 & 4 & 20 & 1 & 0 & 31 & 64.52 \\
\hline Other Deciduous & 0 & 0 & 2 & 0 & 0 & 0 & 0 & 1 & 1 & 6 & 0 & 10 & 60.00 \\
\hline Other Conifer & 1 & 1 & 0 & 0 & 1 & 0 & 2 & 0 & 0 & 2 & 3 & 10 & 30.00 \\
\hline Count & 15 & 12 & 9 & 21 & 9 & 43 & 42 & 18 & 35 & 13 & 6 & Accuracy & Kappa \\
\hline User's & 80.00 & 83.33 & 55.56 & 100.00 & 66.67 & 72.09 & 80.95 & 33.33 & 57.14 & 46.15 & 50.00 & 69.06 & 0.648 \\
\hline $0.3 \mathrm{~m} \# 4$ & BO & DC & $E$ & GP & IC & LO & PP & VO & $\mathrm{BO}$ & OD & OC & Count & Producer's \\
\hline Blue Oak & 10 & 0 & 0 & 1 & 0 & 5 & 0 & 2 & 3 & 0 & 0 & 21 & 47.62 \\
\hline Deodar Cedar & 0 & 7 & 1 & 1 & 0 & 0 & 1 & 0 & 1 & 0 & 0 & 11 & 63.64 \\
\hline Eucalyptus & 0 & 0 & 6 & 0 & 0 & 0 & 0 & 0 & 0 & 1 & 0 & 7 & 85.71 \\
\hline Gray Pine & 0 & 0 & 0 & 22 & 0 & 0 & 0 & 0 & 0 & 0 & 0 & 22 & 100.00 \\
\hline Incense Cedar & 0 & 0 & 0 & 0 & 12 & 0 & 3 & 0 & 0 & 0 & 0 & 15 & 80.00 \\
\hline Live Oak & 3 & 1 & 0 & 0 & 0 & 21 & 0 & 7 & 4 & 1 & 0 & 37 & 56.76 \\
\hline Ponderosa Pine & 0 & 0 & 0 & 0 & 1 & 1 & 36 & 0 & 0 & 1 & 1 & 40 & 90.00 \\
\hline Valley Oak & 2 & 0 & 0 & 0 & 0 & 4 & 0 & 11 & 3 & 0 & 0 & 20 & 55.00 \\
\hline Black Oak & 3 & 1 & 0 & 0 & 0 & 7 & 0 & 3 & 16 & 1 & 0 & 31 & 51.61 \\
\hline Other Deciduous & 0 & 1 & 0 & 0 & 2 & 2 & 1 & 0 & 3 & 4 & 0 & 13 & 30.77 \\
\hline Other Conifer & 0 & 1 & 0 & 0 & 3 & 0 & 1 & 0 & 0 & 0 & 5 & 10 & 50.00 \\
\hline Count & 18 & 11 & 7 & 24 & 18 & 40 & 42 & 23 & 30 & 8 & 6 & Accuracy & Kappa \\
\hline User's & 55.56 & 63.64 & 85.71 & 91.67 & 66.67 & 52.50 & 85.71 & 47.83 & 53.33 & 50.00 & 83.33 & 66.08 & 0.616 \\
\hline $0.3 \mathrm{~m} \# 5$ & BO & DC & $\mathrm{E}$ & GP & IC & LO & PP & vo & BO & $O D$ & OC & Count & Producer's \\
\hline Blue Oak & 12 & 0 & 0 & 0 & 0 & 5 & 0 & 1 & 1 & 0 & 0 & 19 & 63.16 \\
\hline Deodar Cedar & 0 & 9 & 0 & 0 & 0 & 0 & 1 & 1 & 0 & 0 & 0 & 11 & 81.82 \\
\hline Eucalyptus & 1 & 0 & 6 & 0 & 0 & 0 & 0 & 0 & 0 & 1 & 0 & 8 & 75.00 \\
\hline Gray Pine & 0 & 0 & 0 & 21 & 0 & 0 & 0 & 0 & 0 & 0 & 0 & 21 & 100.00 \\
\hline Incense Cedar & 0 & 1 & 0 & 0 & 9 & 0 & 5 & 0 & 0 & 0 & 0 & 15 & 60.00 \\
\hline Live Oak & 2 & 1 & 0 & 0 & 0 & 25 & 0 & 3 & 8 & 0 & 0 & 39 & 64.10 \\
\hline Ponderosa Pine & 0 & 0 & 0 & 0 & 1 & 1 & 38 & 1 & 0 & 0 & 1 & 42 & 90.48 \\
\hline Valley Oak & 4 & 0 & 0 & 0 & 0 & 3 & 0 & 7 & 6 & 0 & 0 & 20 & 35.00 \\
\hline Black Oak & 1 & 1 & 0 & 0 & 0 & 5 & 1 & 4 & 20 & 0 & 0 & 32 & 62.50 \\
\hline Other Deciduous & 0 & 0 & 0 & 0 & 0 & 3 & 1 & 0 & 0 & 8 & 0 & 12 & 66.67 \\
\hline Other Conifer & 0 & 3 & 0 & 0 & 1 & 0 & 2 & 0 & 0 & 0 & 4 & 10 & 40.00 \\
\hline Count & 20 & 15 & 6 & 21 & 11 & 42 & 48 & 17 & 35 & 9 & 5 & Accuracy & Карра \\
\hline
\end{tabular}




\begin{tabular}{|c|c|c|c|c|c|c|c|c|c|c|c|c|c|}
\hline $0.3 \mathrm{~m} \# 6$ & BO & DC & E & GP & IC & LO & PP & Vo & $\mathrm{BO}$ & OD & OC & Count & Producer's \\
\hline Blue Oak & 14 & 0 & 1 & 0 & 0 & 2 & 0 & 2 & 1 & 0 & 0 & 20 & 70.00 \\
\hline Deodar Cedar & 0 & 7 & 0 & 1 & 0 & 0 & 1 & 0 & 1 & 0 & 1 & 11 & 63.64 \\
\hline Eucalyptus & 1 & 0 & 6 & 0 & 0 & 0 & 0 & 0 & 0 & 0 & 0 & 7 & 85.71 \\
\hline Gray Pine & 0 & 0 & 0 & 21 & 0 & 0 & 0 & 0 & 0 & 0 & 0 & 21 & 100.00 \\
\hline Incense Cedar & 0 & 0 & 1 & 0 & 12 & 0 & 1 & 0 & 0 & 0 & 1 & 15 & 80.00 \\
\hline Live Oak & 6 & 1 & 0 & 0 & 0 & 25 & 0 & 3 & 3 & 1 & 0 & 39 & 64.10 \\
\hline Ponderosa Pine & 0 & 1 & 0 & 0 & 2 & 0 & 37 & 0 & 0 & 1 & 0 & 41 & 90.24 \\
\hline Valley Oak & 3 & 0 & 0 & 0 & 0 & 1 & 0 & 11 & 5 & 0 & 0 & 20 & 55.00 \\
\hline Black Oak & 1 & 1 & 0 & 0 & 0 & 2 & 0 & 5 & 21 & 1 & 0 & 31 & 67.74 \\
\hline Other Deciduous & 0 & 1 & 0 & 0 & 0 & 1 & 0 & 0 & 3 & 5 & 3 & 13 & 38.46 \\
\hline Other Conifer & 0 & 1 & 0 & 0 & 3 & 0 & 1 & 0 & 0 & 0 & 5 & 10 & 50.00 \\
\hline Count & 25 & 12 & 8 & 22 & 17 & 31 & 40 & 21 & 34 & 8 & 10 & Accuracy & Kappa \\
\hline User's & 56.00 & 58.33 & 75.00 & 95.45 & 70.59 & 80.65 & 92.50 & 52.38 & 61.76 & 62.50 & 50.00 & 71.93 & 0.683 \\
\hline $0.3 \mathrm{~m} \# 7$ & BO & DC & $\mathrm{E}$ & GP & IC & LO & PP & vo & BO & $O D$ & OC & Count & Producer's \\
\hline Blue Oak & 7 & 0 & 0 & 0 & 0 & 6 & 0 & 6 & 0 & 0 & 0 & 19 & 36.84 \\
\hline Deodar Cedar & 0 & 10 & 0 & 0 & 0 & 0 & 1 & 0 & 0 & 0 & 0 & 11 & 90.91 \\
\hline Eucalyptus & 0 & 0 & 7 & 0 & 0 & 0 & 0 & 0 & 0 & 1 & 0 & 8 & 87.50 \\
\hline Gray Pine & 0 & 2 & 0 & 19 & 0 & 0 & 0 & 0 & 0 & 0 & 0 & 21 & 90.48 \\
\hline Incense Cedar & 0 & 1 & 0 & 0 & 12 & 0 & 2 & 0 & 0 & 0 & 0 & 15 & 80.00 \\
\hline Live Oak & 0 & 0 & 0 & 0 & 0 & 25 & 1 & 4 & 7 & 2 & 0 & 39 & 64.10 \\
\hline Ponderosa Pine & 0 & 1 & 0 & 0 & 1 & 0 & 35 & 0 & 0 & 1 & 1 & 39 & 89.74 \\
\hline Valley Oak & 2 & 0 & 0 & 0 & 0 & 2 & 2 & 8 & 7 & 0 & 0 & 21 & 38.10 \\
\hline Black Oak & 1 & 1 & 0 & 0 & 0 & 5 & 0 & 3 & 20 & 2 & 0 & 32 & 62.50 \\
\hline Other Deciduous & 0 & 1 & 0 & 0 & 0 & 1 & 0 & 0 & 1 & 8 & 2 & 13 & 61.54 \\
\hline Other Conifer & 0 & 2 & 0 & 0 & 4 & 0 & 0 & 0 & 0 & 0 & 4 & 10 & 40.00 \\
\hline Count & 10 & 18 & 7 & 19 & 17 & 39 & 41 & 21 & 35 & 14 & 7 & Accuracy & Kappa \\
\hline User's & 70.00 & 55.56 & 100.00 & 100.00 & 70.59 & 64.10 & 85.37 & 38.10 & 57.14 & 57.14 & 57.14 & 67.98 & 0.638 \\
\hline $0.3 \mathrm{~m} \# 8$ & BO & $D C$ & $\mathrm{E}$ & GP & IC & LO & PP & VO & $\mathrm{BO}$ & $O D$ & OC & Count & Producer's \\
\hline Blue Oak & 9 & 0 & 0 & 2 & 0 & 6 & 0 & 3 & 0 & 0 & 0 & 20 & 45.00 \\
\hline Deodar Cedar & 0 & 8 & 0 & 1 & 0 & 0 & 0 & 0 & 1 & 0 & 1 & 11 & 72.73 \\
\hline Eucalyptus & 1 & 0 & 6 & 0 & 0 & 0 & 0 & 0 & 0 & 1 & 0 & 8 & 75.00 \\
\hline Gray Pine & 0 & 0 & 0 & 21 & 0 & 0 & 0 & 0 & 0 & 0 & 0 & 21 & 100.00 \\
\hline Incense Cedar & 0 & 0 & 0 & 0 & 12 & 0 & 3 & 0 & 0 & 0 & 0 & 15 & 80.00 \\
\hline Live Oak & 4 & 3 & 0 & 0 & 0 & 23 & 0 & 2 & 6 & 0 & 0 & 38 & 60.53 \\
\hline Ponderosa Pine & 0 & 0 & 1 & 0 & 2 & 0 & 35 & 0 & 0 & 0 & 1 & 39 & 89.74 \\
\hline Valley Oak & 2 & 0 & 0 & 0 & 0 & 5 & 1 & 8 & 3 & 1 & 0 & 20 & 40.00 \\
\hline Black Oak & 2 & 0 & 0 & 0 & 0 & 4 & 0 & 3 & 22 & 1 & 0 & 32 & 68.75 \\
\hline Other Deciduous & 0 & 2 & 0 & 0 & 0 & 2 & 2 & 0 & 0 & 5 & 3 & 14 & 35.71 \\
\hline Other Conifer & 0 & 1 & 0 & 0 & 1 & 0 & 0 & 1 & 0 & 0 & 7 & 10 & 70.00 \\
\hline Count & 18 & 14 & 7 & 24 & 15 & 40 & 41 & 17 & 32 & 8 & 12 & Accuracy & Kappa \\
\hline User's & 50.00 & 57.14 & 85.71 & 87.50 & 80.00 & 57.50 & 85.37 & 47.06 & 68.75 & 62.50 & 58.33 & 68.42 & 0.643 \\
\hline $0.3 m \# 9$ & BO & DC & $\mathrm{E}$ & GP & IC & LO & PP & Vo & $\mathrm{BO}$ & OD & OC & Count & Producer's \\
\hline Blue Oak & 12 & 0 & 0 & 0 & 0 & 7 & 0 & 1 & 0 & 0 & 0 & 20 & 60.00 \\
\hline Deodar Cedar & 0 & 9 & 0 & 1 & 0 & 0 & 0 & 0 & 1 & 0 & 0 & 11 & 81.82 \\
\hline Eucalyptus & 1 & 0 & 5 & 0 & 0 & 0 & 0 & 0 & 0 & 1 & 0 & 7 & 71.43 \\
\hline Gray Pine & 0 & 0 & 0 & 20 & 0 & 1 & 0 & 0 & 0 & 0 & 0 & 21 & 95.24 \\
\hline Incense Cedar & 0 & 0 & 0 & 0 & 11 & 0 & 4 & 0 & 0 & 0 & 0 & 15 & 73.33 \\
\hline Live Oak & 3 & 2 & 0 & 0 & 0 & 24 & 0 & 5 & 6 & 0 & 0 & 40 & 60.00 \\
\hline Ponderosa Pine & 0 & 0 & 0 & 0 & 1 & 1 & 40 & 0 & 0 & 1 & 0 & 43 & 93.02 \\
\hline Valley Oak & 4 & 0 & 0 & 0 & 0 & 2 & 1 & 11 & 2 & 1 & 0 & 21 & 52.38 \\
\hline Black Oak & 3 & 0 & 0 & 0 & 0 & 5 & 0 & 2 & 21 & 1 & 0 & 32 & 65.63 \\
\hline Other Deciduous & 0 & 0 & 0 & 0 & 0 & 1 & 1 & 1 & 1 & 5 & 2 & 11 & 45.45 \\
\hline Other Conifer & 0 & 2 & 0 & 0 & 1 & 0 & 3 & 0 & 1 & 1 & 2 & 10 & 20.00 \\
\hline Count & 23 & 13 & 5 & 21 & 13 & 41 & 49 & 20 & 32 & 10 & 4 & Accuracy & Kappa \\
\hline User's & 52.17 & 69.23 & 100.00 & 95.24 & 84.62 & 58.54 & 81.63 & 55.00 & 65.63 & 50.00 & 50.00 & 69.26 & 0.649 \\
\hline $0.3 \mathrm{~m} \# 10$ & BO & DC & $\mathrm{E}$ & GP & IC & LO & PP & Vo & BO & OD & OC & Count & Producer's \\
\hline Blue Oak & 10 & 0 & 0 & 1 & 0 & 5 & 0 & 3 & 1 & 0 & 0 & 20 & 50.00 \\
\hline Deodar Cedar & 0 & 7 & 0 & 1 & 1 & 0 & 2 & 0 & 0 & 0 & 0 & 11 & 63.64 \\
\hline Eucalyptus & 0 & 0 & 6 & 1 & 0 & 0 & 0 & 0 & 0 & 1 & 0 & 8 & 75.00 \\
\hline Gray Pine & 0 & 0 & 0 & 22 & 0 & 0 & 0 & 0 & 0 & 0 & 0 & 22 & 100.00 \\
\hline Incense Cedar & 0 & 0 & 0 & 0 & 12 & 0 & 2 & 0 & 0 & 0 & 0 & 14 & 85.71 \\
\hline Live Oak & 3 & 0 & 0 & 1 & 0 & 28 & 0 & 4 & 3 & 1 & 0 & 40 & 70.00 \\
\hline Ponderosa Pine & 0 & 0 & 1 & 0 & 2 & 1 & 35 & 0 & 0 & 1 & 0 & 40 & 87.50 \\
\hline Valley Oak & 1 & 0 & 0 & 0 & 0 & 2 & 0 & 11 & 6 & 0 & 0 & 20 & 55.00 \\
\hline Black Oak & 1 & 1 & 0 & 0 & 0 & 3 & 1 & 3 & 21 & 1 & 0 & 31 & 67.74 \\
\hline Other Deciduous & 0 & 0 & 0 & 0 & 1 & 2 & 0 & 0 & 1 & 6 & 2 & 12 & 50.00 \\
\hline Other Conifer & 1 & 0 & 0 & 0 & 2 & 0 & 1 & 0 & 3 & 0 & 3 & 10 & 30.00 \\
\hline Count & 16 & 8 & 7 & 26 & 18 & 41 & 41 & 21 & 35 & 10 & 5 & Accuracy & Карра \\
\hline User's & 62.50 & 87.50 & 85.71 & 84.62 & 66.67 & 68.29 & 85.37 & 52.38 & 60.00 & 60.00 & 60.00 & 70.61 & 0.666 \\
\hline
\end{tabular}


B. Confusion matrix for individual classification runs of $0.5 \mathrm{~m}$ images.

\begin{tabular}{|c|c|c|c|c|c|c|c|c|c|c|c|c|c|}
\hline $0.5 \mathrm{~m} \# 1$ & BO & DC & $\mathrm{E}$ & GP & IC & LO & PP & vo & BO & $O D$ & $\mathrm{OC}$ & Count & Producer's \\
\hline Blue Oak & 12 & 0 & 0 & 1 & 0 & 3 & 0 & 3 & 2 & 0 & 0 & 21 & 57.14 \\
\hline Deodar Cedar & 0 & 8 & 0 & 0 & 0 & 0 & 2 & 0 & 0 & 0 & 1 & 11 & 72.73 \\
\hline Eucalyptus & 1 & 0 & 7 & 0 & 0 & 0 & 0 & 0 & 0 & 0 & 0 & 8 & 87.50 \\
\hline Gray Pine & 0 & 0 & 0 & 21 & 0 & 0 & 0 & 0 & 0 & 0 & 0 & 21 & 100.00 \\
\hline Incense Cedar & 0 & 1 & 0 & 0 & 11 & 0 & 1 & 0 & 0 & 0 & 1 & 14 & 78.57 \\
\hline Live Oak & 8 & 1 & 0 & 0 & 0 & 26 & 0 & 1 & 2 & 0 & 0 & 38 & 68.42 \\
\hline Ponderosa Pine & 0 & 0 & 0 & 0 & 1 & 2 & 37 & 1 & 1 & 0 & 0 & 42 & 88.10 \\
\hline Valley Oak & 2 & 0 & 0 & 0 & 0 & 0 & 0 & 12 & 7 & 0 & 0 & 21 & 57.14 \\
\hline Black Oak & 1 & 0 & 0 & 0 & 0 & 7 & 0 & 5 & 18 & 1 & 0 & 32 & 56.25 \\
\hline Other Deciduous & 0 & 0 & 1 & 0 & 0 & 1 & 0 & 0 & 1 & 6 & 1 & 10 & 60.00 \\
\hline Other Conifer & 0 & 1 & 0 & 0 & 3 & 0 & 1 & 1 & 0 & 0 & 4 & 10 & 40.00 \\
\hline User's & 50.00 & 72.73 & 87.50 & 95.45 & 73.33 & 66.67 & 90.24 & 52.17 & 58.06 & 85.71 & 57.14 & 71.05 & 0.671 \\
\hline $0.5 \mathrm{~m} \# 2$ & BO & DC & $\mathrm{E}$ & GP & IC & LO & PP & vo & BO & $O D$ & $\mathrm{OC}$ & Count & Producer's \\
\hline Blue Oak & 14 & 0 & 1 & 0 & 0 & 1 & 0 & 1 & 4 & 0 & 0 & 21 & 66.67 \\
\hline Deodar Cedar & 0 & 8 & 0 & 2 & 1 & 0 & 0 & 0 & 0 & 0 & 0 & 11 & 72.73 \\
\hline Eucalyptus & 1 & 0 & 5 & 0 & 0 & 0 & 0 & 0 & 0 & 1 & 0 & 7 & 71.43 \\
\hline Gray Pine & 0 & 0 & 0 & 22 & 0 & 0 & 0 & 0 & 0 & 0 & 0 & 22 & 100.00 \\
\hline Incense Cedar & 0 & 1 & 0 & 0 & 10 & 0 & 3 & 0 & 0 & 0 & 0 & 14 & 71.43 \\
\hline Live Oak & 2 & 1 & 0 & 0 & 0 & 26 & 0 & 3 & 7 & 0 & 0 & 39 & 66.67 \\
\hline Ponderosa Pine & 1 & 0 & 0 & 0 & 3 & 0 & 32 & 0 & 0 & 2 & 1 & 39 & 82.05 \\
\hline Valley Oak & 3 & 0 & 0 & 0 & 0 & 1 & 1 & 12 & 3 & 0 & 0 & 20 & 60.00 \\
\hline Black Oak & 2 & 0 & 0 & 0 & 0 & 6 & 0 & 6 & 19 & 0 & 0 & 33 & 57.58 \\
\hline Other Deciduous & 0 & 1 & 0 & 0 & 0 & 2 & 1 & 0 & 1 & 6 & 1 & 12 & 50.00 \\
\hline Other Conifer & 1 & 1 & 0 & 0 & 3 & 0 & 1 & 0 & 0 & 0 & 4 & 10 & 40.00 \\
\hline Count & 24 & 12 & 6 & 24 & 17 & 36 & 38 & 22 & 34 & 9 & 6 & Accuracy & Kappa \\
\hline User's & 58.33 & 66.67 & 83.33 & 91.67 & 58.82 & 72.22 & 84.21 & 54.55 & 55.88 & 66.67 & 66.67 & 69.30 & 0.652 \\
\hline $0.5 \mathrm{~m} \# 3$ & BO & DC & $E$ & GP & IC & LO & PP & vo & BO & OD & $O C$ & Count & Producer's \\
\hline Blue Oak & 11 & 0 & 0 & 0 & 0 & 7 & 0 & 1 & 2 & 0 & 0 & 21 & 52.38 \\
\hline Deodar Cedar & 0 & 9 & 0 & 0 & 0 & 0 & 0 & 0 & 0 & 1 & 1 & 11 & 81.82 \\
\hline Eucalyptus & 0 & 0 & 6 & 0 & 0 & 0 & 0 & 0 & 0 & 1 & 0 & 7 & 85.71 \\
\hline Gray Pine & 0 & 0 & 0 & 21 & 0 & 0 & 0 & 0 & 1 & 0 & 0 & 22 & 95.45 \\
\hline Incense Cedar & 0 & 2 & 0 & 0 & 7 & 0 & 5 & 0 & 0 & 0 & 1 & 15 & 46.67 \\
\hline Live Oak & 0 & 0 & 0 & 0 & 0 & 31 & 0 & 3 & 4 & 0 & 0 & 38 & 81.58 \\
\hline Ponderosa Pine & 0 & 0 & 1 & 0 & 4 & 2 & 32 & 0 & 0 & 1 & 0 & 40 & 80.00 \\
\hline Valley Oak & 0 & 0 & 0 & 0 & 0 & 2 & 1 & 11 & 6 & 0 & 0 & 20 & 55.00 \\
\hline Black Oak & 1 & 0 & 0 & 0 & 0 & 4 & 0 & 4 & 21 & 1 & 0 & 31 & 67.74 \\
\hline Other Deciduous & 0 & 0 & 1 & 0 & 0 & 0 & 1 & 0 & 1 & 6 & 1 & 10 & 60.00 \\
\hline Other Conifer & 0 & 1 & 0 & 0 & 2 & 0 & 2 & 0 & 1 & 0 & 4 & 10 & 40.00 \\
\hline Count & 12 & 12 & 8 & 21 & 13 & 46 & 41 & 19 & 36 & 10 & 7 & Accuracy & Kappa \\
\hline User's & 91.67 & 75.00 & 75.00 & 100.00 & 53.85 & 67.39 & 78.05 & 57.89 & 58.33 & 60.00 & 57.14 & 70.67 & 0.666 \\
\hline $0.5 \mathrm{~m} \# 4$ & BO & DC & $\mathrm{E}$ & GP & IC & LO & PP & vo & BO & $O D$ & $\mathrm{OC}$ & Count & Producer's \\
\hline Blue Oak & 12 & 0 & 0 & 1 & 0 & 4 & 0 & 1 & 3 & 0 & 0 & 21 & 57.14 \\
\hline Deodar Cedar & 0 & 7 & 1 & 0 & 0 & 0 & 2 & 0 & 0 & 0 & 1 & 11 & 63.64 \\
\hline Eucalyptus & 0 & 1 & 6 & 0 & 0 & 0 & 0 & 0 & 0 & 0 & 0 & 7 & 85.71 \\
\hline Gray Pine & 0 & 0 & 0 & 22 & 0 & 0 & 0 & 0 & 0 & 0 & 0 & 22 & 100.00 \\
\hline Incense Cedar & 0 & 0 & 0 & 0 & 10 & 0 & 4 & 0 & 0 & 0 & 0 & 14 & 71.43 \\
\hline Live Oak & 6 & 3 & 0 & 0 & 0 & 24 & 0 & 1 & 3 & 1 & 0 & 38 & 63.16 \\
\hline Ponderosa Pine & 0 & 0 & 0 & 0 & 0 & 1 & 37 & 1 & 0 & 0 & 1 & 40 & 92.50 \\
\hline Valley Oak & 2 & 0 & 0 & 0 & 0 & 2 & 0 & 13 & 3 & 0 & 0 & 20 & 65.00 \\
\hline Black Oak & 2 & 0 & 0 & 0 & 0 & 5 & 0 & 4 & 19 & 0 & 1 & 31 & 61.29 \\
\hline Other Deciduous & 0 & 1 & 0 & 0 & 1 & 3 & 2 & 0 & 0 & 4 & 2 & 13 & 30.77 \\
\hline Other Conifer & 0 & 0 & 0 & 0 & 4 & 0 & 2 & 0 & 0 & 0 & 4 & 10 & 40.00 \\
\hline Count & 22 & 12 & 7 & 23 & 15 & 39 & 47 & 20 & 28 & 5 & 9 & Accuracy & Kappa \\
\hline User's & 54.55 & 58.33 & 85.71 & 95.65 & 66.67 & 61.54 & 78.72 & 65.00 & 67.86 & 80.00 & 44.44 & 69.60 & 0.655 \\
\hline $0.5 \mathrm{~m} \# 5$ & BO & DC & E & GP & IC & LO & PP & vo & BO & $O D$ & $O C$ & Count & Producer's \\
\hline Blue Oak & 13 & 0 & 1 & 0 & 0 & 3 & 1 & 0 & 2 & 0 & 0 & 20 & 65.00 \\
\hline Deodar Cedar & 0 & 9 & 0 & 0 & 0 & 0 & 2 & 0 & 0 & 0 & 0 & 11 & 81.82 \\
\hline Eucalyptus & 1 & 0 & 6 & 0 & 0 & 0 & 1 & 0 & 0 & 0 & 0 & 8 & 75.00 \\
\hline Gray Pine & 0 & 0 & 0 & 20 & 0 & 1 & 0 & 0 & 0 & 0 & 0 & 21 & 95.24 \\
\hline Incense Cedar & 0 & 0 & 0 & 0 & 11 & 0 & 3 & 0 & 0 & 1 & 0 & 15 & 73.33 \\
\hline Live Oak & 2 & 0 & 0 & 0 & 0 & 34 & 0 & 0 & 3 & 0 & 0 & 39 & 87.18 \\
\hline Ponderosa Pine & 0 & 0 & 0 & 0 & 1 & 1 & 38 & 1 & 0 & 0 & 1 & 42 & 90.48 \\
\hline Valley Oak & 2 & 0 & 0 & 0 & 0 & 2 & 0 & 10 & 6 & 0 & 0 & 20 & 50.00 \\
\hline Black Oak & 0 & 1 & 0 & 0 & 0 & 4 & 0 & 7 & 20 & 0 & 0 & 32 & 62.50 \\
\hline Other Deciduous & 0 & 0 & 0 & 0 & 0 & 3 & 2 & 0 & 2 & 5 & 0 & 12 & 41.67 \\
\hline Other Conifer & 0 & 3 & 0 & 0 & 2 & 0 & 3 & 0 & 0 & 0 & 2 & 10 & 20.00 \\
\hline Count & 18 & 13 & 7 & 20 & 14 & 48 & 50 & 18 & 33 & 6 & 3 & racy & Kappa \\
\hline User's & 72.22 & 69.23 & 85.71 & 100.00 & 78.57 & 70.83 & 76.00 & 55.56 & 60.61 & 83.33 & 66.67 & 73.04 & 0.691 \\
\hline
\end{tabular}




\begin{tabular}{|c|c|c|c|c|c|c|c|c|c|c|c|c|c|}
\hline $0.5 \mathrm{~m} \# 6$ & $\mathrm{BO}$ & DC & $\mathrm{E}$ & GP & IC & LO & PP & VO & $\mathrm{BO}$ & OD & OC & Count & Producer's \\
\hline Blue Oak & 16 & 0 & 0 & 0 & 0 & 2 & 0 & 1 & 1 & 0 & 0 & 20 & 80.00 \\
\hline Deodar Cedar & 0 & 7 & 0 & 1 & 0 & 0 & 1 & 1 & 0 & 0 & 1 & 11 & 63.64 \\
\hline Eucalyptus & 1 & 0 & 6 & 0 & 0 & 0 & 0 & 0 & 0 & 0 & 0 & 7 & 85.71 \\
\hline Gray Pine & 0 & 0 & 0 & 21 & 0 & 0 & 0 & 0 & 0 & 0 & 0 & 21 & 100.00 \\
\hline Incense Cedar & 0 & 1 & 0 & 0 & 12 & 0 & 1 & 0 & 0 & 0 & 1 & 15 & 80.00 \\
\hline Live Oak & 6 & 0 & 0 & 0 & 0 & 27 & 0 & 3 & 3 & 0 & 0 & 39 & 69.23 \\
\hline Ponderosa Pine & 1 & 0 & 0 & 0 & 3 & 0 & 36 & 1 & 0 & 0 & 0 & 41 & 87.80 \\
\hline Valley Oak & 1 & 0 & 0 & 0 & 0 & 0 & 0 & 13 & 7 & 0 & 0 & 21 & 61.90 \\
\hline Black Oak & 1 & 1 & 0 & 0 & 0 & 4 & 0 & 5 & 19 & 1 & 0 & 31 & 61.29 \\
\hline Other Deciduous & 0 & 0 & 0 & 0 & 0 & 2 & 0 & 0 & 2 & 4 & 5 & 13 & 30.77 \\
\hline Other Conifer & 0 & 1 & 0 & 0 & 3 & 0 & 2 & 0 & 1 & 0 & 3 & 10 & 30.00 \\
\hline Count & 26 & 10 & 6 & 22 & 18 & 35 & 40 & 24 & 33 & 5 & 10 & Accuracy & Карра \\
\hline User's & 61.54 & 70.00 & 100.00 & 95.45 & 66.67 & 77.14 & 90.00 & 54.17 & 57.58 & 80.00 & 30.00 & 71.62 & 0.679 \\
\hline $0.5 \mathrm{~m} \# 7$ & BO & DC & $\mathrm{E}$ & GP & IC & LO & PP & Vo & BO & OD & $\mathrm{OC}$ & Count & Producer's \\
\hline Blue Oak & 11 & 0 & 0 & 0 & 0 & 4 & 0 & 3 & 2 & 0 & 0 & 20 & 55.00 \\
\hline Deodar Cedar & 0 & 10 & 0 & 0 & 0 & 0 & 1 & 0 & 0 & 0 & 0 & 11 & 90.91 \\
\hline Eucalyptus & 0 & 1 & 7 & 0 & 0 & 0 & 0 & 0 & 0 & 0 & 0 & 8 & 87.50 \\
\hline Gray Pine & 0 & 1 & 0 & 19 & 0 & 0 & 0 & 0 & 1 & 0 & 0 & 21 & 90.48 \\
\hline Incense Cedar & 0 & 1 & 0 & 0 & 13 & 0 & 1 & 0 & 0 & 0 & 0 & 15 & 86.67 \\
\hline Live Oak & 2 & 0 & 0 & 0 & 0 & 30 & 0 & 1 & 7 & 0 & 0 & 40 & 75.00 \\
\hline Ponderosa Pine & 0 & 0 & 0 & 0 & 1 & 1 & 36 & 0 & 0 & 1 & 0 & 39 & 92.31 \\
\hline Valley Oak & 2 & 0 & 0 & 0 & 0 & 3 & 1 & 10 & 6 & 0 & 0 & 22 & 45.45 \\
\hline Black Oak & 1 & 0 & 0 & 0 & 0 & 7 & 0 & 1 & 21 & 2 & 0 & 32 & 65.63 \\
\hline Other Deciduous & 0 & 1 & 0 & 0 & 0 & 2 & 1 & 0 & 1 & 7 & 1 & 13 & 53.85 \\
\hline Other Conifer & 0 & 2 & 0 & 0 & 4 & 0 & 0 & 0 & 0 & 0 & 4 & 10 & 40.00 \\
\hline Count & 16 & 16 & 7 & 19 & 18 & 47 & 40 & 15 & 38 & 10 & 5 & Accuracy & Kappa \\
\hline User's & 68.75 & 62.50 & 100.00 & 100.00 & 72.22 & 63.83 & 90.00 & 66.67 & 55.26 & 70.00 & 80.00 & 72.73 & 0.690 \\
\hline $0.5 \mathrm{~m} \# 8$ & $\mathrm{BO}$ & $D C$ & $\mathrm{E}$ & GP & IC & LO & PP & VO & $\mathrm{BO}$ & OD & $\mathrm{OC}$ & Count & Producer's \\
\hline Blue Oak & 8 & 0 & 0 & 1 & 0 & 8 & 0 & 3 & 0 & 0 & 0 & 20 & 40.00 \\
\hline Deodar Cedar & 0 & 8 & 0 & 1 & 1 & 0 & 1 & 0 & 0 & 0 & 0 & 11 & 72.73 \\
\hline Eucalyptus & 0 & 0 & 6 & 1 & 0 & 1 & 0 & 0 & 0 & 0 & 0 & 8 & 75.00 \\
\hline Gray Pine & 0 & 0 & 0 & 21 & 0 & 0 & 0 & 0 & 0 & 0 & 0 & 21 & 100.00 \\
\hline Incense Cedar & 0 & 0 & 0 & 0 & 12 & 1 & 1 & 0 & 0 & 0 & 0 & 14 & 85.71 \\
\hline Live Oak & 3 & 1 & 0 & 2 & 0 & 28 & 0 & 2 & 3 & 0 & 0 & 39 & 71.79 \\
\hline Ponderosa Pine & 0 & 0 & 0 & 0 & 1 & 0 & 38 & 0 & 0 & 0 & 0 & 39 & 97.44 \\
\hline Valley Oak & 2 & 0 & 0 & 0 & 0 & 2 & 1 & 10 & 5 & 0 & 0 & 20 & 50.00 \\
\hline Black Oak & 2 & 0 & 0 & 0 & 0 & 2 & 0 & 5 & 22 & 1 & 0 & 32 & 68.75 \\
\hline Other Deciduous & 1 & 2 & 0 & 0 & 0 & 1 & 2 & 0 & 0 & 4 & 4 & 14 & 28.57 \\
\hline Other Conifer & 0 & 1 & 0 & 0 & 1 & 0 & 0 & 1 & 0 & 0 & 7 & 10 & 70.00 \\
\hline Count & 16 & 12 & 6 & 26 & 15 & 43 & 43 & 21 & 30 & 5 & 11 & Accuracy & Карра \\
\hline User's & 50.00 & 66.67 & 100.00 & 80.77 & 80.00 & 65.12 & 88.37 & 47.62 & 73.33 & 80.00 & 63.64 & 71.93 & 0.681 \\
\hline $0.5 \mathrm{~m} \# 9$ & BO & $D C$ & $\mathrm{E}$ & GP & IC & LO & PP & VO & BO & OD & $\mathrm{OC}$ & Count & Producer's \\
\hline Blue Oak & 16 & 0 & 0 & 0 & 0 & 4 & 0 & 0 & 0 & 0 & 0 & 20 & 80.00 \\
\hline Deodar Cedar & 0 & 9 & 0 & 1 & 0 & 0 & 0 & 0 & 1 & 0 & 0 & 11 & 81.82 \\
\hline Eucalyptus & 0 & 0 & 6 & 0 & 0 & 0 & 0 & 0 & 0 & 1 & 0 & 7 & 85.71 \\
\hline Gray Pine & 0 & 0 & 0 & 20 & 0 & 0 & 1 & 0 & 0 & 0 & 0 & 21 & 95.24 \\
\hline Incense Cedar & 0 & 0 & 0 & 0 & 11 & 0 & 3 & 0 & 0 & 0 & 0 & 14 & 78.57 \\
\hline Live Oak & 5 & 0 & 0 & 0 & 0 & 27 & 1 & 1 & 6 & 0 & 0 & 40 & 67.50 \\
\hline Ponderosa Pine & 0 & 2 & 0 & 0 & 3 & 0 & 37 & 0 & 0 & 1 & 0 & 43 & 86.05 \\
\hline Valley Oak & 4 & 0 & 0 & 0 & 0 & 0 & 2 & 11 & 4 & 0 & 0 & 21 & 52.38 \\
\hline Black Oak & 2 & 0 & 0 & 0 & 0 & 6 & 0 & 2 & 22 & 0 & 0 & 32 & 68.75 \\
\hline Other Deciduous & 0 & 1 & 0 & 0 & 0 & 1 & 1 & 0 & 1 & 5 & 2 & 11 & 45.45 \\
\hline Other Conifer & 1 & 1 & 0 & 0 & 2 & 0 & 2 & 0 & 0 & 0 & 4 & 10 & 40.00 \\
\hline Count & 28 & 13 & 6 & 21 & 16 & 38 & 47 & 14 & 34 & 7 & 6 & Accuracy & Kappa \\
\hline User's & 57.14 & 69.23 & 100.00 & 95.24 & 68.75 & 71.05 & 78.72 & 78.57 & 64.71 & 71.43 & 66.67 & 73.04 & 0.693 \\
\hline $0.5 \mathrm{~m} \# 10$ & BO & $D C$ & $\mathrm{E}$ & GP & IC & LO & PP & Vo & BO & $O D$ & $\mathrm{OC}$ & Count & Producer's \\
\hline Blue Oak & 12 & 0 & 0 & 1 & 0 & 4 & 0 & 0 & 3 & 0 & 0 & 20 & 60.00 \\
\hline Deodar Cedar & 0 & 6 & 0 & 1 & 1 & 0 & 3 & 0 & 0 & 0 & 0 & 11 & 54.55 \\
\hline Eucalyptus & 0 & 0 & 6 & 0 & 0 & 0 & 0 & 0 & 0 & 2 & 0 & 8 & 75.00 \\
\hline Gray Pine & 0 & 0 & 0 & 22 & 0 & 0 & 0 & 0 & 0 & 0 & 0 & 22 & 100.00 \\
\hline Incense Cedar & 0 & 0 & 0 & 0 & 11 & 0 & 1 & 0 & 0 & 0 & 1 & 13 & 84.62 \\
\hline Live Oak & 4 & 0 & 0 & 0 & 0 & 30 & 0 & 3 & 3 & 0 & 0 & 40 & 75.00 \\
\hline Ponderosa Pine & 0 & 0 & 0 & 0 & 1 & 0 & 38 & 1 & 0 & 0 & 0 & 40 & 95.00 \\
\hline Valley Oak & 0 & 0 & 0 & 0 & 0 & 4 & 0 & 12 & 4 & 0 & 0 & 20 & 60.00 \\
\hline Black Oak & 0 & 0 & 0 & 0 & 0 & 4 & 0 & 5 & 21 & 1 & 0 & 31 & 67.74 \\
\hline Other Deciduous & 0 & 0 & 0 & 0 & 1 & 1 & 0 & 0 & 1 & 8 & 1 & 12 & 66.67 \\
\hline Other Conifer & 1 & 0 & 0 & 0 & 2 & 0 & 2 & 0 & 1 & 0 & 4 & 10 & 40.00 \\
\hline Count & 17 & 6 & 6 & 24 & 16 & 43 & 44 & 21 & 33 & 11 & 6 & Accuracy & Карра \\
\hline User's & 70.59 & 100.00 & 100.00 & 91.67 & 68.75 & 69.77 & 86.36 & 57.14 & 63.64 & 72.73 & 66.67 & 74.89 & 0.714 \\
\hline
\end{tabular}


C. Confusion matrix for individual classification runs of $1.0 \mathrm{~m}$ images.

\begin{tabular}{|c|c|c|c|c|c|c|c|c|c|c|c|c|c|}
\hline $1.0 \mathrm{~m} \# 1$ & BO & DC & E & GP & IC & LO & PP & vo & BO & OD & $O C$ & Count & Producer's \\
\hline Blue Oak & 12 & 0 & 0 & 0 & 0 & 3 & 0 & 5 & 0 & 0 & 0 & 20 & 60.00 \\
\hline Deodar Cedar & 0 & 8 & 0 & 1 & 0 & 0 & 0 & 0 & 1 & 0 & 1 & 11 & 72.73 \\
\hline Eucalyptus & 1 & 0 & 7 & 0 & 0 & 0 & 0 & 0 & 0 & 0 & 0 & 8 & 87.50 \\
\hline Gray Pine & 0 & 1 & 0 & 20 & 0 & 0 & 0 & 0 & 0 & 0 & 0 & 21 & 95.24 \\
\hline Incense Cedar & 0 & 0 & 0 & 0 & 11 & 0 & 3 & 0 & 0 & 0 & 1 & 15 & 73.33 \\
\hline Live Oak & 3 & 1 & 0 & 0 & 0 & 31 & 0 & 2 & 2 & 0 & 0 & 39 & 79.49 \\
\hline Ponderosa Pine & 0 & 1 & 0 & 0 & 3 & 1 & 35 & 0 & 0 & 1 & 1 & 42 & 83.33 \\
\hline Valley Oak & 1 & 0 & 0 & 0 & 0 & 0 & 0 & 14 & 7 & 0 & 0 & 22 & 63.64 \\
\hline Black Oak & 1 & 0 & 0 & 0 & 0 & 3 & 0 & 4 & 23 & 1 & 0 & 32 & 71.88 \\
\hline Other Deciduous & 1 & 1 & 0 & 0 & 0 & 0 & 1 & 0 & 1 & 6 & 0 & 10 & 60.00 \\
\hline Other Conifer & 0 & 0 & 0 & 0 & 3 & 0 & 2 & 1 & 0 & 0 & 4 & 10 & 40.00 \\
\hline Count & 19 & 12 & 7 & 21 & 17 & 38 & 41 & 26 & 34 & 8 & 7 & Accuracy & Kappa \\
\hline User's & 63.16 & 66.67 & 100.00 & 95.24 & 64.71 & 81.58 & 85.37 & 53.85 & 67.65 & 75.00 & 57.14 & 74.35 & 0.709 \\
\hline $1.0 \mathrm{~m} \# 2$ & BO & DC & $\mathrm{E}$ & GP & IC & LO & PP & vo & BO & OD & $\mathrm{OC}$ & Count & Producer's \\
\hline Blue Oak & 14 & 0 & 0 & 0 & 0 & 3 & 0 & 2 & 1 & 0 & 0 & 20 & 70.00 \\
\hline Deodar Cedar & 0 & 9 & 0 & 1 & 1 & 0 & 0 & 0 & 0 & 0 & 0 & 11 & 81.82 \\
\hline Eucalyptus & 1 & 0 & 6 & 0 & 0 & 0 & 0 & 0 & 0 & 0 & 0 & 7 & 85.71 \\
\hline Gray Pine & 0 & 0 & 0 & 22 & 0 & 0 & 0 & 0 & 0 & 0 & 0 & 22 & 100.00 \\
\hline Incense Cedar & 0 & 0 & 0 & 0 & 10 & 0 & 4 & 0 & 0 & 1 & 0 & 15 & 66.67 \\
\hline Live Oak & 1 & 0 & 0 & 1 & 0 & 30 & 0 & 3 & 5 & 0 & 0 & 40 & 75.00 \\
\hline Ponderosa Pine & 0 & 0 & 0 & 0 & 3 & 1 & 32 & 1 & 0 & 1 & 1 & 39 & 82.05 \\
\hline Valley Oak & 3 & 0 & 0 & 0 & 0 & 2 & 1 & 12 & 3 & 0 & 0 & 21 & 57.14 \\
\hline Black Oak & 2 & 0 & 0 & 0 & 0 & 1 & 0 & 5 & 25 & 0 & 0 & 33 & 75.76 \\
\hline Other Deciduous & 0 & 0 & 0 & 0 & 1 & 1 & 1 & 0 & 0 & 7 & 2 & 12 & 58.33 \\
\hline Other Conifer & 0 & 1 & 0 & 0 & 3 & 0 & 0 & 1 & 1 & 0 & 4 & 10 & 40.00 \\
\hline Count & 21 & 10 & 6 & 24 & 18 & 38 & 38 & 24 & 35 & 9 & 7 & Accuracy & Kappa \\
\hline User's & 66.67 & 90.00 & 100.00 & 91.67 & 55.56 & 78.95 & 84.21 & 50.00 & 71.43 & 77.78 & 57.14 & 74.35 & 0.709 \\
\hline $1.0 \mathrm{~m} \# 3$ & BO & DC & $\mathrm{E}$ & GP & IC & LO & PP & Vo & BO & OD & $\mathrm{OC}$ & Count & Producer's \\
\hline Blue Oak & 10 & 0 & 0 & 0 & 0 & 6 & 0 & 3 & 1 & 0 & 0 & 20 & 50.00 \\
\hline Deodar Cedar & 1 & 7 & 0 & 0 & 0 & 0 & 1 & 0 & 0 & 1 & 1 & 11 & 63.64 \\
\hline Eucalyptus & 0 & 0 & 6 & 0 & 0 & 0 & 0 & 0 & 0 & 0 & 0 & 6 & 100.00 \\
\hline Gray Pine & 0 & 0 & 0 & 22 & 0 & 0 & 0 & 0 & 0 & 0 & 0 & 22 & 100.00 \\
\hline Incense Cedar & 0 & 0 & 0 & 0 & 5 & 0 & 5 & 0 & 0 & 1 & 4 & 15 & 33.33 \\
\hline Live Oak & 2 & 0 & 0 & 0 & 0 & 29 & 1 & 2 & 5 & 0 & 0 & 39 & 74.36 \\
\hline Ponderosa Pine & 0 & 0 & 1 & 0 & 5 & 0 & 33 & 0 & 0 & 1 & 0 & 40 & 82.50 \\
\hline Valley Oak & 1 & 0 & 0 & 0 & 0 & 2 & 1 & 14 & 3 & 0 & 0 & 21 & 66.67 \\
\hline Black Oak & 0 & 0 & 0 & 0 & 0 & 5 & 0 & 3 & 22 & 1 & 0 & 31 & 70.97 \\
\hline Other Deciduous & 0 & 0 & 1 & 0 & 0 & 0 & 0 & 0 & 2 & 6 & 1 & 10 & 60.00 \\
\hline Other Conifer & 0 & 1 & 0 & 0 & 2 & 0 & 2 & 1 & 0 & 0 & 3 & 9 & 33.33 \\
\hline Count & 14 & 8 & 8 & 22 & 12 & 42 & 43 & 23 & 33 & 10 & 9 & Accuracy & Kappa \\
\hline User's & 71.43 & 87.50 & 75.00 & 100.00 & 41.67 & 69.05 & 76.74 & 60.87 & 66.67 & 60.00 & 33.33 & 70.09 & 0.659 \\
\hline $1.0 \mathrm{~m} \# 4$ & BO & DC & $E$ & GP & IC & LO & PP & Vo & BO & OD & $\mathrm{OC}$ & Count & Producer's \\
\hline Blue Oak & 13 & 0 & 0 & 0 & 0 & 4 & 0 & 3 & 1 & 0 & 0 & 21 & 61.90 \\
\hline Deodar Cedar & 0 & 6 & 2 & 0 & 0 & 0 & 2 & 0 & 1 & 0 & 0 & 11 & 54.55 \\
\hline Eucalyptus & 0 & 0 & 6 & 0 & 0 & 0 & 0 & 0 & 0 & 1 & 0 & 7 & 85.71 \\
\hline Gray Pine & 0 & 0 & 0 & 22 & 0 & 0 & 0 & 0 & 0 & 0 & 0 & 22 & 100.00 \\
\hline Incense Cedar & 0 & 0 & 0 & 0 & 13 & 0 & 2 & 0 & 0 & 0 & 0 & 15 & 86.67 \\
\hline Live Oak & 10 & 0 & 0 & 0 & 0 & 26 & 0 & 2 & 1 & 0 & 0 & 39 & 66.67 \\
\hline Ponderosa Pine & 0 & 0 & 0 & 0 & 0 & 1 & 37 & 0 & 0 & 1 & 1 & 40 & 92.50 \\
\hline Valley Oak & 1 & 1 & 0 & 0 & 0 & 2 & 0 & 15 & 2 & 0 & 0 & 21 & 71.43 \\
\hline Black Oak & 2 & 0 & 0 & 0 & 0 & 3 & 1 & 4 & 21 & 0 & 0 & 31 & 67.74 \\
\hline Other Deciduous & 0 & 0 & 0 & 0 & 2 & 2 & 4 & 0 & 0 & 5 & 0 & 13 & 38.46 \\
\hline Other Conifer & 0 & 1 & 0 & 0 & 3 & 0 & 1 & 0 & 0 & 0 & 5 & 10 & 50.00 \\
\hline Count & 26 & 8 & 8 & 22 & 18 & 38 & 47 & 24 & 26 & 7 & 6 & Accuracy & Kappa \\
\hline User's & 50.00 & 75.00 & 75.00 & 100.00 & 72.22 & 68.42 & 78.72 & 62.50 & 80.77 & 71.43 & 83.33 & 73.48 & 0.699 \\
\hline $1.0 \mathrm{~m} \# 5$ & BO & DC & $\mathrm{E}$ & GP & IC & LO & PP & vo & BO & $O D$ & $\mathrm{OC}$ & Count & Producer's \\
\hline Blue Oak & 13 & 0 & 0 & 1 & 1 & 2 & 0 & 0 & 2 & 0 & 0 & 19 & 68.42 \\
\hline Deodar Cedar & 0 & 10 & 0 & 0 & 0 & 0 & 0 & 0 & 0 & 0 & 1 & 11 & 90.91 \\
\hline Eucalyptus & 0 & 1 & 6 & 0 & 0 & 0 & 0 & 0 & 0 & 0 & 0 & 7 & 85.71 \\
\hline Gray Pine & 0 & 1 & 0 & 20 & 0 & 0 & 0 & 0 & 0 & 0 & 0 & 21 & 95.24 \\
\hline Incense Cedar & 0 & 1 & 0 & 0 & 10 & 0 & 4 & 0 & 0 & 0 & 0 & 15 & 66.67 \\
\hline Live Oak & 1 & 0 & 0 & 0 & 0 & 33 & 0 & 0 & 6 & 0 & 0 & 40 & 82.50 \\
\hline Ponderosa Pine & 0 & 0 & 0 & 0 & 0 & 1 & 37 & 1 & 0 & 0 & 3 & 42 & 88.10 \\
\hline Valley Oak & 3 & 0 & 0 & 0 & 1 & 1 & 0 & 10 & 6 & 0 & 0 & 21 & 47.62 \\
\hline Black Oak & 0 & 1 & 0 & 0 & 0 & 3 & 0 & 7 & 21 & 0 & 0 & 32 & 65.63 \\
\hline Other Deciduous & 0 & 0 & 0 & 0 & 0 & 3 & 4 & 0 & 1 & 4 & 0 & 12 & 33.33 \\
\hline Other Conifer & 0 & 2 & 0 & 0 & 3 & 0 & 2 & 0 & 0 & 0 & 2 & 9 & 22.22 \\
\hline Count & 17 & 16 & 6 & 21 & 15 & 43 & 47 & 18 & 36 & 4 & 6 & Accuracy & Kарра \\
\hline User's & 76.47 & 62.50 & 100.00 & 95.24 & 66.67 & 76.74 & 78.72 & 55.56 & 58.33 & 0.00 & 33.33 & 72.49 & 0.686 \\
\hline
\end{tabular}




\begin{tabular}{|c|c|c|c|c|c|c|c|c|c|c|c|c|c|}
\hline $1.0 \mathrm{~m} \# 6$ & $\mathrm{BO}$ & DC & $\mathrm{E}$ & GP & IC & LO & PP & VO & $\mathrm{BO}$ & OD & OC & Count & Producer's \\
\hline Blue Oak & 16 & 0 & 0 & 0 & 0 & 1 & 0 & 2 & 1 & 0 & 0 & 20 & 80.00 \\
\hline Deodar Cedar & 0 & 7 & 0 & 1 & 0 & 0 & 0 & 0 & 1 & 0 & 2 & 11 & 63.64 \\
\hline Eucalyptus & 0 & 0 & 6 & 0 & 0 & 0 & 0 & 0 & 0 & 0 & 0 & 6 & 100.00 \\
\hline Gray Pine & 0 & 0 & 0 & 21 & 0 & 0 & 0 & 0 & 0 & 0 & 0 & 21 & 100.00 \\
\hline Incense Cedar & 0 & 0 & 0 & 0 & 10 & 0 & 1 & 1 & 0 & 1 & 2 & 15 & 66.67 \\
\hline Live Oak & 7 & 0 & 0 & 0 & 0 & 24 & 1 & 3 & 4 & 0 & 0 & 39 & 61.54 \\
\hline Ponderosa Pine & 0 & 0 & 0 & 0 & 4 & 0 & 36 & 1 & 0 & 0 & 0 & 41 & 87.80 \\
\hline Valley Oak & 1 & 0 & 0 & 0 & 0 & 2 & 1 & 13 & 4 & 0 & 0 & 21 & 61.90 \\
\hline Black Oak & 2 & 1 & 0 & 0 & 0 & 2 & 0 & 4 & 21 & 1 & 0 & 31 & 67.74 \\
\hline Other Deciduous & 0 & 0 & 0 & 0 & 0 & 1 & 1 & 1 & 2 & 4 & 4 & 13 & 30.77 \\
\hline Other Conifer & 0 & 1 & 0 & 0 & 4 & 0 & 1 & 1 & 0 & 0 & 2 & 9 & 22.22 \\
\hline Count & 26 & 9 & 6 & 22 & 18 & 30 & 41 & 26 & 33 & 6 & 10 & Accuracy & Карра \\
\hline User's & 61.54 & 77.78 & 100.00 & 95.45 & 55.56 & 80.00 & 87.80 & 50.00 & 63.64 & 66.67 & 20.00 & 70.48 & 0.666 \\
\hline $1.0 \mathrm{~m} \# 7$ & BO & DC & $\mathrm{E}$ & GP & IC & LO & PP & Vo & BO & OD & $\mathrm{OC}$ & Count & Producer's \\
\hline Blue Oak & 13 & 0 & 0 & 0 & 0 & 4 & 0 & 2 & 0 & 0 & 0 & 19 & 68.42 \\
\hline Deodar Cedar & 0 & 10 & 0 & 0 & 0 & 0 & 0 & 0 & 0 & 0 & 1 & 11 & 90.91 \\
\hline Eucalyptus & 0 & 1 & 7 & 0 & 0 & 0 & 0 & 0 & 0 & 0 & 0 & 8 & 87.50 \\
\hline Gray Pine & 0 & 1 & 0 & 20 & 0 & 0 & 0 & 0 & 0 & 0 & 0 & 21 & 95.24 \\
\hline Incense Cedar & 0 & 0 & 0 & 0 & 12 & 0 & 2 & 0 & 0 & 1 & 0 & 15 & 80.00 \\
\hline Live Oak & 2 & 0 & 1 & 0 & 0 & 31 & 0 & 1 & 5 & 0 & 0 & 40 & 77.50 \\
\hline Ponderosa Pine & 0 & 1 & 0 & 0 & 1 & 1 & 35 & 0 & 0 & 1 & 0 & 39 & 89.74 \\
\hline Valley Oak & 0 & 0 & 0 & 0 & 0 & 4 & 1 & 12 & 5 & 0 & 0 & 22 & 54.55 \\
\hline Black Oak & 1 & 0 & 0 & 0 & 0 & 3 & 0 & 4 & 22 & 2 & 0 & 32 & 68.75 \\
\hline Other Deciduous & 0 & 1 & 0 & 0 & 0 & 1 & 2 & 1 & 1 & 7 & 0 & 13 & 53.85 \\
\hline Other Conifer & 0 & 2 & 0 & 0 & 2 & 0 & 0 & 0 & 0 & 0 & 5 & 9 & 55.56 \\
\hline Count & 16 & 16 & 8 & 20 & 15 & 44 & 40 & 20 & 33 & 11 & 6 & Accuracy & Kappa \\
\hline User's & 81.25 & 62.50 & 87.50 & 100.00 & 80.00 & 70.45 & 87.50 & 60.00 & 66.67 & 63.64 & 83.33 & 75.98 & 0.728 \\
\hline $1.0 \mathrm{~m} \# 8$ & $\mathrm{BO}$ & $D C$ & $\mathrm{E}$ & GP & IC & LO & PP & VO & $\mathrm{BO}$ & OD & $\mathrm{OC}$ & Count & Producer's \\
\hline Blue Oak & 9 & 0 & 0 & 1 & 0 & 5 & 0 & 5 & 0 & 0 & 0 & 20 & 45.00 \\
\hline Deodar Cedar & 0 & 7 & 0 & 1 & 0 & 0 & 1 & 0 & 0 & 0 & 2 & 11 & 63.64 \\
\hline Eucalyptus & 0 & 0 & 6 & 0 & 0 & 0 & 0 & 0 & 0 & 1 & 0 & 7 & 85.71 \\
\hline Gray Pine & 0 & 0 & 0 & 21 & 0 & 0 & 0 & 0 & 0 & 0 & 0 & 21 & 100.00 \\
\hline Incense Cedar & 0 & 0 & 0 & 0 & 12 & 0 & 2 & 0 & 0 & 1 & 0 & 15 & 80.00 \\
\hline Live Oak & 4 & 1 & 0 & 0 & 0 & 30 & 0 & 1 & 4 & 0 & 0 & 40 & 75.00 \\
\hline Ponderosa Pine & 0 & 0 & 0 & 0 & 1 & 0 & 37 & 0 & 0 & 1 & 0 & 39 & 94.87 \\
\hline Valley Oak & 2 & 0 & 0 & 0 & 0 & 2 & 1 & 12 & 4 & 0 & 0 & 21 & 57.14 \\
\hline Black Oak & 2 & 0 & 0 & 0 & 0 & 5 & 0 & 2 & 23 & 0 & 0 & 32 & 71.88 \\
\hline Other Deciduous & 0 & 2 & 0 & 0 & 1 & 2 & 3 & 0 & 0 & 3 & 3 & 14 & 21.43 \\
\hline Other Conifer & 0 & 1 & 0 & 0 & 0 & 0 & 0 & 1 & 0 & 0 & 8 & 10 & 80.00 \\
\hline Count & 17 & 11 & 6 & 23 & 14 & 44 & 44 & 21 & 31 & 6 & 13 & Accuracy & Карра \\
\hline User's & 52.94 & 63.64 & 100.00 & 91.30 & 85.71 & 68.18 & 84.09 & 57.14 & 74.19 & 50.00 & 61.54 & 73.04 & 0.694 \\
\hline $1.0 \mathrm{~m} \# 9$ & BO & $D C$ & $\mathrm{E}$ & GP & IC & LO & PP & VO & BO & OD & $\mathrm{OC}$ & Count & Producer's \\
\hline Blue Oak & 17 & 0 & 0 & 0 & 0 & 3 & 0 & 0 & 0 & 0 & 0 & 20 & 85.00 \\
\hline Deodar Cedar & 0 & 9 & 0 & 1 & 0 & 0 & 0 & 0 & 1 & 0 & 0 & 11 & 81.82 \\
\hline Eucalyptus & 1 & 0 & 5 & 0 & 0 & 0 & 0 & 0 & 0 & 1 & 0 & 7 & 71.43 \\
\hline Gray Pine & 0 & 0 & 0 & 21 & 0 & 0 & 0 & 0 & 0 & 0 & 0 & 21 & 100.00 \\
\hline Incense Cedar & 0 & 0 & 0 & 0 & 11 & 0 & 4 & 0 & 0 & 0 & 0 & 15 & 73.33 \\
\hline Live Oak & 4 & 0 & 0 & 0 & 0 & 28 & 1 & 2 & 5 & 0 & 0 & 40 & 70.00 \\
\hline Ponderosa Pine & 0 & 1 & 0 & 0 & 2 & 1 & 36 & 0 & 0 & 1 & 2 & 43 & 83.72 \\
\hline Valley Oak & 3 & 0 & 0 & 0 & 0 & 1 & 1 & 12 & 4 & 0 & 0 & 21 & 57.14 \\
\hline Black Oak & 2 & 0 & 0 & 0 & 0 & 5 & 0 & 2 & 23 & 0 & 0 & 32 & 71.88 \\
\hline Other Deciduous & 0 & 1 & 0 & 0 & 2 & 2 & 1 & 0 & 1 & 4 & 0 & 11 & 36.36 \\
\hline Other Conifer & 1 & 2 & 0 & 0 & 3 & 0 & 1 & 0 & 0 & 0 & 3 & 10 & 30.00 \\
\hline Count & 28 & 13 & 5 & 22 & 18 & 40 & 44 & 16 & 34 & 6 & 5 & Accuracy & Kappa \\
\hline User's & 60.71 & 69.23 & 100.00 & 95.45 & 61.11 & 70.00 & 81.82 & 75.00 & 67.65 & 66.67 & 60.00 & 73.16 & 0.694 \\
\hline $1.0 \mathrm{~m} \# 10$ & BO & $D C$ & $\mathrm{E}$ & GP & IC & LO & PP & Vo & BO & $O D$ & $\mathrm{OC}$ & Count & Producer's \\
\hline Blue Oak & 14 & 0 & 0 & 0 & 0 & 5 & 0 & 0 & 1 & 0 & 0 & 20 & 70.00 \\
\hline Deodar Cedar & 0 & 6 & 0 & 1 & 0 & 0 & 2 & 0 & 0 & 1 & 1 & 11 & 54.55 \\
\hline Eucalyptus & 0 & 0 & 6 & 0 & 0 & 0 & 1 & 0 & 0 & 0 & 0 & 7 & 85.71 \\
\hline Gray Pine & 0 & 0 & 0 & 22 & 0 & 0 & 0 & 0 & 0 & 0 & 0 & 22 & 100.00 \\
\hline Incense Cedar & 0 & 0 & 0 & 0 & 11 & 0 & 1 & 0 & 0 & 1 & 1 & 14 & 78.57 \\
\hline Live Oak & 3 & 0 & 0 & 0 & 0 & 32 & 0 & 3 & 2 & 0 & 0 & 40 & 80.00 \\
\hline Ponderosa Pine & 0 & 0 & 0 & 0 & 2 & 0 & 35 & 1 & 0 & 2 & 0 & 40 & 87.50 \\
\hline Valley Oak & 1 & 0 & 0 & 0 & 0 & 3 & 0 & 13 & 4 & 0 & 0 & 21 & 61.90 \\
\hline Black Oak & 0 & 0 & 0 & 0 & 0 & 4 & 0 & 5 & 21 & 1 & 0 & 31 & 67.74 \\
\hline Other Deciduous & 0 & 0 & 0 & 0 & 2 & 1 & 0 & 0 & 2 & 6 & 1 & 12 & 50.00 \\
\hline Other Conifer & 0 & 0 & 0 & 0 & 1 & 0 & 2 & 1 & 0 & 1 & 4 & 9 & 44.44 \\
\hline Count & 18 & 6 & 6 & 23 & 16 & 45 & 41 & 23 & 30 & 12 & 7 & Accuracy & Карра \\
\hline User's & 77.78 & 100.00 & 100.00 & 95.65 & 68.75 & 71.11 & 85.37 & 56.52 & 70.00 & 50.00 & 57.14 & 74.89 & 0.714 \\
\hline
\end{tabular}


D. Confusion matrix for individual classification runs of $2.0 \mathrm{~m}$ images.

\begin{tabular}{|c|c|c|c|c|c|c|c|c|c|c|c|c|c|}
\hline \multirow{3}{*}{$\begin{array}{l}2.0 \mathrm{~m} \# 1 \\
\text { Blue Oak }\end{array}$} & & & & & & & & & & & & \\
\hline & BO & DC & $\mathrm{E}$ & GP & IC & LO & PP & Vo & BO & $O D$ & OC & Count & Producer's \\
\hline & 9 & 0 & 0 & 1 & 0 & 2 & 0 & 5 & 0 & 0 & 1 & 18 & 50.00 \\
\hline Deodar Cedar & 0 & 8 & 0 & 0 & 0 & 0 & 1 & 0 & 0 & 0 & 1 & 10 & 80.00 \\
\hline Eucalyptus & 1 & 0 & 7 & 0 & 0 & 0 & 0 & 0 & 0 & 0 & 0 & 8 & 87.50 \\
\hline Gray Pine & 0 & 1 & 0 & 20 & 0 & 0 & 0 & 0 & 0 & 0 & 0 & 21 & 95.24 \\
\hline Incense Cedar & 0 & 1 & 0 & 0 & 13 & 0 & 2 & 0 & 0 & 0 & 0 & 16 & 81.25 \\
\hline Live Oak & 3 & 0 & 0 & 0 & 0 & 31 & 0 & 2 & 3 & 0 & 0 & 39 & 79.49 \\
\hline Ponderosa Pine & 0 & 0 & 0 & 0 & 1 & 0 & 38 & 1 & 0 & 2 & 0 & 42 & 90.48 \\
\hline Valley Oak & 2 & 0 & 0 & 0 & 0 & 1 & 0 & 12 & 7 & 0 & 0 & 22 & 54.55 \\
\hline Black Oak & 1 & 1 & 1 & 0 & 0 & 3 & 0 & 2 & 22 & 2 & 0 & 32 & 68.75 \\
\hline Other Deciduous & 0 & 0 & 0 & 0 & 0 & 2 & 3 & 0 & 1 & 3 & 1 & 10 & 30.00 \\
\hline Other Conifer & 0 & 2 & 0 & 0 & 4 & 0 & 0 & 1 & 0 & 0 & 3 & 10 & 30.00 \\
\hline Count & 16 & 13 & 8 & 21 & 18 & 39 & 44 & 23 & 33 & 7 & 6 & Accuracy & Kappa \\
\hline User's & 56.25 & 61.54 & 87.50 & 95.24 & 72.22 & 79.49 & 86.36 & 52.17 & 66.67 & 42.86 & 50.00 & 72.81 & 0.691 \\
\hline $2.0 \mathrm{~m} \# 2$ & BO & DC & $\mathrm{E}$ & GP & IC & LO & PP & Vo & BO & $\mathrm{OD}$ & $\mathrm{OC}$ & Count & Producer's \\
\hline Blue Oak & 16 & 1 & 0 & 0 & 0 & 0 & 0 & 2 & 0 & 1 & 0 & 20 & 80.00 \\
\hline Deodar Cedar & 0 & 8 & 0 & 0 & 2 & 0 & 0 & 0 & 0 & 0 & 0 & 10 & 80.00 \\
\hline Eucalyptus & 1 & 1 & 5 & 0 & 0 & 0 & 0 & 0 & 0 & 0 & 0 & 7 & 71.43 \\
\hline Gray Pine & 0 & 1 & 0 & 21 & 0 & 0 & 0 & 0 & 1 & 0 & 0 & 23 & 91.30 \\
\hline Incense Cedar & 0 & 1 & 0 & 0 & 10 & 0 & 4 & 0 & 0 & 0 & 0 & 15 & 66.67 \\
\hline Live Oak & 8 & 2 & 0 & 0 & 0 & 29 & 0 & 1 & 0 & 0 & 0 & 40 & 72.50 \\
\hline Ponderosa Pine & 0 & 0 & 0 & 0 & 3 & 1 & 32 & 1 & 0 & 1 & 1 & 39 & 82.05 \\
\hline Valley Oak & 3 & 0 & 0 & 0 & 0 & 4 & 1 & 11 & 2 & 0 & 0 & 21 & 52.38 \\
\hline Black Oak & 2 & 0 & 0 & 0 & 0 & 0 & 0 & 7 & 24 & 0 & 0 & 33 & 72.73 \\
\hline Other Deciduous & 0 & 1 & 0 & 0 & 1 & 1 & 1 & 0 & 0 & 6 & 2 & 12 & 50.00 \\
\hline Other Conifer & 0 & 1 & 0 & 0 & 3 & 1 & 0 & 0 & 0 & 1 & 4 & 10 & 40.00 \\
\hline Count & 30 & 16 & 5 & 21 & 19 & 36 & 38 & 22 & 27 & 9 & 7 & Accuracy & Kappa \\
\hline User's & 53.33 & 50.00 & 100.00 & 100.00 & 52.63 & 80.56 & 84.21 & 50.00 & 88.89 & 66.67 & 57.14 & 72.17 & 0.686 \\
\hline $2.0 \mathrm{~m} \# 3$ & BO & DC & $\mathrm{E}$ & GP & IC & LO & PP & vo & BO & OD & OC & Count & Producer's \\
\hline Blue Oak & 12 & 0 & 0 & 0 & 1 & 2 & 0 & 4 & 1 & 0 & 0 & 20 & 60.00 \\
\hline Deodar Cedar & 0 & 9 & 0 & 0 & 0 & 0 & 2 & 0 & 0 & 0 & 0 & 11 & 81.82 \\
\hline Eucalyptus & 0 & 0 & 5 & 1 & 0 & 1 & 0 & 0 & 0 & 0 & 0 & 7 & 71.43 \\
\hline Gray Pine & 0 & 1 & 0 & 22 & 0 & 0 & 0 & 0 & 0 & 0 & 0 & 23 & 95.65 \\
\hline Incense Cedar & 0 & 1 & 0 & 0 & 6 & 1 & 4 & 0 & 0 & 0 & 4 & 16 & 37.50 \\
\hline Live Oak & 1 & 0 & 0 & 0 & 0 & 36 & 0 & 0 & 2 & 0 & 0 & 39 & 92.31 \\
\hline Ponderosa Pine & 0 & 0 & 0 & 0 & 4 & 2 & 33 & 0 & 0 & 0 & 1 & 40 & 82.50 \\
\hline Valley Oak & 1 & 0 & 0 & 0 & 0 & 2 & 1 & 11 & 6 & 0 & 0 & 21 & 52.38 \\
\hline Black Oak & 1 & 0 & 0 & 0 & 0 & 4 & 1 & 1 & 23 & 1 & 0 & 31 & 74.19 \\
\hline Other Deciduous & 0 & 0 & 1 & 0 & 0 & 2 & 1 & 0 & 1 & 5 & 0 & 10 & 50.00 \\
\hline Other Conifer & 0 & 1 & 0 & 0 & 2 & 0 & 1 & 1 & 0 & 0 & 4 & 9 & 44.44 \\
\hline Count & 15 & 12 & 6 & 23 & 13 & 50 & 43 & 17 & 33 & 6 & 9 & Accuracy & Карра \\
\hline User's & 80.00 & 75.00 & 83.33 & 95.65 & 46.15 & 72.00 & 76.74 & 64.71 & 69.70 & 83.33 & 44.44 & 73.13 & 0.693 \\
\hline $2.0 \mathrm{~m} \# 4$ & $\mathrm{BO}$ & DC & $\mathrm{E}$ & GP & IC & LO & PP & Vo & BO & $O D$ & $\mathrm{OC}$ & Count & Producer's \\
\hline Blue Oak & 13 & 0 & 0 & 0 & 1 & 3 & 0 & 3 & 0 & 0 & 0 & 20 & 65.00 \\
\hline Deodar Cedar & 0 & 6 & 0 & 0 & 0 & 1 & 2 & 0 & 0 & 0 & 1 & 10 & 60.00 \\
\hline Eucalyptus & 0 & 0 & 6 & 0 & 0 & 1 & 0 & 0 & 0 & 0 & 0 & 7 & 85.71 \\
\hline Gray Pine & 0 & 0 & 0 & 21 & 0 & 0 & 0 & 0 & 1 & 0 & 0 & 22 & 95.45 \\
\hline Incense Cedar & 0 & 1 & 0 & 0 & 13 & 0 & 1 & 0 & 0 & 0 & 1 & 16 & 81.25 \\
\hline Live Oak & 8 & 2 & 0 & 0 & 0 & 27 & 0 & 1 & 1 & 0 & 0 & 39 & 69.23 \\
\hline Ponderosa Pine & 0 & 0 & 0 & 0 & 0 & 0 & 37 & 1 & 0 & 1 & 1 & 40 & 92.50 \\
\hline Valley Oak & 1 & 0 & 0 & 0 & 0 & 3 & 0 & 14 & 3 & 0 & 0 & 21 & 66.67 \\
\hline Black Oak & 1 & 0 & 0 & 0 & 0 & 5 & 0 & 3 & 21 & 1 & 0 & 31 & 67.74 \\
\hline Other Deciduous & 1 & 1 & 0 & 0 & 1 & 1 & 4 & 0 & 0 & 5 & 0 & 13 & 38.46 \\
\hline Other Conifer & 0 & 1 & 0 & 1 & 2 & 0 & 1 & 0 & 0 & 0 & 5 & 10 & 50.00 \\
\hline Count & 24 & 11 & 6 & 22 & 17 & 41 & 45 & 22 & 26 & 7 & 8 & Accuracy & Kappa \\
\hline User's & 54.17 & 54.55 & 100.00 & 95.45 & 76.47 & 65.85 & 82.22 & 63.64 & 80.77 & 71.43 & 62.50 & 73.36 & 0.698 \\
\hline $2.0 \mathrm{~m} \# 5$ & BO & DC & $\mathrm{E}$ & GP & IC & LO & PP & Vo & BO & $O D$ & $\mathrm{OC}$ & Count & Producer's \\
\hline Blue Oak & 12 & 0 & 0 & 0 & 1 & 3 & 0 & 1 & 1 & 0 & 0 & 18 & 66.67 \\
\hline Deodar Cedar & 0 & 10 & 0 & 0 & 0 & 0 & 0 & 0 & 0 & 0 & 1 & 11 & 90.91 \\
\hline Eucalyptus & 0 & 0 & 6 & 0 & 0 & 2 & 0 & 0 & 0 & 0 & 0 & 8 & 75.00 \\
\hline Gray Pine & 0 & 0 & 0 & 20 & 0 & 0 & 1 & 0 & 1 & 0 & 0 & 22 & 90.91 \\
\hline Incense Cedar & 0 & 1 & 0 & 0 & 10 & 0 & 4 & 0 & 0 & 0 & 1 & 16 & 62.50 \\
\hline Live Oak & 1 & 0 & 0 & 0 & 0 & 35 & 0 & 0 & 4 & 0 & 0 & 40 & 87.50 \\
\hline Ponderosa Pine & 0 & 0 & 0 & 0 & 2 & 2 & 36 & 1 & 0 & 0 & 1 & 42 & 85.71 \\
\hline Valley Oak & 3 & 0 & 0 & 0 & 1 & 2 & 0 & 9 & 6 & 0 & 0 & 21 & 42.86 \\
\hline Black Oak & 0 & 0 & 0 & 0 & 0 & 3 & 0 & 8 & 21 & 0 & 0 & 32 & 65.63 \\
\hline Other Deciduous & 0 & 0 & 0 & 0 & 0 & 3 & 4 & 1 & 1 & 2 & 1 & 12 & 16.67 \\
\hline Other Conifer & 0 & 2 & 0 & 0 & 4 & 0 & 0 & 0 & 0 & 1 & 2 & 9 & 22.22 \\
\hline Count & 16 & 13 & 6 & 20 & 18 & 50 & 45 & 20 & 34 & 3 & 6 & Accuracy & Kарра \\
\hline User's & 75.00 & 76.92 & 100.00 & 100.00 & 55.56 & 70.00 & 80.00 & 45.00 & 61.76 & 66.67 & 33.33 & 70.56 & 0.663 \\
\hline
\end{tabular}




\begin{tabular}{|c|c|c|c|c|c|c|c|c|c|c|c|c|c|}
\hline $2.0 \mathrm{~m} \# 6$ & $\mathrm{BO}$ & DC & $\mathrm{E}$ & GP & IC & LO & PP & vo & BO & OD & OC & Count & Producer's \\
\hline Blue Oak & 15 & 0 & 0 & 0 & 0 & 3 & 0 & 1 & 0 & 0 & 0 & 19 & 78.95 \\
\hline Deodar Cedar & 0 & 7 & 0 & 0 & 0 & 0 & 0 & 0 & 1 & 0 & 2 & 10 & 70.00 \\
\hline Eucalyptus & 0 & 0 & 6 & 1 & 0 & 0 & 0 & 0 & 0 & 0 & 0 & 7 & 85.71 \\
\hline Gray Pine & 0 & 1 & 0 & 20 & 0 & 1 & 0 & 0 & 0 & 0 & 0 & 22 & 90.91 \\
\hline Incense Cedar & 0 & 0 & 1 & 0 & 9 & 0 & 1 & 1 & 0 & 1 & 3 & 16 & 56.25 \\
\hline Live Oak & 5 & 0 & 0 & 0 & 0 & 27 & 0 & 2 & 5 & 0 & 0 & 39 & 69.23 \\
\hline Ponderosa Pine & 0 & 0 & 0 & 0 & 5 & 0 & 35 & 1 & 0 & 0 & 0 & 41 & 85.37 \\
\hline Valley Oak & 1 & 0 & 0 & 0 & 0 & 1 & 0 & 13 & 6 & 0 & 0 & 21 & 61.90 \\
\hline Black Oak & 1 & 1 & 1 & 0 & 0 & 1 & 0 & 3 & 23 & 1 & 0 & 31 & 74.19 \\
\hline Other Deciduous & 0 & 0 & 0 & 0 & 0 & 0 & 3 & 1 & 2 & 6 & 1 & 13 & 46.15 \\
\hline Other Conifer & 0 & 0 & 0 & 1 & 3 & 0 & 0 & 1 & 0 & 0 & 4 & 9 & 44.44 \\
\hline Count & 22 & 9 & 8 & 22 & 17 & 33 & 39 & 23 & 37 & 8 & 10 & Accuracy & Kappa \\
\hline User's & 68.18 & 77.78 & 75.00 & 90.91 & 52.94 & 81.82 & 89.74 & 56.52 & 62.16 & 75.00 & 40.00 & 72.37 & 0.687 \\
\hline $2.0 \mathrm{~m} \# 7$ & BO & DC & $\mathrm{E}$ & GP & IC & LO & PP & vo & BO & OD & OC & Count & Producer's \\
\hline Blue Oak & 12 & 0 & 0 & 0 & 1 & 1 & 0 & 4 & 0 & 0 & 0 & 18 & 66.67 \\
\hline Deodar Cedar & 0 & 10 & 1 & 0 & 0 & 0 & 0 & 0 & 0 & 0 & 0 & 11 & 90.91 \\
\hline Eucalyptus & 0 & 0 & 7 & 0 & 0 & 0 & 0 & 0 & 0 & 1 & 0 & 8 & 87.50 \\
\hline Gray Pine & 0 & 0 & 0 & 22 & 0 & 0 & 0 & 0 & 0 & 0 & 0 & 22 & 100.00 \\
\hline Incense Cedar & 0 & 2 & 0 & 0 & 11 & 0 & 2 & 0 & 0 & 0 & 0 & 15 & 73.33 \\
\hline Live Oak & 3 & 0 & 1 & 0 & 0 & 30 & 1 & 2 & 3 & 0 & 0 & 40 & 75.00 \\
\hline Ponderosa Pine & 0 & 1 & 0 & 0 & 1 & 0 & 36 & 0 & 0 & 1 & 0 & 39 & 92.31 \\
\hline Valley Oak & 1 & 0 & 0 & 0 & 0 & 3 & 2 & 12 & 4 & 0 & 0 & 22 & 54.55 \\
\hline Black Oak & 2 & 0 & 0 & 0 & 0 & 4 & 0 & 4 & 21 & 1 & 0 & 32 & 65.63 \\
\hline Other Deciduous & 0 & 1 & 0 & 0 & 0 & 2 & 1 & 0 & 1 & 7 & 1 & 13 & 53.85 \\
\hline Other Conifer & 0 & 2 & 0 & 0 & 2 & 0 & 1 & 0 & 0 & 0 & 4 & 9 & 44.44 \\
\hline Count & 18 & 16 & 9 & 22 & 15 & 40 & 43 & 22 & 29 & 10 & 5 & Accuracy & Kappa \\
\hline User's & 66.67 & 62.50 & 77.78 & 100.00 & 73.33 & 75.00 & 83.72 & 54.55 & 72.41 & 70.00 & 80.00 & 75.11 & 0.718 \\
\hline $2.0 \mathrm{~m} \# 8$ & BO & DC & $\mathrm{E}$ & GP & IC & LO & PP & vo & BO & $O D$ & $O C$ & Count & Producer's \\
\hline Blue Oak & 9 & 0 & 0 & 1 & 0 & 5 & 0 & 4 & 0 & 0 & 0 & 19 & 47.37 \\
\hline Deodar Cedar & 1 & 7 & 0 & 0 & 1 & 0 & 0 & 0 & 0 & 0 & 1 & 10 & 70.00 \\
\hline Eucalyptus & 0 & 0 & 6 & 1 & 0 & 0 & 1 & 0 & 0 & 0 & 0 & 8 & 75.00 \\
\hline Gray Pine & 0 & 1 & 0 & 19 & 1 & 0 & 0 & 0 & 0 & 0 & 0 & 21 & 90.48 \\
\hline Incense Cedar & 0 & 1 & 0 & 0 & 9 & 0 & 3 & 0 & 0 & 0 & 2 & 15 & 60.00 \\
\hline Live Oak & 2 & 1 & 0 & 0 & 0 & 34 & 0 & 1 & 2 & 0 & 0 & 40 & 85.00 \\
\hline Ponderosa Pine & 0 & 0 & 0 & 0 & 1 & 1 & 36 & 0 & 0 & 1 & 0 & 39 & 92.31 \\
\hline Valley Oak & 2 & 0 & 0 & 1 & 0 & 3 & 1 & 10 & 4 & 0 & 0 & 21 & 47.62 \\
\hline Black Oak & 2 & 1 & 0 & 0 & 0 & 6 & 0 & 4 & 19 & 0 & 0 & 32 & 59.38 \\
\hline Other Deciduous & 0 & 1 & 0 & 0 & 0 & 1 & 4 & 1 & 1 & 4 & 2 & 14 & 28.57 \\
\hline Other Conifer & 0 & 1 & 1 & 0 & 2 & 1 & 1 & 0 & 0 & 0 & 4 & 10 & 40.00 \\
\hline Count & 16 & 13 & 7 & 22 & 14 & 51 & 46 & 20 & 26 & 5 & 9 & Accuracy & Kappa \\
\hline User's & 56.25 & 53.85 & 85.71 & 86.36 & 64.29 & 66.67 & 78.26 & 50.00 & 73.08 & 80.00 & 44.44 & 68.56 & 0.642 \\
\hline $2.0 \mathrm{~m} \# 9$ & BO & DC & $\mathrm{E}$ & GP & IC & LO & PP & vo & BO & $O D$ & $O C$ & Count & Producer's \\
\hline Blue Oak & 13 & 0 & 0 & 0 & 0 & 3 & 0 & 2 & 0 & 0 & 0 & 18 & 72.22 \\
\hline Deodar Cedar & 0 & 9 & 0 & 1 & 0 & 1 & 0 & 0 & 0 & 0 & 0 & 11 & 81.82 \\
\hline Eucalyptus & 1 & 0 & 4 & 0 & 0 & 0 & 0 & 0 & 0 & 1 & 1 & 7 & 57.14 \\
\hline Gray Pine & 0 & 0 & 0 & 21 & 0 & 0 & 0 & 0 & 0 & 0 & 0 & 21 & 100.00 \\
\hline Incense Cedar & 0 & 0 & 0 & 0 & 10 & 0 & 3 & 0 & 0 & 0 & 3 & 16 & 62.50 \\
\hline Live Oak & 5 & 2 & 0 & 0 & 0 & 26 & 0 & 3 & 4 & 0 & 0 & 40 & 65.00 \\
\hline Ponderosa Pine & 0 & 0 & 0 & 0 & 4 & 1 & 35 & 0 & 0 & 2 & 1 & 43 & 81.40 \\
\hline Valley Oak & 1 & 0 & 0 & 0 & 0 & 1 & 1 & 10 & 8 & 0 & 0 & 21 & 47.62 \\
\hline Black Oak & 1 & 0 & 0 & 0 & 0 & 6 & 0 & 1 & 24 & 0 & 0 & 32 & 75.00 \\
\hline Other Deciduous & 0 & 0 & 0 & 0 & 2 & 2 & 3 & 0 & 0 & 2 & 2 & 11 & 18.18 \\
\hline Other Conifer & 1 & 2 & 0 & 0 & 4 & 0 & 0 & 0 & 0 & 0 & 3 & 10 & 30.00 \\
\hline Count & 22 & 13 & 4 & 22 & 20 & 40 & 42 & 16 & 36 & 5 & 10 & Accuracy & Kappa \\
\hline User's & 59.09 & 69.23 & 100.00 & 95.45 & 50.00 & 65.00 & 83.33 & 62.50 & 66.67 & 40.00 & 30.00 & 68.26 & 0.639 \\
\hline $2.0 \mathrm{~m} \# 10$ & BO & DC & $\mathrm{E}$ & GP & IC & LO & PP & vo & BO & OD & OC & Count & Producer's \\
\hline Blue Oak & 15 & 0 & 0 & 1 & 0 & 3 & 0 & 1 & 0 & 0 & 0 & 20 & 75.00 \\
\hline Deodar Cedar & 0 & 6 & 0 & 0 & 0 & 1 & 2 & 0 & 0 & 0 & 1 & 10 & 60.00 \\
\hline Eucalyptus & 0 & 0 & 6 & 1 & 0 & 0 & 1 & 0 & 0 & 0 & 0 & 8 & 75.00 \\
\hline Gray Pine & 0 & 0 & 0 & 22 & 0 & 0 & 0 & 0 & 0 & 0 & 0 & 22 & 100.00 \\
\hline Incense Cedar & 0 & 0 & 0 & 0 & 12 & 0 & 1 & 0 & 0 & 0 & 2 & 15 & 80.00 \\
\hline Live Oak & 2 & 0 & 0 & 0 & 0 & 34 & 0 & 2 & 2 & 0 & 0 & 40 & 85.00 \\
\hline Ponderosa Pine & 0 & 0 & 0 & 0 & 1 & 1 & 34 & 1 & 0 & 2 & 1 & 40 & 85.00 \\
\hline Valley Oak & 2 & 0 & 0 & 0 & 0 & 2 & 0 & 11 & 6 & 0 & 0 & 21 & 52.38 \\
\hline Black Oak & 0 & 0 & 0 & 0 & 0 & 1 & 0 & 5 & 24 & 1 & 0 & 31 & 77.42 \\
\hline Other Deciduous & 0 & 0 & 0 & 0 & 0 & 1 & 3 & 0 & 0 & 6 & 2 & 12 & 50.00 \\
\hline Other Conifer & 1 & 0 & 0 & 0 & 2 & 0 & 2 & 0 & 0 & 1 & 3 & 9 & 33.33 \\
\hline Count & 20 & 6 & 6 & 24 & 15 & 43 & 43 & 20 & 32 & 10 & 9 & Accuracy & Kappa \\
\hline User's & 75.00 & 100.00 & 100.00 & 91.67 & 80.00 & 79.07 & 79.07 & 55.00 & 75.00 & 60.00 & 33.33 & 75.88 & 0.725 \\
\hline
\end{tabular}


E. Confusion matrix for individual classification runs of $3.0 \mathrm{~m}$ images.

\begin{tabular}{|c|c|c|c|c|c|c|c|c|c|c|c|c|c|}
\hline $3.0 \mathrm{~m} \# 1$ & BO & DC & $\mathrm{E}$ & GP & IC & LO & PP & vo & BO & OD & OC & Count & Producer's \\
\hline Blue Oak & 11 & 0 & 0 & 2 & 1 & 2 & 0 & 5 & 0 & 0 & 0 & 21 & 52.38 \\
\hline Deodar Cedar & 0 & 9 & 0 & 0 & 1 & 0 & 1 & 0 & 0 & 0 & 0 & 11 & 81.82 \\
\hline Eucalyptus & 0 & 0 & 8 & 0 & 0 & 0 & 0 & 0 & 0 & 0 & 0 & 8 & 100.00 \\
\hline Gray Pine & 0 & 1 & 0 & 21 & 0 & 0 & 0 & 0 & 0 & 0 & 0 & 22 & 95.45 \\
\hline Incense Cedar & 0 & 0 & 0 & 0 & 13 & 0 & 3 & 0 & 0 & 0 & 0 & 16 & 81.25 \\
\hline Live Oak & 1 & 0 & 0 & 0 & 0 & 36 & 0 & 1 & 1 & 0 & 0 & 39 & 92.31 \\
\hline Ponderosa Pine & 0 & 1 & 0 & 0 & 2 & 0 & 35 & 1 & 0 & 3 & 0 & 42 & 83.33 \\
\hline Valley Oak & 3 & 0 & 0 & 0 & 0 & 1 & 0 & 9 & 9 & 0 & 0 & 22 & 40.91 \\
\hline Black Oak & 1 & 0 & 0 & 0 & 0 & 8 & 0 & 4 & 18 & 0 & 0 & 31 & 58.06 \\
\hline Other Deciduous & 0 & 0 & 0 & 0 & 0 & 3 & 1 & 0 & 1 & 5 & 0 & 10 & 50.00 \\
\hline Other Conifer & 0 & 0 & 0 & 0 & 4 & 0 & 1 & 0 & 0 & 0 & 5 & 10 & 50.00 \\
\hline Count & 16 & 11 & 8 & 23 & 21 & 50 & 41 & 20 & 29 & 8 & 5 & Accuracy & Карра \\
\hline User's & 68.75 & 81.82 & 100.00 & 91.30 & 61.90 & 72.00 & 85.37 & 45.00 & 62.07 & 62.50 & 100.00 & 73.28 & 0.696 \\
\hline $3.0 \mathrm{~m} \# 2$ & BO & DC & E & GP & IC & LO & PP & vo & BO & OD & OC & Count & Producer's \\
\hline Blue Oak & 15 & 0 & 0 & 1 & 0 & 1 & 0 & 3 & 1 & 0 & 0 & 21 & 71.43 \\
\hline Deodar Cedar & 0 & 8 & 0 & 0 & 1 & 0 & 0 & 0 & 0 & 0 & 1 & 10 & 80.00 \\
\hline Eucalyptus & 1 & 0 & 5 & 0 & 0 & 0 & 0 & 0 & 0 & 1 & 0 & 7 & 71.43 \\
\hline Gray Pine & 0 & 0 & 0 & 22 & 0 & 0 & 0 & 0 & 0 & 0 & 0 & 22 & 100.00 \\
\hline Incense Cedar & 0 & 0 & 0 & 0 & 10 & 0 & 4 & 0 & 0 & 0 & 1 & 15 & 66.67 \\
\hline Live Oak & 4 & 0 & 0 & 0 & 0 & 31 & 0 & 2 & 2 & 1 & 0 & 40 & 77.50 \\
\hline Ponderosa Pine & 0 & 1 & 0 & 0 & 2 & 1 & 33 & 1 & 0 & 1 & 0 & 39 & 84.62 \\
\hline Valley Oak & 2 & 0 & 0 & 0 & 0 & 1 & 1 & 9 & 7 & 0 & 1 & 21 & 42.86 \\
\hline Black Oak & 0 & 0 & 0 & 0 & 0 & 1 & 0 & 8 & 24 & 0 & 0 & 33 & 72.73 \\
\hline Other Deciduous & 0 & 0 & 0 & 0 & 1 & 2 & 4 & 0 & 0 & 2 & 1 & 10 & 20.00 \\
\hline Other Conifer & 0 & 1 & 0 & 0 & 2 & 0 & 3 & 0 & 0 & 1 & 3 & 10 & 30.00 \\
\hline Count & 22 & 10 & 5 & 23 & 16 & 37 & 45 & 23 & 34 & 6 & 7 & Accuracy & Карра \\
\hline User's & 68.18 & 80.00 & 100.00 & 95.65 & 62.50 & 83.78 & 73.33 & 39.13 & 70.59 & 33.33 & 42.86 & 71.05 & 0.671 \\
\hline $3.0 \mathrm{~m} \# 3$ & $\mathrm{BO}$ & DC & $\mathrm{E}$ & GP & IC & LO & PP & vo & $\mathrm{BO}$ & OD & OC & Count & Producer's \\
\hline Blue Oak & 13 & 0 & 0 & 0 & 0 & 3 & 0 & 4 & 1 & 0 & 0 & 21 & 61.90 \\
\hline Deodar Cedar & 0 & 9 & 0 & 0 & 0 & 1 & 1 & 0 & 0 & 0 & 0 & 11 & 81.82 \\
\hline Eucalyptus & 0 & 0 & 6 & 0 & 0 & 1 & 0 & 0 & 0 & 0 & 0 & 7 & 85.71 \\
\hline Gray Pine & 0 & 0 & 0 & 21 & 0 & 0 & 0 & 0 & 1 & 0 & 0 & 22 & 95.45 \\
\hline Incense Cedar & 0 & 2 & 0 & 0 & 5 & 0 & 5 & 0 & 0 & 1 & 3 & 16 & 31.25 \\
\hline Live Oak & 0 & 0 & 0 & 0 & 0 & 36 & 0 & 1 & 1 & 1 & 0 & 39 & 92.31 \\
\hline Ponderosa Pine & 0 & 1 & 1 & 0 & 5 & 1 & 30 & 1 & 0 & 1 & 0 & 40 & 75.00 \\
\hline Valley Oak & 0 & 0 & 0 & 0 & 0 & 2 & 1 & 12 & 6 & 0 & 0 & 21 & 57.14 \\
\hline Black Oak & 1 & 0 & 0 & 0 & 0 & 4 & 0 & 3 & 22 & 1 & 0 & 31 & 70.97 \\
\hline Other Deciduous & 0 & 0 & 1 & 0 & 0 & 3 & 0 & 0 & 3 & 3 & 0 & 10 & 30.00 \\
\hline Other Conifer & 0 & 1 & 0 & 0 & 3 & 0 & 0 & 1 & 0 & 1 & 3 & 9 & 33.33 \\
\hline Count & 14 & 13 & 8 & 21 & 13 & 51 & 37 & 22 & 34 & 8 & 6 & Accuracy & Карра \\
\hline User's & 92.86 & 69.23 & 75.00 & 100.00 & 38.46 & 70.59 & 81.08 & 54.55 & 64.71 & 37.50 & 50.00 & 70.48 & 0.664 \\
\hline $3.0 \mathrm{~m} \# 4$ & $\mathrm{BO}$ & DC & E & GP & IC & LO & PP & vo & $\mathrm{BO}$ & OD & OC & Count & Producer's \\
\hline Blue Oak & 14 & 0 & 0 & 0 & 0 & 4 & 0 & 2 & 0 & 1 & 0 & 21 & 66.67 \\
\hline Deodar Cedar & 0 & 7 & 1 & 1 & 0 & 1 & 1 & 0 & 0 & 0 & 0 & 11 & 63.64 \\
\hline Eucalyptus & 0 & 0 & 6 & 0 & 0 & 1 & 0 & 0 & 0 & 0 & 0 & 7 & 85.71 \\
\hline Gray Pine & 0 & 1 & 0 & 20 & 0 & 0 & 0 & 0 & 1 & 0 & 0 & 22 & 90.91 \\
\hline Incense Cedar & 0 & 2 & 0 & 0 & 12 & 0 & 1 & 0 & 0 & 0 & 0 & 15 & 80.00 \\
\hline Live Oak & 6 & 0 & 0 & 0 & 0 & 31 & 0 & 2 & 0 & 0 & 0 & 39 & 79.49 \\
\hline Ponderosa Pine & 0 & 0 & 0 & 0 & 1 & 0 & 37 & 1 & 0 & 0 & 1 & 40 & 92.50 \\
\hline Valley Oak & 2 & 0 & 0 & 0 & 0 & 2 & 0 & 12 & 5 & 0 & 0 & 21 & 57.14 \\
\hline Black Oak & 0 & 0 & 0 & 0 & 0 & 6 & 0 & 4 & 20 & 1 & 0 & 31 & 64.52 \\
\hline Other Deciduous & 0 & 1 & 0 & 0 & 0 & 0 & 2 & 0 & 1 & 6 & 2 & 12 & 50.00 \\
\hline Other Conifer & 0 & 1 & 1 & 2 & 2 & 0 & 1 & 0 & 0 & 0 & 3 & 10 & 30.00 \\
\hline Count & 22 & 12 & 8 & 23 & 15 & 45 & 42 & 21 & 27 & 8 & 6 & Accuracy & Kappa \\
\hline User's & 63.64 & 58.33 & 75.00 & 86.96 & 80.00 & 68.89 & 88.10 & 57.14 & 74.07 & 75.00 & 50.00 & 73.36 & 0.698 \\
\hline $3.0 \mathrm{~m} \# 5$ & BO & DC & $\mathrm{E}$ & GP & IC & LO & PP & vo & BO & $O D$ & OC & Count & Producer's \\
\hline Blue Oak & 13 & 0 & 0 & 1 & 0 & 3 & 2 & 1 & 0 & 0 & 0 & 20 & 65.00 \\
\hline Deodar Cedar & 0 & 8 & 0 & 0 & 0 & 1 & 1 & 1 & 0 & 0 & 0 & 11 & 72.73 \\
\hline Eucalyptus & 0 & 0 & 5 & 0 & 0 & 2 & 0 & 0 & 0 & 0 & 1 & 8 & 62.50 \\
\hline Gray Pine & 0 & 0 & 0 & 19 & 0 & 1 & 0 & 0 & 1 & 0 & 0 & 21 & 90.48 \\
\hline Incense Cedar & 0 & 1 & 0 & 0 & 9 & 0 & 5 & 0 & 0 & 0 & 1 & 16 & 56.25 \\
\hline Live Oak & 4 & 0 & 0 & 0 & 0 & 32 & 0 & 0 & 4 & 0 & 0 & 40 & 80.00 \\
\hline Ponderosa Pine & 0 & 0 & 0 & 0 & 1 & 0 & 38 & 1 & 0 & 0 & 2 & 42 & 90.48 \\
\hline Valley Oak & 1 & 0 & 0 & 1 & 0 & 3 & 0 & 11 & 4 & 0 & 1 & 21 & 52.38 \\
\hline Black Oak & 0 & 2 & 0 & 0 & 0 & 2 & 0 & 8 & 20 & 0 & 0 & 32 & 62.50 \\
\hline Other Deciduous & 1 & 0 & 0 & 0 & 0 & 2 & 2 & 0 & 3 & 2 & 1 & 11 & 18.18 \\
\hline Other Conifer & 0 & 3 & 0 & 0 & 1 & 0 & 3 & 0 & 0 & 0 & 2 & 9 & 22.22 \\
\hline Count & 19 & 14 & 5 & 21 & 11 & 46 & 51 & 22 & 32 & 2 & 8 & Accuracy & Карра \\
\hline User's & 68.42 & 57.14 & 100.00 & 90.48 & 81.82 & 69.57 & 74.51 & 50.00 & 62.50 & 0.00 & 25.00 & 68.83 & 0.643 \\
\hline
\end{tabular}




\begin{tabular}{|c|c|c|c|c|c|c|c|c|c|c|c|c|c|}
\hline $3.0 \mathrm{~m} \# 6$ & $\mathrm{BO}$ & DC & E & GP & IC & LO & PP & Vo & $\mathrm{BO}$ & OD & OC & Count & Producer's \\
\hline Blue Oak & 13 & 0 & 0 & 2 & 1 & 3 & 0 & 1 & 0 & 0 & 0 & 20 & 65.00 \\
\hline Deodar Cedar & 0 & 9 & 0 & 0 & 1 & 0 & 0 & 0 & 0 & 1 & 0 & 11 & 81.82 \\
\hline Eucalyptus & 0 & 0 & 7 & 0 & 0 & 0 & 0 & 0 & 0 & 0 & 0 & 7 & 100.00 \\
\hline Gray Pine & 1 & 1 & 0 & 18 & 0 & 0 & 0 & 1 & 0 & 0 & 0 & 21 & 85.71 \\
\hline Incense Cedar & 0 & 1 & 0 & 0 & 11 & 0 & 2 & 0 & 0 & 1 & 0 & 15 & 73.33 \\
\hline Live Oak & 6 & 0 & 0 & 0 & 0 & 26 & 0 & 2 & 5 & 0 & 0 & 39 & 66.67 \\
\hline Ponderosa Pine & 0 & 1 & 0 & 0 & 4 & 0 & 35 & 0 & 1 & 0 & 0 & 41 & 85.37 \\
\hline Valley Oak & 2 & 0 & 0 & 0 & 1 & 0 & 0 & 14 & 4 & 0 & 0 & 21 & 66.67 \\
\hline Black Oak & 1 & 0 & 0 & 0 & 0 & 7 & 0 & 3 & 19 & 1 & 0 & 31 & 61.29 \\
\hline Other Deciduous & 1 & 0 & 0 & 0 & 2 & 2 & 3 & 0 & 2 & 1 & 1 & 12 & 8.33 \\
\hline Other Conifer & 0 & 0 & 0 & 1 & 4 & 0 & 0 & 0 & 0 & 0 & 4 & 9 & 44.44 \\
\hline Count & 24 & 12 & 7 & 21 & 24 & 38 & 40 & 21 & 31 & 4 & 5 & Accuracy & Kappa \\
\hline User's & 54.17 & 75.00 & 100.00 & 85.71 & 45.83 & 68.42 & 87.50 & 66.67 & 61.29 & 25.00 & 80.00 & 69.16 & 0.650 \\
\hline $3.0 \mathrm{~m} \# 7$ & BO & DC & $E$ & GP & IC & LO & PP & vo & BO & $O D$ & OC & Count & Producer's \\
\hline Blue Oak & 12 & 0 & 0 & 0 & 1 & 3 & 0 & 4 & 0 & 0 & 0 & 20 & 60.00 \\
\hline Deodar Cedar & 1 & 5 & 0 & 1 & 0 & 1 & 2 & 0 & 0 & 0 & 1 & 11 & 45.45 \\
\hline Eucalyptus & 0 & 0 & 7 & 0 & 0 & 1 & 0 & 0 & 0 & 0 & 0 & 8 & 87.50 \\
\hline Gray Pine & 1 & 1 & 0 & 18 & 0 & 1 & 0 & 0 & 0 & 0 & 0 & 21 & 85.71 \\
\hline Incense Cedar & 0 & 0 & 0 & 0 & 11 & 0 & 3 & 0 & 0 & 0 & 0 & 14 & 78.57 \\
\hline Live Oak & 2 & 0 & 0 & 0 & 0 & 33 & 0 & 2 & 3 & 0 & 0 & 40 & 82.50 \\
\hline Ponderosa Pine & 0 & 1 & 0 & 0 & 1 & 0 & 37 & 0 & 0 & 0 & 0 & 39 & 94.87 \\
\hline Valley Oak & 2 & 0 & 0 & 0 & 0 & 3 & 1 & 14 & 2 & 0 & 0 & 22 & 63.64 \\
\hline Black Oak & 1 & 0 & 0 & 0 & 0 & 5 & 0 & 5 & 20 & 1 & 0 & 32 & 62.50 \\
\hline Other Deciduous & 2 & 1 & 0 & 0 & 0 & 1 & 0 & 1 & 1 & 2 & 2 & 10 & 20.00 \\
\hline Other Conifer & 0 & 2 & 0 & 0 & 1 & 0 & 2 & 0 & 0 & 0 & 4 & 9 & 44.44 \\
\hline Count & 21 & 10 & 7 & 19 & 14 & 48 & 45 & 26 & 26 & 3 & 7 & Accuracy & Карра \\
\hline User's & 57.14 & 50.00 & 100.00 & 94.74 & 78.57 & 68.75 & 82.22 & 53.85 & 76.92 & 66.67 & 57.14 & 72.12 & 0.682 \\
\hline $3.0 \mathrm{~m} \# 8$ & $\mathrm{BO}$ & DC & $\mathrm{E}$ & GP & IC & LO & PP & vo & $\mathrm{BO}$ & OD & OC & Count & Producer's \\
\hline Blue Oak & 11 & 0 & 0 & 2 & 0 & 3 & 0 & 5 & 0 & 0 & 0 & 21 & 52.38 \\
\hline Deodar Cedar & 0 & 6 & 1 & 2 & 1 & 0 & 1 & 0 & 0 & 0 & 0 & 11 & 54.55 \\
\hline Eucalyptus & 0 & 0 & 7 & 0 & 0 & 1 & 0 & 0 & 0 & 0 & 0 & 8 & 87.50 \\
\hline Gray Pine & 0 & 0 & 0 & 21 & 0 & 0 & 0 & 0 & 1 & 0 & 0 & 22 & 95.45 \\
\hline Incense Cedar & 0 & 0 & 0 & 0 & 7 & 0 & 4 & 0 & 0 & 0 & 4 & 15 & 46.67 \\
\hline Live Oak & 5 & 0 & 0 & 0 & 0 & 31 & 0 & 2 & 2 & 0 & 0 & 40 & 77.50 \\
\hline Ponderosa Pine & 0 & 0 & 0 & 0 & 1 & 2 & 36 & 0 & 0 & 0 & 0 & 39 & 92.31 \\
\hline Valley Oak & 1 & 0 & 0 & 2 & 0 & 1 & 1 & 10 & 6 & 0 & 0 & 21 & 47.62 \\
\hline Black Oak & 1 & 0 & 0 & 0 & 0 & 3 & 0 & 3 & 25 & 0 & 0 & 32 & 78.13 \\
\hline Other Deciduous & 1 & 1 & 0 & 0 & 0 & 1 & 3 & 0 & 0 & 4 & 1 & 11 & 36.36 \\
\hline Other Conifer & 0 & 1 & 1 & 0 & 1 & 0 & 2 & 0 & 0 & 0 & 5 & 10 & 50.00 \\
\hline Count & 19 & 8 & 9 & 27 & 10 & 42 & 47 & 20 & 34 & 4 & 10 & Accuracy & Kappa \\
\hline User's & 57.89 & 75.00 & 77.78 & 77.78 & 70.00 & 73.81 & 76.60 & 50.00 & 73.53 & 100.00 & 50.00 & 70.87 & 0.668 \\
\hline $3.0 \mathrm{~m} \# 9$ & BO & DC & $E$ & GP & IC & LO & PP & vo & BO & $O D$ & $O C$ & Count & Producer's \\
\hline Blue Oak & 13 & 0 & 0 & 1 & 0 & 3 & 0 & 2 & 1 & 0 & 0 & 20 & 65.00 \\
\hline Deodar Cedar & 0 & 8 & 0 & 1 & 0 & 1 & 0 & 0 & 0 & 0 & 0 & 10 & 80.00 \\
\hline Eucalyptus & 0 & 0 & 3 & 0 & 0 & 3 & 0 & 0 & 0 & 0 & 1 & 7 & 42.86 \\
\hline Gray Pine & 0 & 0 & 0 & 22 & 0 & 0 & 0 & 0 & 0 & 0 & 0 & 22 & 100.00 \\
\hline Incense Cedar & 0 & 1 & 0 & 0 & 11 & 0 & 2 & 0 & 0 & 0 & 1 & 15 & 73.33 \\
\hline Live Oak & 4 & 0 & 0 & 0 & 0 & 32 & 0 & 3 & 1 & 0 & 0 & 40 & 80.00 \\
\hline Ponderosa Pine & 0 & 0 & 0 & 0 & 3 & 0 & 37 & 0 & 0 & 2 & 1 & 43 & 86.05 \\
\hline Valley Oak & 1 & 0 & 0 & 0 & 0 & 1 & 1 & 10 & 8 & 0 & 0 & 21 & 47.62 \\
\hline Black Oak & 1 & 0 & 0 & 0 & 0 & 5 & 0 & 1 & 25 & 0 & 0 & 32 & 78.13 \\
\hline Other Deciduous & 2 & 0 & 0 & 0 & 2 & 2 & 3 & 0 & 0 & 1 & 2 & 12 & 8.33 \\
\hline Other Conifer & 0 & 2 & 0 & 1 & 3 & 0 & 3 & 0 & 0 & 0 & 1 & 10 & 10.00 \\
\hline Count & 21 & 11 & 3 & 25 & 19 & 47 & 46 & 16 & 35 & 3 & 6 & Accuracy & Kappa \\
\hline User's & 61.90 & 72.73 & 100.00 & 88.00 & 57.89 & 68.09 & 80.43 & 62.50 & 71.43 & 33.33 & 16.67 & 70.26 & 0.660 \\
\hline $3.0 \mathrm{~m} \# 10$ & BO & $D C$ & $\mathrm{E}$ & GP & IC & LO & PP & vo & BO & OD & OC & Count & Producer's \\
\hline Blue Oak & 11 & 0 & 0 & 2 & 0 & 4 & 0 & 3 & 0 & 0 & 0 & 20 & 55.00 \\
\hline Deodar Cedar & 0 & 7 & 1 & 1 & 0 & 0 & 0 & 0 & 0 & 0 & 2 & 11 & 63.64 \\
\hline Eucalyptus & 0 & 0 & 7 & 0 & 0 & 0 & 0 & 0 & 0 & 1 & 0 & 8 & 87.50 \\
\hline Gray Pine & 0 & 1 & 0 & 22 & 0 & 0 & 0 & 0 & 0 & 0 & 0 & 23 & 95.65 \\
\hline Incense Cedar & 0 & 0 & 0 & 0 & 10 & 0 & 3 & 0 & 0 & 1 & 0 & 14 & 71.43 \\
\hline Live Oak & 3 & 0 & 0 & 0 & 0 & 34 & 0 & 1 & 2 & 0 & 0 & 40 & 85.00 \\
\hline Ponderosa Pine & 0 & 1 & 0 & 0 & 3 & 0 & 34 & 0 & 0 & 2 & 0 & 40 & 85.00 \\
\hline Valley Oak & 2 & 0 & 0 & 0 & 0 & 0 & 0 & 11 & 8 & 0 & 0 & 21 & 52.38 \\
\hline Black Oak & 1 & 0 & 0 & 1 & 0 & 2 & 0 & 4 & 23 & 0 & 0 & 31 & 74.19 \\
\hline Other Deciduous & 0 & 0 & 0 & 0 & 1 & 1 & 4 & 0 & 0 & 3 & 1 & 10 & 30.00 \\
\hline Other Conifer & 0 & 0 & 0 & 0 & 0 & 0 & 3 & 0 & 0 & 1 & 5 & 9 & 55.56 \\
\hline Count & 17 & 9 & 8 & 26 & 14 & 41 & 44 & 19 & 33 & 8 & 8 & Accuracy & Kappa \\
\hline User's & 64.71 & 77.78 & 87.50 & 84.62 & 71.43 & 82.93 & 77.27 & 57.89 & 69.70 & 37.50 & 62.50 & 73.57 & 0.699 \\
\hline
\end{tabular}


F. Confusion matrix for individual classification runs of $5.0 \mathrm{~m}$ images.

\begin{tabular}{|c|c|c|c|c|c|c|c|c|c|c|c|c|c|}
\hline $5.0 \mathrm{~m} \# 1$ & $\mathrm{BO}$ & DC & $\mathrm{E}$ & GP & IC & LO & PP & Vo & BO & OD & OC & Count & Producer's \\
\hline Blue Oak & 12 & 0 & 0 & 1 & 0 & 4 & 0 & 2 & 0 & 0 & 0 & 19 & 63.16 \\
\hline Deodar Cedar & 0 & 3 & 0 & 2 & 1 & 3 & 1 & 0 & 0 & 0 & 0 & 10 & 30.00 \\
\hline Eucalyptus & 0 & 0 & 6 & 0 & 0 & 0 & 0 & 0 & 1 & 0 & 0 & 7 & 85.71 \\
\hline Gray Pine & 0 & 0 & 0 & 21 & 0 & 0 & 0 & 0 & 0 & 0 & 0 & 21 & 100.00 \\
\hline Incense Cedar & 0 & 0 & 0 & 0 & 5 & 0 & 6 & 1 & 0 & 1 & 2 & 15 & 33.33 \\
\hline Live Oak & 3 & 0 & 0 & 0 & 0 & 27 & 0 & 0 & 5 & 0 & 0 & 35 & 77.14 \\
\hline Ponderosa Pine & 0 & 1 & 0 & 1 & 1 & 0 & 33 & 1 & 0 & 2 & 1 & 40 & 82.50 \\
\hline Valley Oak & 3 & 0 & 0 & 1 & 0 & 0 & 0 & 12 & 6 & 0 & 0 & 22 & 54.55 \\
\hline Black Oak & 3 & 0 & 0 & 0 & 0 & 6 & 0 & 2 & 19 & 0 & 0 & 30 & 63.33 \\
\hline Other Deciduous & 0 & 0 & 1 & 0 & 0 & 3 & 2 & 0 & 1 & 3 & 0 & 10 & 30.00 \\
\hline Other Conifer & 0 & 0 & 0 & 0 & 4 & 0 & 3 & 0 & 1 & 0 & 1 & 9 & 11.11 \\
\hline Count & 21 & 4 & 7 & 26 & 11 & 43 & 45 & 18 & 33 & 6 & 4 & Accuracy & Kappa \\
\hline User's & 57.14 & 75.00 & 85.71 & 80.77 & 45.45 & 62.79 & 73.33 & 66.67 & 57.58 & 50.00 & 25.00 & 65.14 & 0.601 \\
\hline $5.0 \mathrm{~m} \# 2$ & BO & $D C$ & $\mathrm{E}$ & GP & IC & LO & PP & vo & BO & OD & $\mathrm{OC}$ & Count & Producer's \\
\hline Blue Oak & 13 & 1 & 0 & 0 & 0 & 1 & 0 & 4 & 0 & 0 & 0 & 19 & 68.42 \\
\hline Deodar Cedar & 1 & 4 & 1 & 1 & 1 & 1 & 0 & 0 & 0 & 0 & 1 & 10 & 40.00 \\
\hline Eucalyptus & 0 & 0 & 4 & 0 & 0 & 0 & 1 & 0 & 1 & 0 & 0 & 6 & 66.67 \\
\hline Gray Pine & 0 & 3 & 0 & 20 & 0 & 0 & 0 & 0 & 0 & 0 & 0 & 23 & 86.96 \\
\hline Incense Cedar & 0 & 1 & 0 & 0 & 5 & 0 & 8 & 0 & 0 & 1 & 0 & 15 & 33.33 \\
\hline Live Oak & 4 & 0 & 1 & 1 & 0 & 26 & 2 & 0 & 3 & 1 & 0 & 38 & 68.42 \\
\hline Ponderosa Pine & 1 & 0 & 0 & 0 & 1 & 2 & 30 & 0 & 1 & 2 & 0 & 37 & 81.08 \\
\hline Valley Oak & 4 & 0 & 0 & 0 & 0 & 1 & 1 & 10 & 5 & 0 & 0 & 21 & 47.62 \\
\hline Black Oak & 3 & 1 & 0 & 0 & 0 & 3 & 0 & 7 & 19 & 0 & 0 & 33 & 57.58 \\
\hline Other Deciduous & 0 & 1 & 0 & 0 & 1 & 1 & 3 & 0 & 2 & 1 & 0 & 9 & 11.11 \\
\hline Other Conifer & 1 & 0 & 0 & 1 & 3 & 0 & 2 & 0 & 0 & 0 & 3 & 10 & 30.00 \\
\hline Count & 27 & 11 & 6 & 23 & 11 & 35 & 47 & 21 & 31 & 5 & 4 & Accuracy & Kappa \\
\hline User's & 48.15 & 36.36 & 66.67 & 86.96 & 45.45 & 74.29 & 63.83 & 47.62 & 61.29 & 20.00 & 75.00 & 61.09 & 0.557 \\
\hline $5.0 \mathrm{~m} \# 3$ & $\mathrm{BO}$ & $D C$ & $\mathrm{E}$ & GP & IC & LO & PP & vo & BO & OD & $\mathrm{OC}$ & Count & Producer's \\
\hline Blue Oak & 12 & 0 & 0 & 0 & 0 & 3 & 0 & 4 & 1 & 0 & 0 & 20 & 60.00 \\
\hline Deodar Cedar & 0 & 5 & 0 & 3 & 0 & 0 & 0 & 0 & 0 & 1 & 0 & 9 & 55.56 \\
\hline Eucalyptus & 0 & 0 & 6 & 0 & 0 & 0 & 0 & 0 & 0 & 0 & 0 & 6 & 100.00 \\
\hline Gray Pine & 0 & 0 & 0 & 21 & 0 & 2 & 0 & 0 & 0 & 0 & 0 & 23 & 91.30 \\
\hline Incense Cedar & 0 & 1 & 0 & 0 & 5 & 0 & 6 & 0 & 1 & 0 & 1 & 14 & 35.71 \\
\hline Live Oak & 0 & 0 & 0 & 0 & 0 & 34 & 0 & 1 & 1 & 1 & 0 & 37 & 91.89 \\
\hline Ponderosa Pine & 0 & 0 & 1 & 1 & 2 & 3 & 29 & 1 & 1 & 0 & 0 & 38 & 76.32 \\
\hline Valley Oak & 2 & 0 & 0 & 0 & 0 & 2 & 1 & 10 & 6 & 0 & 0 & 21 & 47.62 \\
\hline Black Oak & 1 & 0 & 0 & 0 & 0 & 7 & 0 & 3 & 18 & 1 & 0 & 30 & 60.00 \\
\hline Other Deciduous & 0 & 0 & 0 & 0 & 0 & 1 & 0 & 0 & 3 & 5 & 0 & 9 & 55.56 \\
\hline Other Conifer & 0 & 1 & 0 & 0 & 1 & 0 & 3 & 0 & 0 & 2 & 3 & 10 & 30.00 \\
\hline Count & 15 & 7 & 7 & 25 & 8 & 52 & 39 & 19 & 31 & 10 & 4 & Accuracy & Kappa \\
\hline User's & 80.00 & 71.43 & 85.71 & 84.00 & 62.50 & 65.38 & 74.36 & 52.63 & 58.06 & 50.00 & 75.00 & 68.20 & 0.636 \\
\hline $5.0 \mathrm{~m} \# 4$ & $\mathrm{BO}$ & DC & $\mathrm{E}$ & GP & IC & LO & PP & vo & BO & OD & $\mathrm{OC}$ & Count & Producer's \\
\hline Blue Oak & 13 & 0 & 0 & 0 & 0 & 5 & 0 & 3 & 0 & 0 & 0 & 21 & 61.90 \\
\hline Deodar Cedar & 0 & 2 & 0 & 2 & 1 & 1 & 2 & 0 & 0 & 1 & 0 & 9 & 22.22 \\
\hline Eucalyptus & 0 & 0 & 6 & 0 & 1 & 0 & 0 & 0 & 0 & 0 & 0 & 7 & 85.71 \\
\hline Gray Pine & 0 & 2 & 0 & 20 & 0 & 0 & 0 & 0 & 0 & 0 & 0 & 22 & 90.91 \\
\hline Incense Cedar & 0 & 0 & 0 & 0 & 6 & 0 & 6 & 1 & 0 & 0 & 1 & 14 & 42.86 \\
\hline Live Oak & 2 & 2 & 0 & 1 & 0 & 25 & 0 & 3 & 2 & 2 & 0 & 37 & 67.57 \\
\hline Ponderosa Pine & 0 & 1 & 1 & 1 & 0 & 2 & 31 & 0 & 0 & 1 & 0 & 37 & 83.78 \\
\hline Valley Oak & 2 & 0 & 0 & 0 & 0 & 3 & 0 & 12 & 3 & 1 & 0 & 21 & 57.14 \\
\hline Black Oak & 1 & 0 & 0 & 0 & 0 & 7 & 0 & 3 & 18 & 1 & 0 & 30 & 60.00 \\
\hline Other Deciduous & 0 & 0 & 0 & 0 & 0 & 2 & 7 & 0 & 0 & 4 & 0 & 13 & 30.77 \\
\hline Other Conifer & 1 & 0 & 2 & 1 & 1 & 0 & 2 & 0 & 0 & 0 & 3 & 10 & 30.00 \\
\hline Count & 19 & 7 & 9 & 25 & 9 & 45 & 48 & 22 & 23 & 10 & 4 & Accuracy & Kappa \\
\hline User's & 68.42 & 28.57 & 66.67 & 80.00 & 66.67 & 55.56 & 64.58 & 54.55 & 78.26 & 40.00 & 75.00 & 63.35 & 0.583 \\
\hline $5.0 \mathrm{~m} \# 5$ & $\mathrm{BO}$ & DC & $\mathrm{E}$ & GP & IC & LO & PP & vo & BO & $O D$ & $\mathrm{OC}$ & Count & Producer's \\
\hline Blue Oak & 12 & 0 & 0 & 1 & 0 & 3 & 0 & 0 & 2 & 0 & 0 & 18 & 66.67 \\
\hline Deodar Cedar & 0 & 4 & 0 & 0 & 0 & 3 & 1 & 0 & 0 & 1 & 0 & 9 & 44.44 \\
\hline Eucalyptus & 0 & 0 & 5 & 0 & 0 & 3 & 0 & 0 & 0 & 0 & 0 & 8 & 62.50 \\
\hline Gray Pine & 0 & 1 & 0 & 18 & 0 & 2 & 0 & 0 & 0 & 0 & 0 & 21 & 85.71 \\
\hline Incense Cedar & 0 & 3 & 0 & 0 & 5 & 0 & 5 & 0 & 0 & 0 & 2 & 15 & 33.33 \\
\hline Live Oak & 1 & 0 & 0 & 0 & 0 & 28 & 0 & 1 & 6 & 1 & 0 & 37 & 75.68 \\
\hline Ponderosa Pine & 0 & 1 & 0 & 3 & 2 & 2 & 30 & 1 & 0 & 0 & 1 & 40 & 75.00 \\
\hline Valley Oak & 5 & 0 & 0 & 0 & 0 & 3 & 0 & 10 & 3 & 0 & 0 & 21 & 47.62 \\
\hline Black Oak & 0 & 0 & 0 & 0 & 0 & 4 & 0 & 6 & 20 & 0 & 0 & 30 & 66.67 \\
\hline Other Deciduous & 0 & 0 & 0 & 0 & 0 & 5 & 5 & 0 & 1 & 1 & 0 & 12 & 8.33 \\
\hline Other Conifer & 1 & 1 & 0 & 2 & 1 & 0 & 3 & 0 & 0 & 0 & 2 & 10 & 20.00 \\
\hline Count & 19 & 10 & 5 & 24 & 8 & 53 & 44 & 18 & 32 & 3 & 5 & dracy & Kappa \\
\hline User's & 63.16 & 40.00 & 100.00 & 75.00 & 62.50 & 52.83 & 68.18 & 55.56 & 62.50 & 33.33 & 40.00 & 61.09 & 0.554 \\
\hline
\end{tabular}




\begin{tabular}{|c|c|c|c|c|c|c|c|c|c|c|c|c|c|}
\hline $5.0 \mathrm{~m} \# 6$ & BO & DC & $\mathrm{E}$ & GP & IC & LO & PP & vo & BO & OD & OC & Count & Producer's \\
\hline Blue Oak & 13 & 0 & 0 & 1 & 0 & 3 & 0 & 2 & 0 & 0 & 0 & 19 & 68.42 \\
\hline Deodar Cedar & 0 & 4 & 1 & 0 & 0 & 2 & 0 & 0 & 0 & 0 & 1 & 8 & 50.00 \\
\hline Eucalyptus & 0 & 0 & 6 & 0 & 0 & 0 & 0 & 0 & 0 & 0 & 0 & 6 & 100.00 \\
\hline Gray Pine & 0 & 1 & 0 & 21 & 0 & 0 & 0 & 0 & 0 & 0 & 0 & 22 & 95.45 \\
\hline Incense Cedar & 0 & 1 & 0 & 1 & 5 & 0 & 8 & 0 & 0 & 0 & 0 & 15 & 33.33 \\
\hline Live Oak & 5 & 0 & 1 & 0 & 0 & 27 & 0 & 1 & 4 & 1 & 0 & 39 & 69.23 \\
\hline Ponderosa Pine & 0 & 0 & 0 & 2 & 2 & 0 & 34 & 1 & 0 & 1 & 0 & 40 & 85.00 \\
\hline Valley Oak & 2 & 0 & 0 & 0 & 0 & 0 & 0 & 13 & 6 & 0 & 0 & 21 & 61.90 \\
\hline Black Oak & 1 & 0 & 0 & 0 & 0 & 3 & 0 & 5 & 19 & 1 & 0 & 29 & 65.52 \\
\hline Other Deciduous & 0 & 0 & 0 & 0 & 2 & 3 & 1 & 0 & 2 & 3 & 0 & 11 & 27.27 \\
\hline Other Conifer & 1 & 0 & 0 & 1 & 1 & 0 & 3 & 0 & 0 & 0 & 3 & 9 & 33.33 \\
\hline Count & 22 & 6 & 8 & 26 & 10 & 38 & 46 & 22 & 31 & 6 & 4 & Accuracy & Kappa \\
\hline User's & 59.09 & 66.67 & 75.00 & 80.77 & 50.00 & 71.05 & 73.91 & 59.09 & 61.29 & 50.00 & 75.00 & 67.58 & 0.629 \\
\hline $5.0 \mathrm{~m} \# 7$ & BO & DC & $\mathrm{E}$ & GP & IC & LO & PP & vo & BO & OD & $O C$ & Count & Producer's \\
\hline Blue Oak & 10 & 0 & 0 & 0 & 0 & 3 & 0 & 4 & 0 & 0 & 0 & 17 & 58.82 \\
\hline Deodar Cedar & 0 & 4 & 0 & 0 & 0 & 3 & 0 & 0 & 0 & 1 & 0 & 8 & 50.00 \\
\hline Eucalyptus & 0 & 0 & 6 & 0 & 0 & 0 & 1 & 0 & 0 & 0 & 0 & 7 & 85.71 \\
\hline Gray Pine & 0 & 1 & 0 & 21 & 0 & 0 & 0 & 0 & 0 & 0 & 0 & 22 & 95.45 \\
\hline Incense Cedar & 0 & 0 & 0 & 1 & 6 & 0 & 7 & 0 & 0 & 0 & 0 & 14 & 42.86 \\
\hline Live Oak & 1 & 0 & 0 & 0 & 0 & 25 & 1 & 2 & 5 & 1 & 0 & 35 & 71.43 \\
\hline Ponderosa Pine & 0 & 0 & 0 & 1 & 1 & 0 & 34 & 0 & 0 & 1 & 0 & 37 & 91.89 \\
\hline Valley Oak & 3 & 0 & 0 & 0 & 0 & 2 & 0 & 13 & 3 & 0 & 1 & 22 & 59.09 \\
\hline Black Oak & 3 & 0 & 0 & 0 & 0 & 8 & 0 & 5 & 15 & 0 & 0 & 31 & 48.39 \\
\hline Other Deciduous & 0 & 0 & 0 & 0 & 1 & 3 & 5 & 0 & 0 & 1 & 0 & 10 & 10.00 \\
\hline Other Conifer & 0 & 1 & 0 & 1 & 1 & 0 & 3 & 0 & 0 & 0 & 4 & 10 & 40.00 \\
\hline Count & 17 & 6 & 6 & 24 & 9 & 44 & 51 & 24 & 23 & 4 & 5 & Accuracy & Kappa \\
\hline User's & 58.82 & 66.67 & 100.00 & 87.50 & 66.67 & 56.82 & 66.67 & 54.17 & 65.22 & 25.00 & 80.00 & 65.26 & 0.602 \\
\hline $5.0 \mathrm{~m} \# 8$ & $\mathrm{BO}$ & DC & $\mathrm{E}$ & GP & IC & LO & PP & vo & $\mathrm{BO}$ & OD & $O C$ & Count & Producer's \\
\hline Blue Oak & 12 & 1 & 0 & 0 & 0 & 3 & 0 & 3 & 2 & 0 & 0 & 21 & 57.14 \\
\hline Deodar Cedar & 1 & 1 & 0 & 2 & 0 & 2 & 0 & 0 & 0 & 0 & 1 & 7 & 14.29 \\
\hline Eucalyptus & 0 & 0 & 6 & 0 & 0 & 1 & 1 & 0 & 0 & 0 & 0 & 8 & 75.00 \\
\hline Gray Pine & 0 & 3 & 0 & 17 & 0 & 0 & 0 & 0 & 0 & 0 & 0 & 20 & 85.00 \\
\hline Incense Cedar & 0 & 0 & 0 & 0 & 3 & 1 & 6 & 1 & 0 & 0 & 4 & 15 & 20.00 \\
\hline Live Oak & 3 & 0 & 0 & 0 & 0 & 24 & 1 & 2 & 5 & 1 & 0 & 36 & 66.67 \\
\hline Ponderosa Pine & 1 & 0 & 0 & 2 & 4 & 0 & 29 & 0 & 0 & 1 & 1 & 38 & 76.32 \\
\hline Valley Oak & 2 & 0 & 0 & 0 & 0 & 1 & 1 & 11 & 5 & 1 & 0 & 21 & 52.38 \\
\hline Black Oak & 0 & 1 & 0 & 0 & 0 & 4 & 3 & 1 & 21 & 0 & 0 & 30 & 70.00 \\
\hline Other Deciduous & 0 & 1 & 0 & 0 & 0 & 2 & 3 & 0 & 0 & 4 & 1 & 11 & 36.36 \\
\hline Other Conifer & 1 & 0 & 0 & 2 & 1 & 1 & 1 & 0 & 0 & 0 & 3 & 9 & 33.33 \\
\hline Count & 20 & 7 & 6 & 23 & 8 & 39 & 45 & 18 & 33 & 7 & 10 & Accuracy & Kappa \\
\hline User's & 60.00 & 14.29 & 100.00 & 73.91 & 37.50 & 61.54 & 64.44 & 61.11 & 63.64 & 57.14 & 30.00 & 60.65 & 0.551 \\
\hline $5.0 \mathrm{~m} \# 9$ & $\mathrm{BO}$ & DC & $\mathrm{E}$ & GP & IC & LO & PP & vo & $\mathrm{BO}$ & OD & OC & Count & Producer's \\
\hline Blue Oak & 11 & 1 & 0 & 0 & 0 & 4 & 0 & 3 & 0 & 0 & 0 & 19 & 57.89 \\
\hline Deodar Cedar & 1 & 4 & 1 & 0 & 0 & 1 & 0 & 0 & 0 & 1 & 0 & 8 & 50.00 \\
\hline Eucalyptus & 0 & 0 & 4 & 0 & 0 & 1 & 0 & 0 & 1 & 0 & 1 & 7 & 57.14 \\
\hline Gray Pine & 0 & 0 & 0 & 21 & 0 & 0 & 0 & 0 & 0 & 0 & 0 & 21 & 100.00 \\
\hline Incense Cedar & 0 & 0 & 0 & 0 & 6 & 0 & 7 & 0 & 0 & 0 & 1 & 14 & 42.86 \\
\hline Live Oak & 6 & 0 & 0 & 0 & 0 & 24 & 0 & 2 & 4 & 1 & 0 & 37 & 64.86 \\
\hline Ponderosa Pine & 1 & 0 & 0 & 1 & 2 & 1 & 35 & 0 & 0 & 2 & 0 & 42 & 83.33 \\
\hline Valley Oak & 3 & 0 & 0 & 0 & 0 & 1 & 1 & 11 & 5 & 0 & 0 & 21 & 52.38 \\
\hline Black Oak & 1 & 0 & 0 & 0 & 0 & 6 & 1 & 2 & 21 & 0 & 0 & 31 & 67.74 \\
\hline Other Deciduous & 0 & 0 & 1 & 0 & 1 & 2 & 3 & 0 & 1 & 2 & 1 & 11 & 18.18 \\
\hline Other Conifer & 0 & 1 & 0 & 1 & 2 & 0 & 4 & 0 & 0 & 0 & 2 & 10 & 20.00 \\
\hline Count & 23 & 6 & 6 & 23 & 11 & 40 & 51 & 18 & 32 & 6 & 5 & Accuracy & Kappa \\
\hline User's & 47.83 & 66.67 & 66.67 & 91.30 & 54.55 & 60.00 & 68.63 & 61.11 & 65.63 & 33.33 & 40.00 & 63.80 & 0.585 \\
\hline $5.0 \mathrm{~m} \# 10$ & $\mathrm{BO}$ & DC & $\mathrm{E}$ & GP & IC & LO & PP & vo & BO & OD & $O C$ & Count & Producer's \\
\hline Blue Oak & 13 & 0 & 0 & 1 & 0 & 4 & 0 & 1 & 0 & 0 & 0 & 19 & 68.42 \\
\hline Deodar Ceda & 0 & 3 & 0 & 3 & 0 & 1 & 1 & 0 & 0 & 0 & 1 & 9 & 33.33 \\
\hline Eucalyptus & 0 & 0 & 5 & 0 & 0 & 1 & 1 & 0 & 0 & 0 & 0 & 7 & 71.43 \\
\hline Gray Pine & 0 & 0 & 0 & 21 & 0 & 1 & 0 & 0 & 0 & 0 & 0 & 22 & 95.45 \\
\hline Incense Cedar & 0 & 1 & 0 & 0 & 6 & 0 & 3 & 1 & 1 & 0 & 0 & 12 & 50.00 \\
\hline Live Oak & 3 & 1 & 0 & 0 & 0 & 27 & 0 & 3 & 4 & 1 & 0 & 39 & 69.23 \\
\hline Ponderosa Pine & 0 & 0 & 0 & 0 & 1 & 0 & 32 & 1 & 0 & 2 & 1 & 37 & 86.49 \\
\hline Valley Oak & 1 & 0 & 0 & 0 & 0 & 2 & 0 & 14 & 4 & 0 & 0 & 21 & 66.67 \\
\hline Black Oak & 1 & 0 & 0 & 1 & 0 & 3 & 0 & 5 & 19 & 0 & 0 & 29 & 65.52 \\
\hline Other Deciduous & 0 & 2 & 0 & 0 & 0 & 2 & 2 & 1 & 1 & 3 & 0 & 11 & 27.27 \\
\hline Other Conifer & 0 & 0 & 0 & 0 & 3 & 0 & 2 & 1 & 0 & 0 & 4 & 10 & 40.00 \\
\hline Count & 18 & 7 & 5 & 26 & 10 & 41 & 41 & 27 & 29 & 6 & 6 & Accuracy & Kappa \\
\hline User's & 72.22 & 42.86 & 100.00 & 80.77 & 60.00 & 65.85 & 78.05 & 51.85 & 65.52 & 50.00 & 66.67 & 68.06 & 0.635 \\
\hline
\end{tabular}

